\title{
Prenylated Bibenzyls from the Chinese Liverwort Radula constricta and Their Mitochondria-Derived Paraptotic Cytotoxic Activities
}

Chunyang Zhang, ${ }^{\dagger, \S}$ Yun Gao $,{ }^{\dagger}, \S$ Rongxiu Zhu, ${ }^{\ddagger}$ Yanan Qiao, ${ }^{\dagger}$ Jinchuan Zhou, ${ }^{\perp}$

Jiaozhen Zhang, ${ }^{\dagger}$ Yi Li, ${ }^{\dagger}$ Siwen $\mathrm{Li},{ }^{\dagger}$ Shenghua Fan, ${ }^{\dagger}$ and Hongxiang $\mathrm{Lou}^{\dagger}, *$

†Department of Natural Products Chemistry, Key Lab of Chemical Biology of the Ministry of Education, Shandong University, Jinan 250012, People's Republic of China

$\$$ School of Chemistry and Chemical Engineering, Shandong University, Jinan 250010, People's Republic of China

${ }^{\perp}$ School of Pharmacy, Linyi University, Linyi 276000, People’s Republic of China 


\section{Contents}

Theory and Calculation Details.

Scheme S1. Putative biosynthesis pathways of 1-20.

\section{Data for compound 1}

Figure S1. ${ }^{1} \mathrm{H}$ NMR spectrum $(600 \mathrm{MHz})$ of 1 in $\mathrm{CDCl}_{3}$.

Figure S2. ${ }^{13} \mathrm{C}$ NMR spectrum $(150 \mathrm{MHz})$ of 1 in $\mathrm{CDCl}_{3}$.

Figure S3. HSQC spectrum $(600 \mathrm{MHz})$ of $\mathbf{1}$ in $\mathrm{CDCl}_{3}$.

Figure S4. ${ }^{1} \mathrm{H}-{ }^{1} \mathrm{H}$ spectrum $(600 \mathrm{MHz})$ of $\mathbf{1}$ in $\mathrm{CDCl}_{3}$.

Figure S5. HMBC spectrum $(600 \mathrm{MHz})$ of 1 in $\mathrm{CDCl}_{3}$.

Figure S6. HRESIMS spectrum of $\mathbf{1}$.

Figure S7. IR ( $\mathrm{KBr}$ disc) spectrum of $\mathbf{1 .}$

Figure S8. UV spectrum of $\mathbf{1}$.

Figure S9. Chiral-phase HPLC analysis of $\mathbf{1 .}$

Figure S10. Experimental ECD spectra of $\mathbf{1 a} / \mathbf{1 b}$ and calculated ECD spectrum of $\mathbf{1 a}$.

\section{Data for compound 2}

Figure S11. ${ }^{1} \mathrm{H}$ NMR spectrum $(600 \mathrm{MHz})$ of 2 in $\mathrm{CDCl}_{3}$.

Figure S12. ${ }^{13} \mathrm{C}$ NMR spectrum $(150 \mathrm{MHz})$ of 2 in $\mathrm{CDCl}_{3}$.

Figure S13. HSQC spectrum $(600 \mathrm{MHz})$ of 2 in $\mathrm{CDCl}_{3}$.

Figure S14. ${ }^{1} \mathrm{H}-{ }^{1} \mathrm{H}$ spectrum $(600 \mathrm{MHz})$ of 2 in $\mathrm{CDCl}_{3}$.

Figure S15. HMBC spectrum $(600 \mathrm{MHz})$ of 2 in $\mathrm{CDCl}_{3}$.

Figure S16. HRESIMS spectrum of 2. 
Figure S17. IR ( $\mathrm{KBr}$ disc) spectrum of 2.

Figure S18. UV spectrum of 2.

Figure S19. Chiral-phase HPLC analysis of 2.

Figure S20. Experimental ECD spectra of $\mathbf{2 a} / \mathbf{2} \mathbf{b}$ and calculated ECD spectrum of $\mathbf{2 a}$.

\section{Data for compound 3}

Figure S21. ${ }^{1} \mathrm{H}$ NMR spectrum $(400 \mathrm{MHz})$ of 3 in $\mathrm{CDCl}_{3}$.

Figure $\mathbf{S 2 2} \cdot{ }^{13} \mathrm{C}$ NMR spectrum $(100 \mathrm{MHz})$ of $\mathbf{3}$ in $\mathrm{CDCl}_{3}$.

Figure S23. HMQC spectrum $(400 \mathrm{MHz})$ of 3 in $\mathrm{CDCl}_{3}$.

Figure S24. ${ }^{1} \mathrm{H}-{ }^{1} \mathrm{H}$ spectrum $(400 \mathrm{MHz})$ of 3 in $\mathrm{CDCl}_{3}$.

Figure S25. HMBC spectrum $(400 \mathrm{MHz})$ of 3 in $\mathrm{CDCl}_{3}$.

Figure S26. HRESIMS Spectrum of 3.

Figure S27. IR ( $\mathrm{KBr}$ disc) spectrum of $\mathbf{3}$.

Figure S28. UV spectrum of $\mathbf{3}$.

Figure S29. Chiral-phase HPLC analysis of 3.

Figure S30. Experimental ECD spectra of $\mathbf{3 a} / \mathbf{3 b}$ and calculated ECD spectrum of $\mathbf{3 a}$.

\section{Data for compound 4}

Figure S31. ${ }^{1} \mathrm{H}$ NMR spectrum $(600 \mathrm{MHz})$ of 4 in $\mathrm{CDCl}_{3}$.

Figure S32. ${ }^{13} \mathrm{C}$ NMR spectrum $(150 \mathrm{MHz})$ of 4 in $\mathrm{CDCl}_{3}$.

Figure S33. HSQC spectrum (600 MHz) of 4 in $\mathrm{CDCl}_{3}$.

Figure S34. ${ }^{1} \mathrm{H}-{ }^{1} \mathrm{H}$ spectrum $(600 \mathrm{MHz})$ of 4 in $\mathrm{CDCl}_{3}$.

Figure S35. HMBC spectrum $(600 \mathrm{MHz})$ of 4 in $\mathrm{CDCl}_{3}$.

Figure S36. HRESIMS spectrum of 4.

Figure S37. IR ( $\mathrm{KBr}$ disc) spectrum of 4. 
Figure S38. UV spectrum of 4.

Figure S39. Chiral-phase HPLC analysis of 4.

Figure S40. Experimental ECD spectra of $\mathbf{4 a / 4 b}$ and calculated ECD spectrum of $\mathbf{4 b}$.

\section{Data for compound 5}

Figure S41. ${ }^{1} \mathrm{H}$ NMR spectrum $(400 \mathrm{MHz})$ of 5 in $\mathrm{CDCl}_{3}$.

Figure $\mathbf{S 4 2} .{ }^{13} \mathrm{C}$ NMR spectrum $(100 \mathrm{MHz})$ of 5 in $\mathrm{CDCl}_{3}$.

Figure S43. HSQC spectrum $(400 \mathrm{MHz})$ of 5 in $\mathrm{CDCl}_{3}$.

Figure S44. ${ }^{1} \mathrm{H}-{ }^{1} \mathrm{H}$ spectrum $(400 \mathrm{MHz})$ of 5 in $\mathrm{CDCl}_{3}$.

Figure S45. HMBC spectrum $(400 \mathrm{MHz})$ of 5 in $\mathrm{CDCl}_{3}$.

Figure S46. HRESIMS spectrum of 5.

Figure S47. IR ( $\mathrm{KBr}$ disc) spectrum of 5.

Figure S48. UV spectrum of 5.

Figure S49. Chiral-phase HPLC analysis of 5.

Figure S50. Experimental ECD spectra of $\mathbf{5 a} / \mathbf{5 b}$ and calculated ECD spectrum of $\mathbf{5 a}$.

\section{Data for compound 6}

Figure S51. ${ }^{1} \mathrm{H}$ NMR spectrum $(600 \mathrm{MHz})$ of 6 in $\mathrm{CDCl}_{3}$.

Figure S52. ${ }^{13} \mathrm{C}$ NMR spectrum $(150 \mathrm{MHz})$ of 6 in $\mathrm{CDCl}_{3}$.

Figure S53. HSQC spectrum $(600 \mathrm{MHz})$ of 6 in $\mathrm{CDCl}_{3}$.

Figure S54. ${ }^{1} \mathrm{H}-{ }^{1} \mathrm{H}$ spectrum $(600 \mathrm{MHz})$ of 6 in $\mathrm{CDCl}_{3}$.

Figure S55. HMBC spectrum $(600 \mathrm{MHz})$ of 6 in $\mathrm{CDCl}_{3}$.

Figure S56. NOESY spectrum $(600 \mathrm{MHz})$ of 6 in $\mathrm{CDCl}_{3}$.

Figure S57. HRESIMS spectrum of 6.

Figure S58. IR ( $\mathrm{KBr}$ disc) spectrum of $\mathbf{6}$. 
Figure S59. UV spectrum of 6.

Figure S60. Chiral-phase HPLC analysis of 6.

Figure S61. Experimental ECD spectra of $\mathbf{6 a} / \mathbf{6 b}$ and calculated ECD spectrum of $\mathbf{6 a}$.

\section{Data for compound 7}

Figure S62. ${ }^{1} \mathrm{H}$ NMR spectrum $(600 \mathrm{MHz})$ of 7 in $\mathrm{CDCl}_{3}$.

Figure S63. ${ }^{13} \mathrm{C}$ NMR spectrum $(150 \mathrm{MHz})$ of 7 in $\mathrm{CDCl}_{3}$.

Figure S64. HSQC spectrum $(600 \mathrm{MHz})$ of 7 in $\mathrm{CDCl}_{3}$.

Figure S65. ${ }^{1} \mathrm{H}-{ }^{1} \mathrm{H}$ spectrum $(600 \mathrm{MHz})$ of 7 in $\mathrm{CDCl}_{3}$.

Figure S66. $\mathrm{HMBC}$ spectrum $(600 \mathrm{MHz})$ of 7 in $\mathrm{CDCl}_{3}$.

Figure S67. HRESIMS spectrum of 7.

Figure S68. IR ( $\mathrm{KBr}$ disc) spectrum of 7.

Figure S69. UV spectrum of 7.

Figure S70. Chiral-phase HPLC analysis of 7.

Figure S71. Experimental and calculated ECD spectra of 7.

\section{Data for compound 8}

Figure S72. ${ }^{1} \mathrm{H}$ NMR spectrum $(600 \mathrm{MHz})$ of 8 in $\mathrm{CDCl}_{3}$.

Figure S73. ${ }^{13} \mathrm{C}$ NMR spectrum $(150 \mathrm{MHz})$ of $\mathbf{8}$ in $\mathrm{CDCl}_{3}$.

Figure S74. HSQC spectrum $(600 \mathrm{MHz})$ of 8 in $\mathrm{CDCl}_{3}$.

Figure S75. ${ }^{1} \mathrm{H}-{ }^{1} \mathrm{H}$ spectrum $(600 \mathrm{MHz})$ of 8 in $\mathrm{CDCl}_{3}$.

Figure S76. $\mathrm{HMBC}$ spectrum $(600 \mathrm{MHz})$ of 8 in $\mathrm{CDCl}_{3}$.

Figure S77. HRESIMS spectrum of 8.

Figure S78. IR ( $\mathrm{KBr}$ disc) spectrum of $\mathbf{8}$.

Figure S79. UV spectrum of 8. 


\section{Data for compound 9}

Figure S80. ${ }^{1} \mathrm{H}$ NMR spectrum $(400 \mathrm{MHz})$ of 9 in $\mathrm{CD}_{3} \mathrm{OD}$.

Figure S81. ${ }^{13} \mathrm{C}$ NMR spectrum $(100 \mathrm{MHz})$ of 9 in $\mathrm{CD}_{3} \mathrm{OD}$.

Figure S82. HSQC spectrum $(400 \mathrm{MHz})$ of 9 in $\mathrm{CD}_{3} \mathrm{OD}$.

Figure S83. ${ }^{1} \mathrm{H}-{ }^{1} \mathrm{H}$ spectrum $(400 \mathrm{MHz})$ of 9 in $\mathrm{CD}_{3} \mathrm{OD}$.

Figure S84. HMBC spectrum $(400 \mathrm{MHz})$ of 9 in $\mathrm{CD}_{3} \mathrm{OD}$.

Figure S85. HRESIMS spectrum of 9.

Figure S86. IR ( $\mathrm{KBr}$ disc) spectrum of 9.

Figure S87. UV spectrum of 9.

Figure S88. Compounds Induces Vacuolization.

Figure S89. The Histogram of Annexin V and PI Staining in A549 and NCI-H1299

Cells (A549 and NCI-H1299 Cells were Treated with the $10 \mu \mathrm{M}$ of Compound $\mathbf{1 0}$ for $24 \mathrm{~h})$.

Table S1. Cytotoxicity of Compounds and Adriamycin in Several Human Cancer Cell Llines. 


\section{Theory and Calculation Details.}

The calculations were performed by the Gaussian 03 program package. The semiempirical AM1 method ${ }^{1}$ and a DFT approach ${ }^{2}$ B3LYP/6-31G* were employed to scan the potential energy surface (PES). The geometries of all ground-state conformations obtained were further optimized at the B3LYP/6-31G* level at $298.15 \mathrm{~K}$, followed by calculations of their harmonic frequency analysis to confirm these minima and thence calculations of room-temperature free energies.

Time-dependent density functional theory (TDDFT) at the same level was used to calculate the electronic excitation energies and rotational strengths in gas phase for the first 30 states. The rotatory strengths were summed and energetically weighted following the Boltzmann statistics and the final ECD spectra were then simulated by overlapping Gaussian functions ${ }^{3}$ according to the following equation.

$$
\Delta \varepsilon(E)=\frac{1}{2.296 \times 10^{-39}} \frac{1}{\sigma \sqrt{\pi}} \times \sum_{i} \Delta E_{i} R_{i} e^{-\left[\left(E-\Delta E_{i}\right) / \sigma\right]^{2}}
$$

Where $\sigma$ is the width of the band at $1 / e$ height, while $\Delta E_{\mathrm{i}}$ and $R_{\mathrm{i}}$ are the excitation energies and rotatory strengths for transition, respectively. $\sigma=0.4 \mathrm{eV}$ and $\mathrm{R}_{\mathrm{vel}}$ were used. 


\section{REFERENCES}

(1) Dewar, M. J. S.; Zoebisch, E. G.; Healy, E. F.; Stewart, J. J. P. J. Am. Chem. Soc.

1985, 107, 3902-3909.

(2) Becke, A. D. J. Chem. Phys. 1993, 98, 5648-5652.

(3) Stephens, P. J.; Harada, N. Chiral-phaseity 2009, 22, 229-233 
Scheme S1. Putative biosynthesis pathways of 1-20.

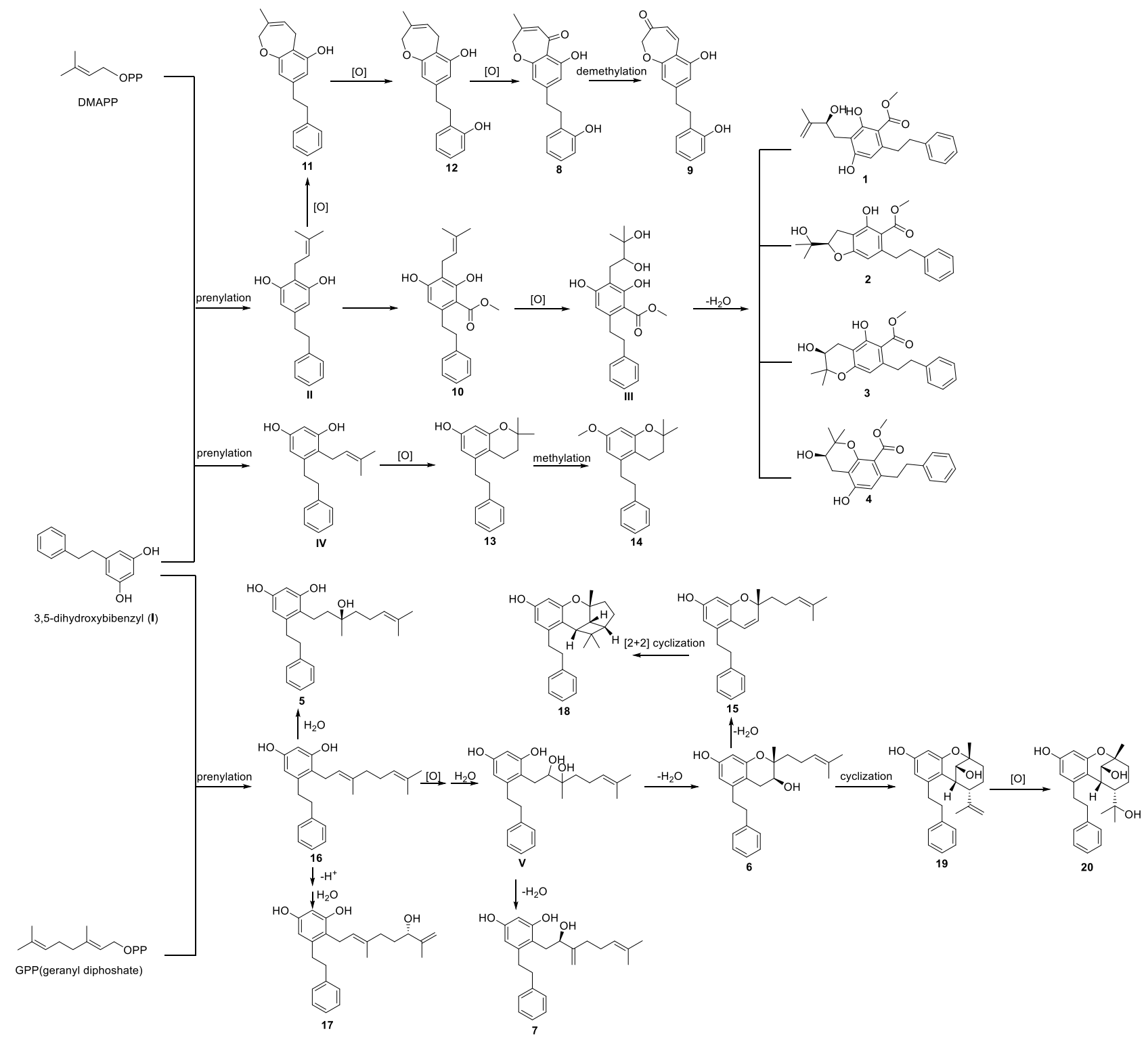


Figure S1. ${ }^{1} \mathrm{H}$ NMR spectrum $(600 \mathrm{MHz})$ of $\mathbf{1}$ in $\mathrm{CDCl}_{3}$.

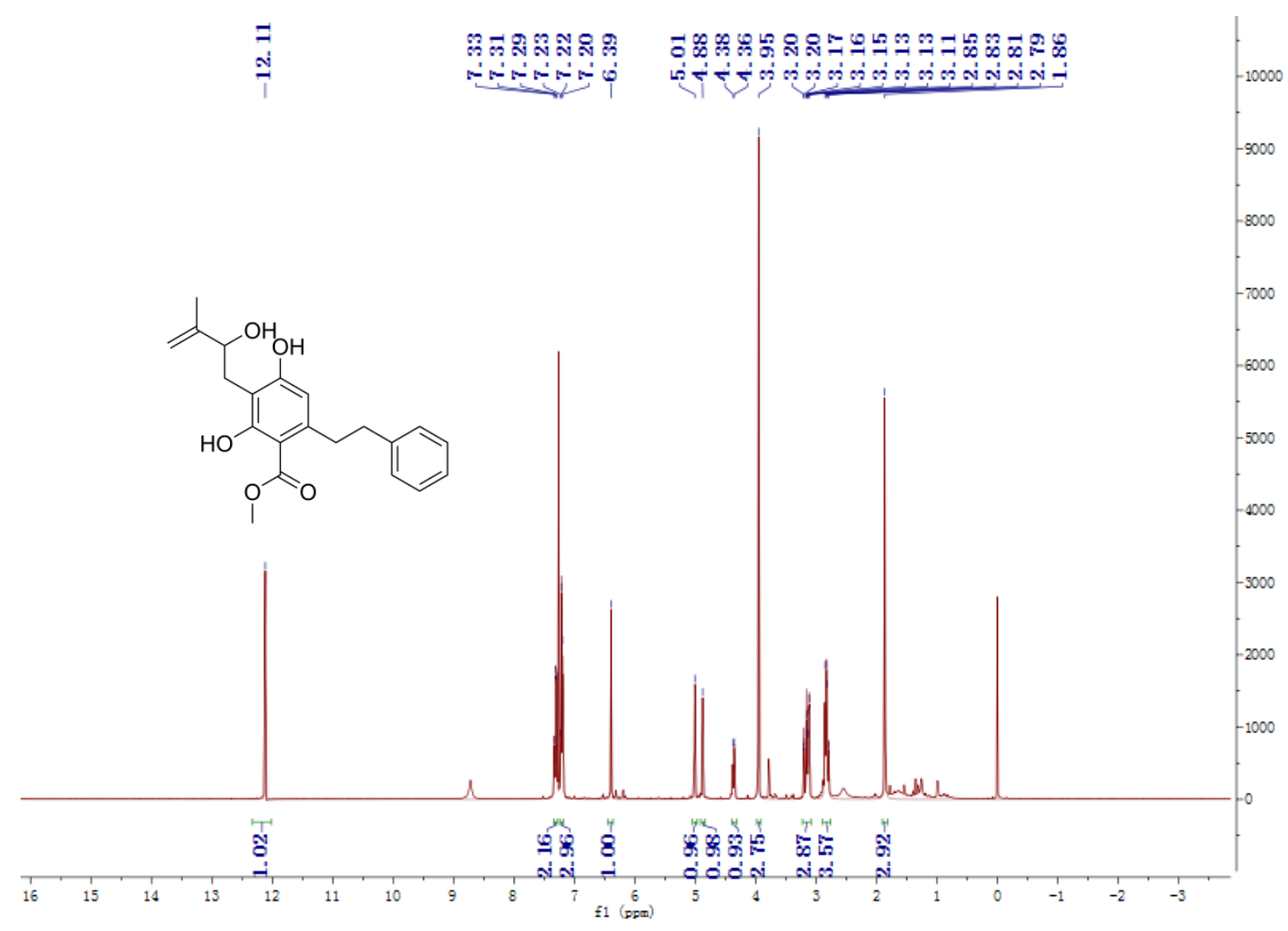

Figure S2. ${ }^{13} \mathrm{C}$ NMR spectrum $(150 \mathrm{MHz})$ of $\mathbf{1}$ in $\mathrm{CDCl}_{3}$.

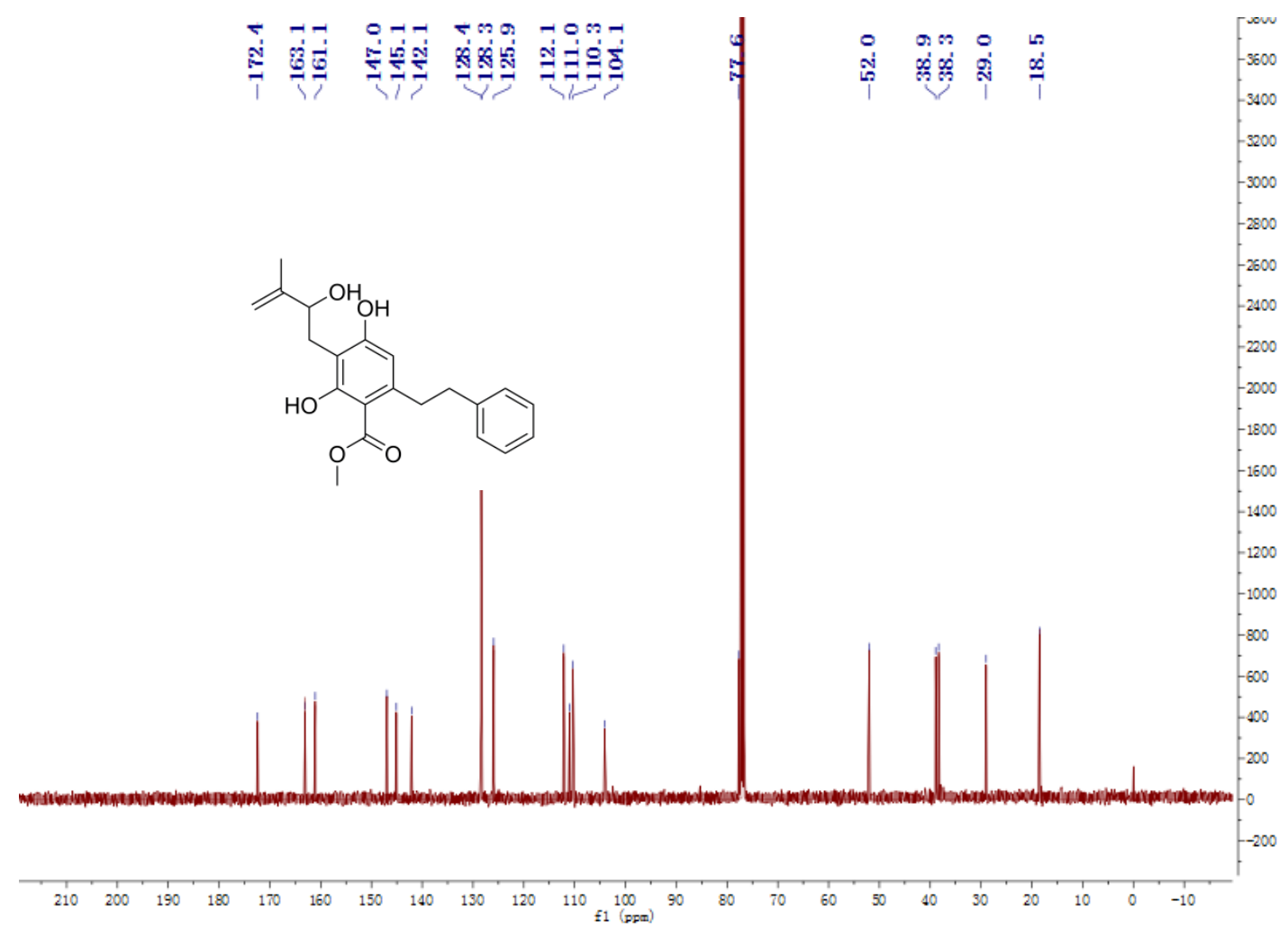


Figure S3. HSQC spectrum $(600 \mathrm{MHz})$ of $\mathbf{1}$ in $\mathrm{CDCl}_{3}$.

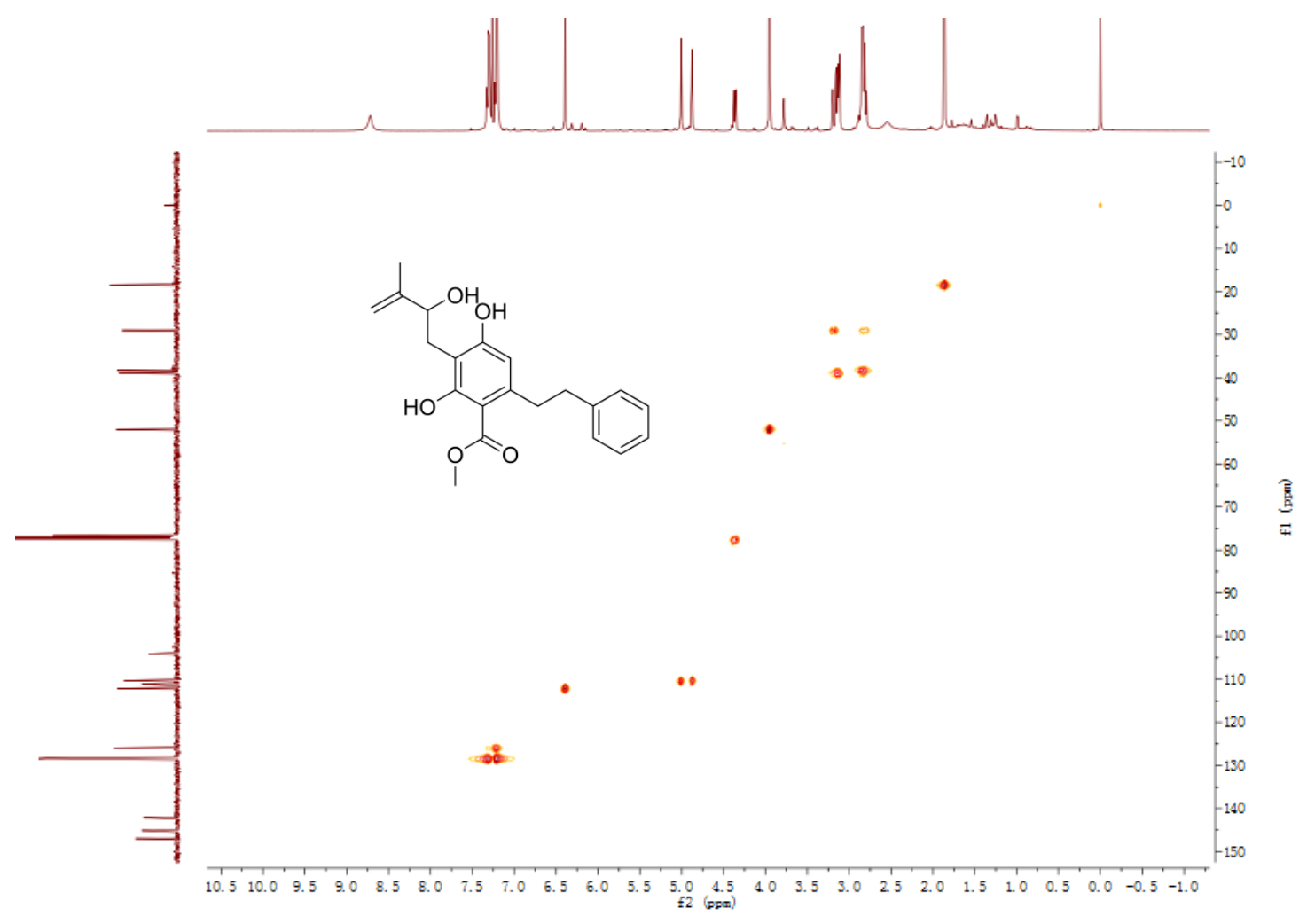

Figure S4. ${ }^{1} \mathrm{H}-{ }^{1} \mathrm{H}$ spectrum $(600 \mathrm{MHz})$ of $\mathbf{1}$ in $\mathrm{CDCl}_{3}$.

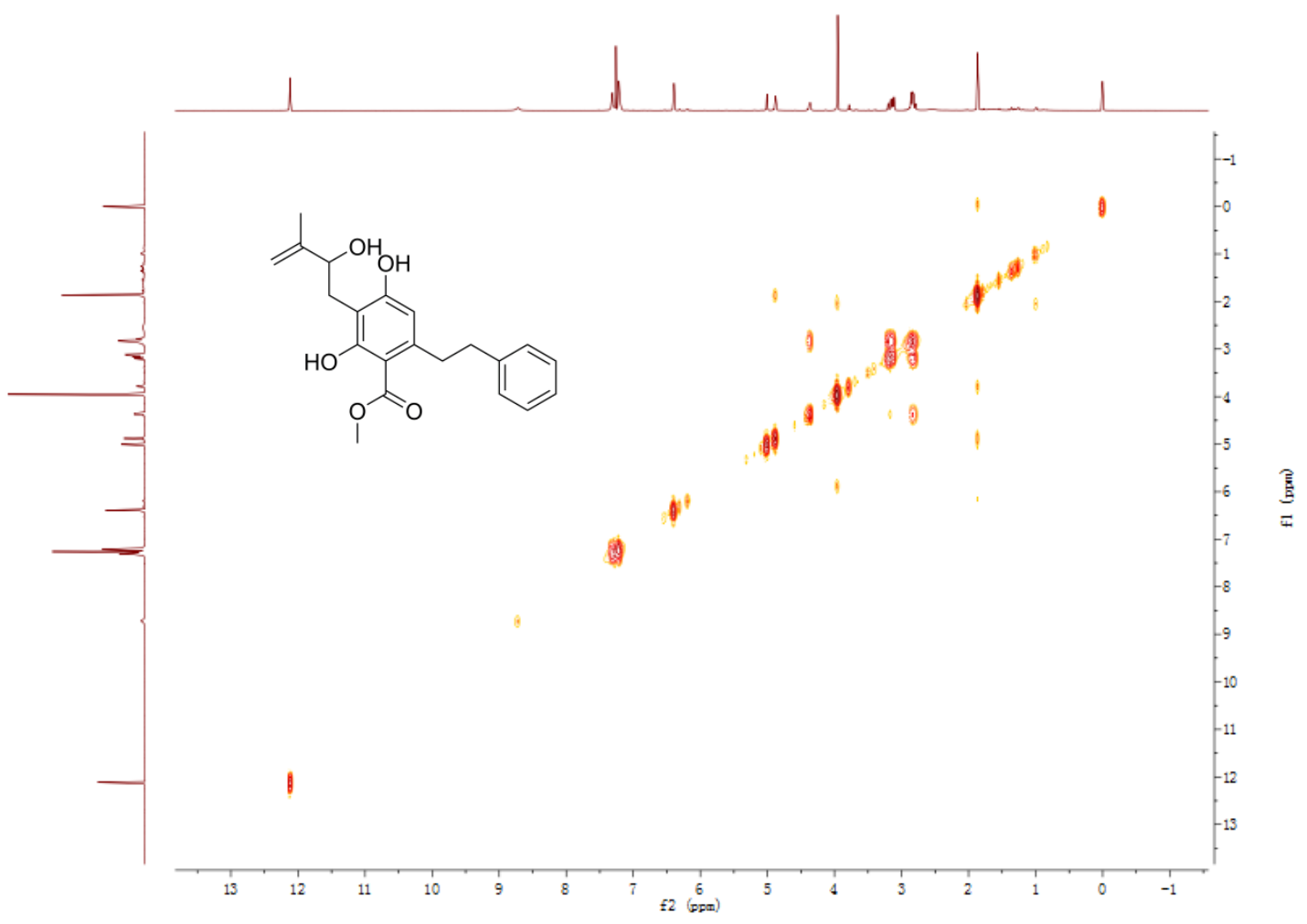


Figure S5. HMBC spectrum $(600 \mathrm{MHz})$ of 1 in $\mathrm{CDCl}_{3}$.

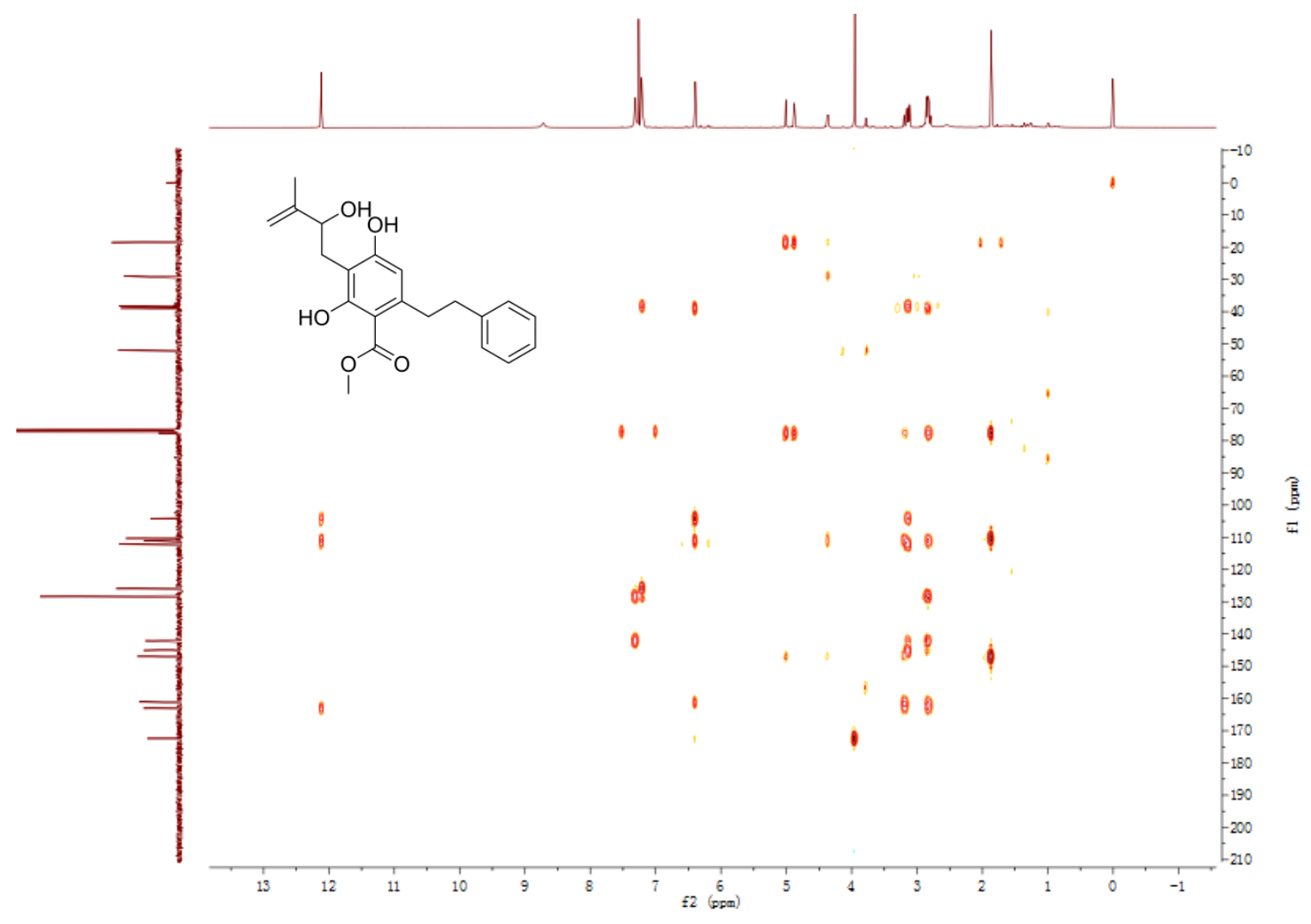

Figure S6. HRESIMS spectrum of $\mathbf{1}$.

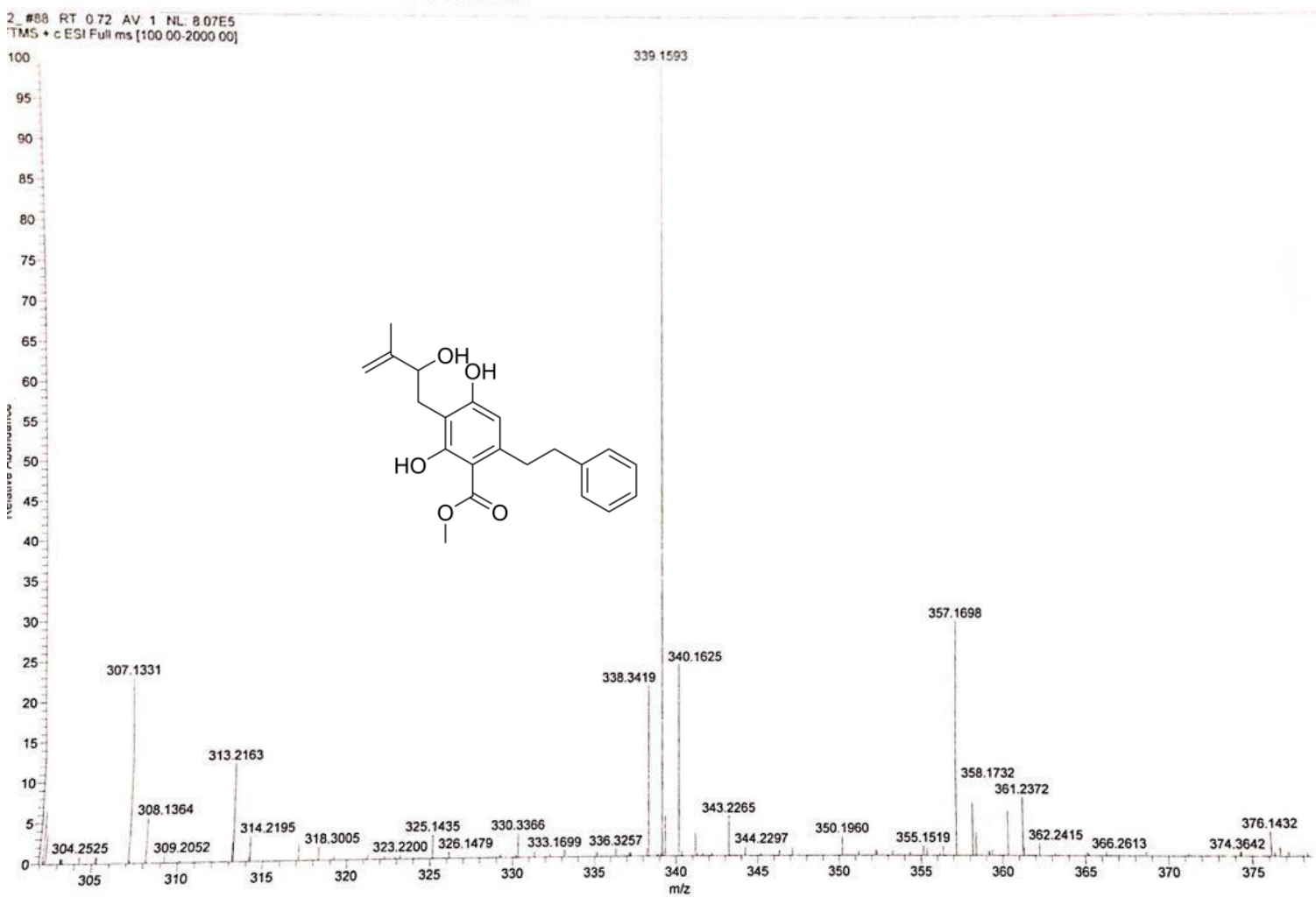


Figure S7. IR ( $\mathrm{KBr}$ disc) spectrum of $\mathbf{1}$.

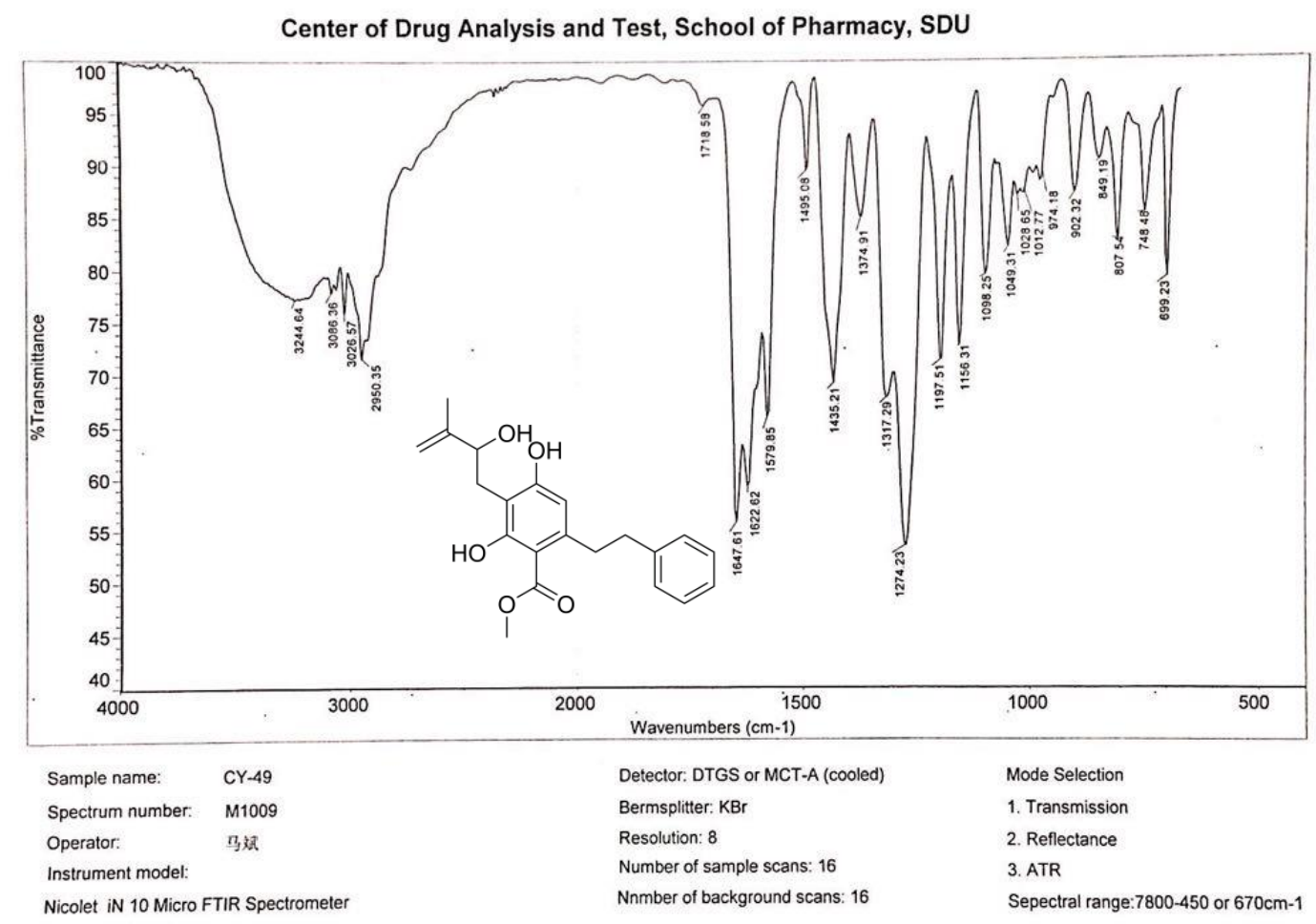

Figure S8. UV spectrum of $\mathbf{1}$.

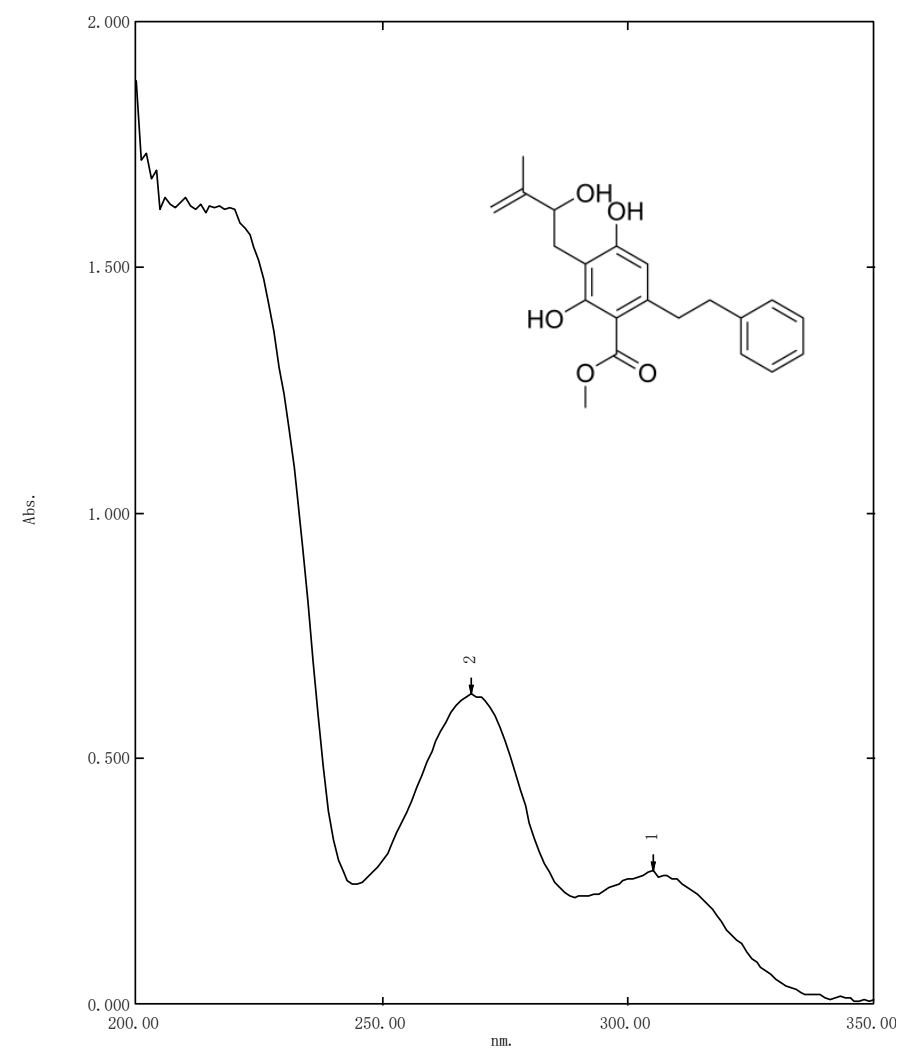


Figure S9. Chiral-phase HPLC analysis of $\mathbf{1 .}$
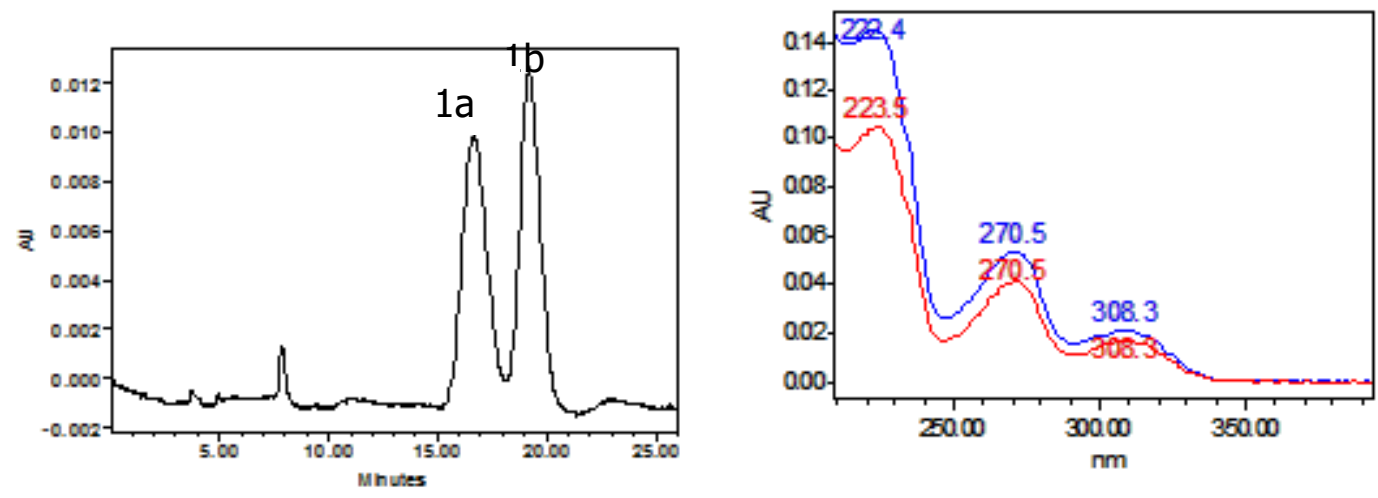

\begin{tabular}{cccccc}
\hline & Retention Time & Area & \% Area & Height & Int Type \\
\hline 1 & 16.659 & 1035702 & 50.21 & 13865 & bb \\
2 & 19.184 & 1026900 & 49.79 & 17068 & bb
\end{tabular}

Figure S10. Experimental ECD spectra of 1a/1b and calculated ECD spectrum of $\mathbf{1 a}$.

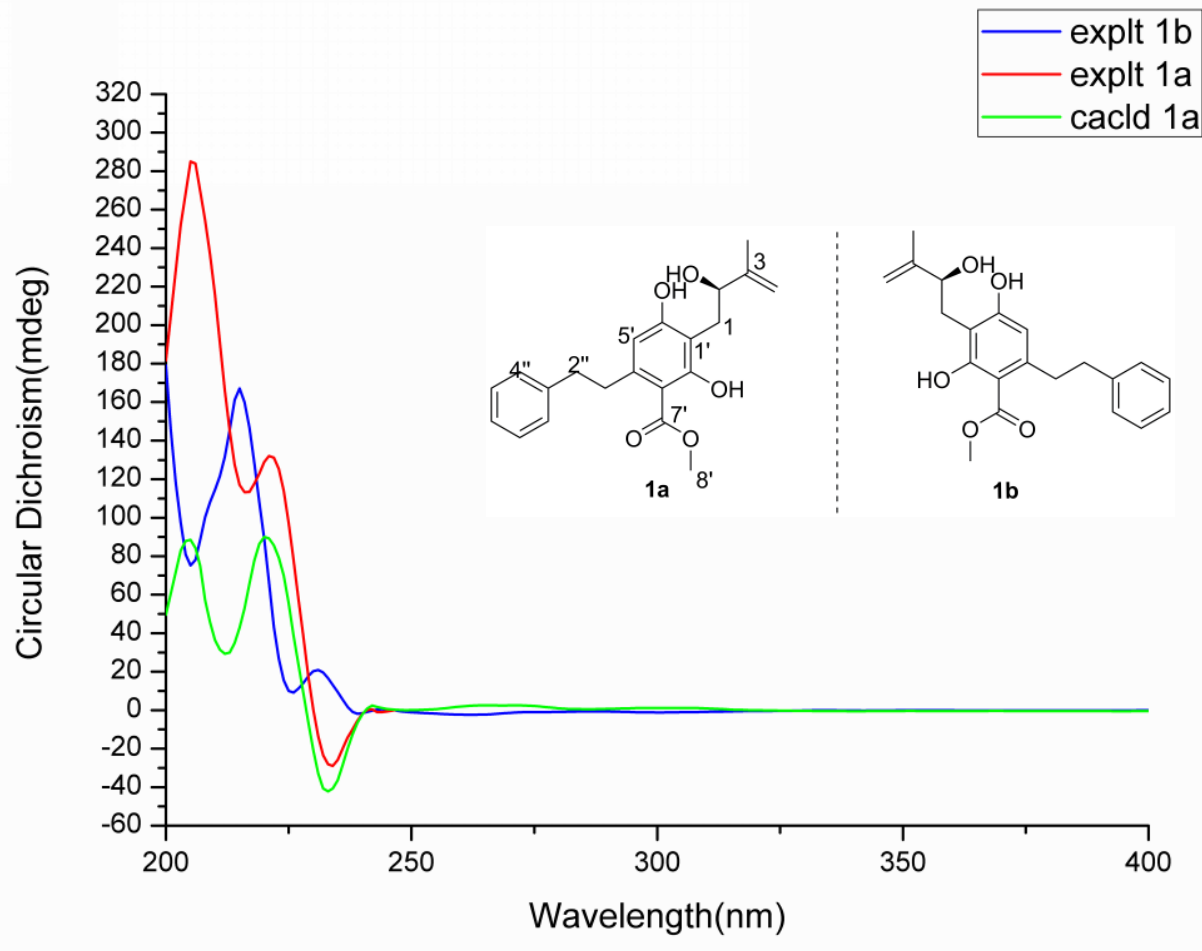


Figure S11. ${ }^{1} \mathrm{H}$ NMR spectrum $(600 \mathrm{MHz})$ of 2 in $\mathrm{CDCl}_{3}$.

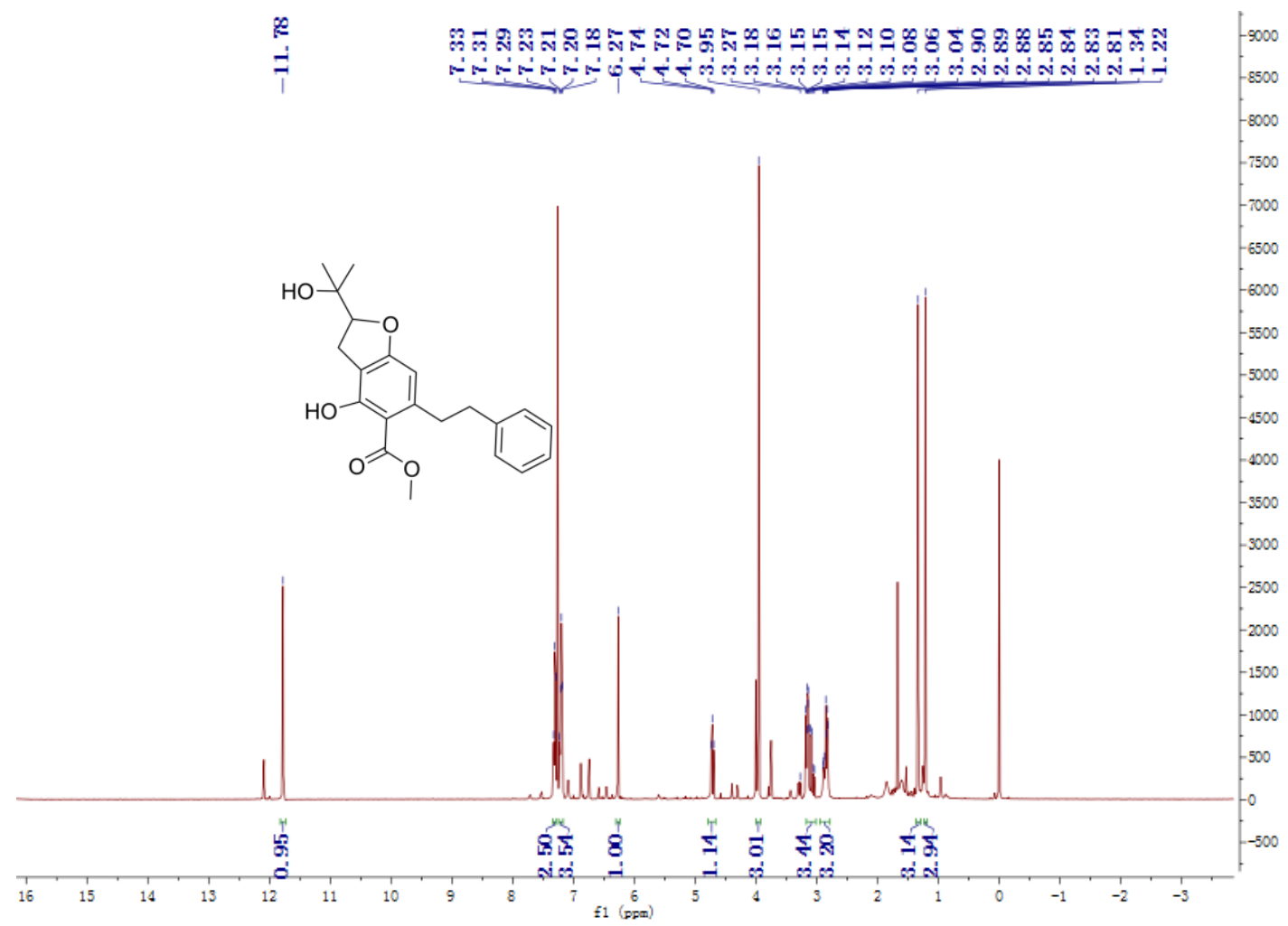

Figure S12. ${ }^{13} \mathrm{C}$ NMR spectrum $(150 \mathrm{MHz})$ of 2 in $\mathrm{CDCl}_{3 .}$.

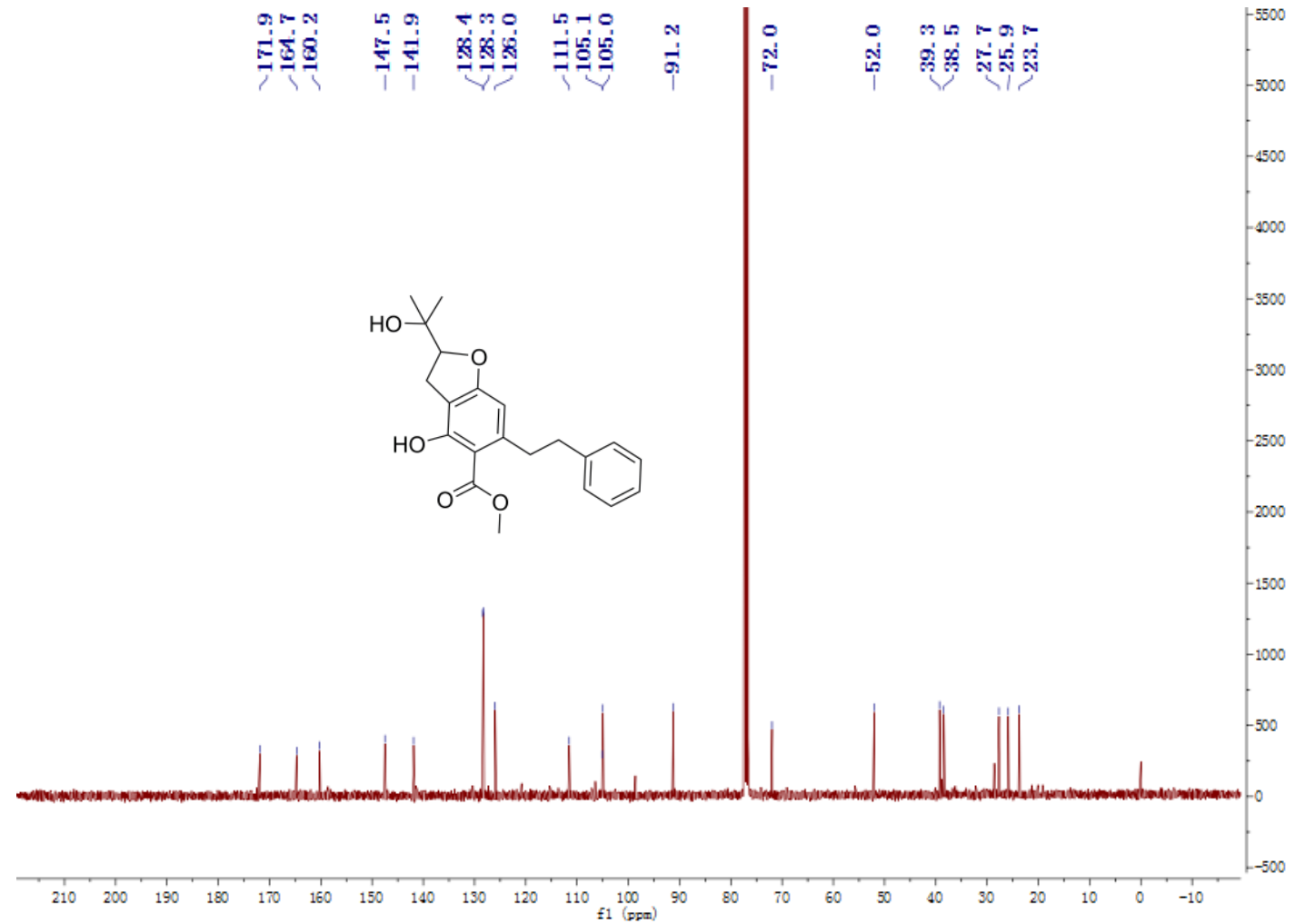


Figure S13. HSQC spectrum $(600 \mathrm{MHz})$ of 2 in $\mathrm{CDCl}_{3}$.

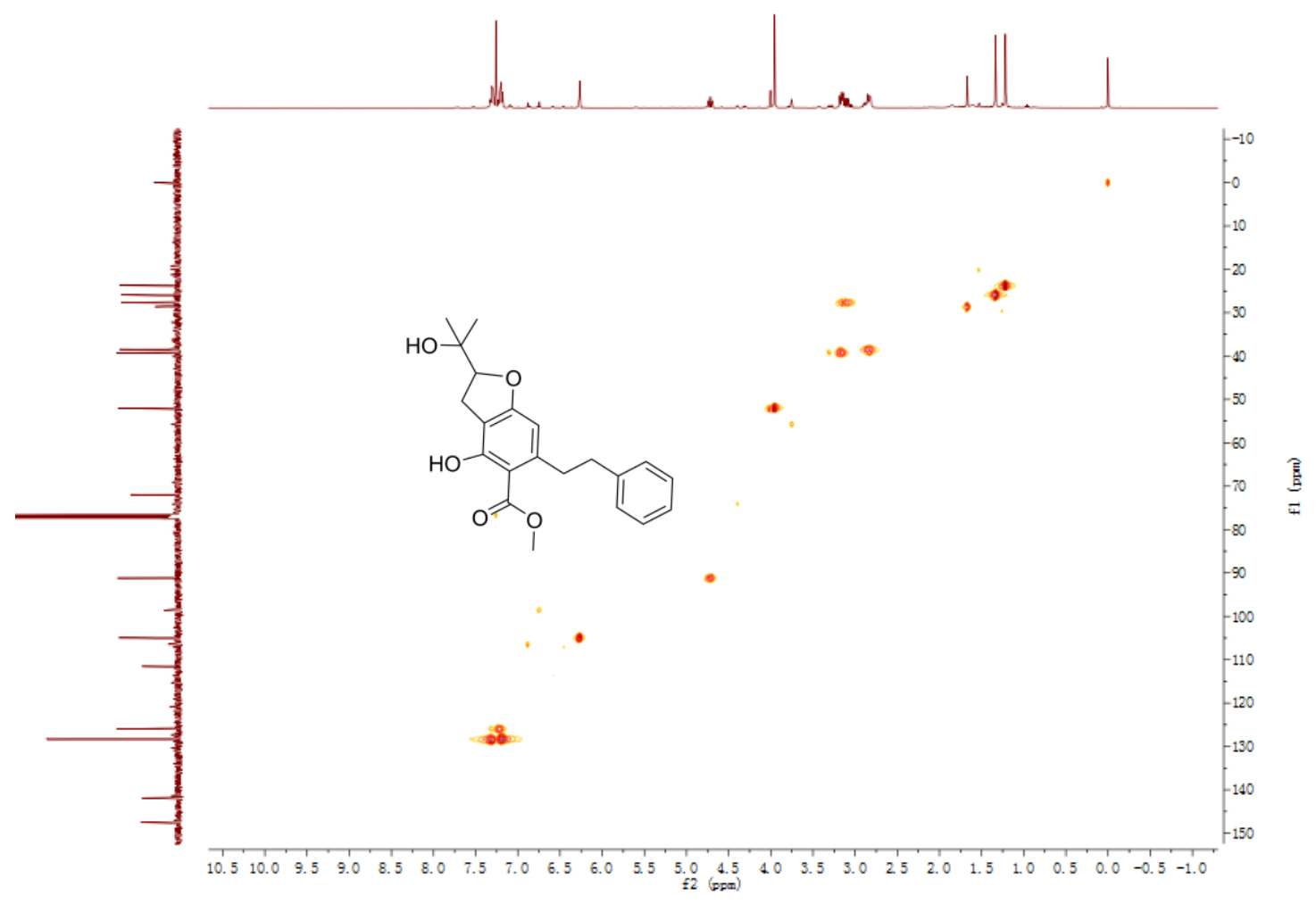

Figure S14. ${ }^{1} \mathrm{H}-{ }^{1} \mathrm{H}$ spectrum $(600 \mathrm{MHz})$ of 2 in $\mathrm{CDCl}_{3}$.

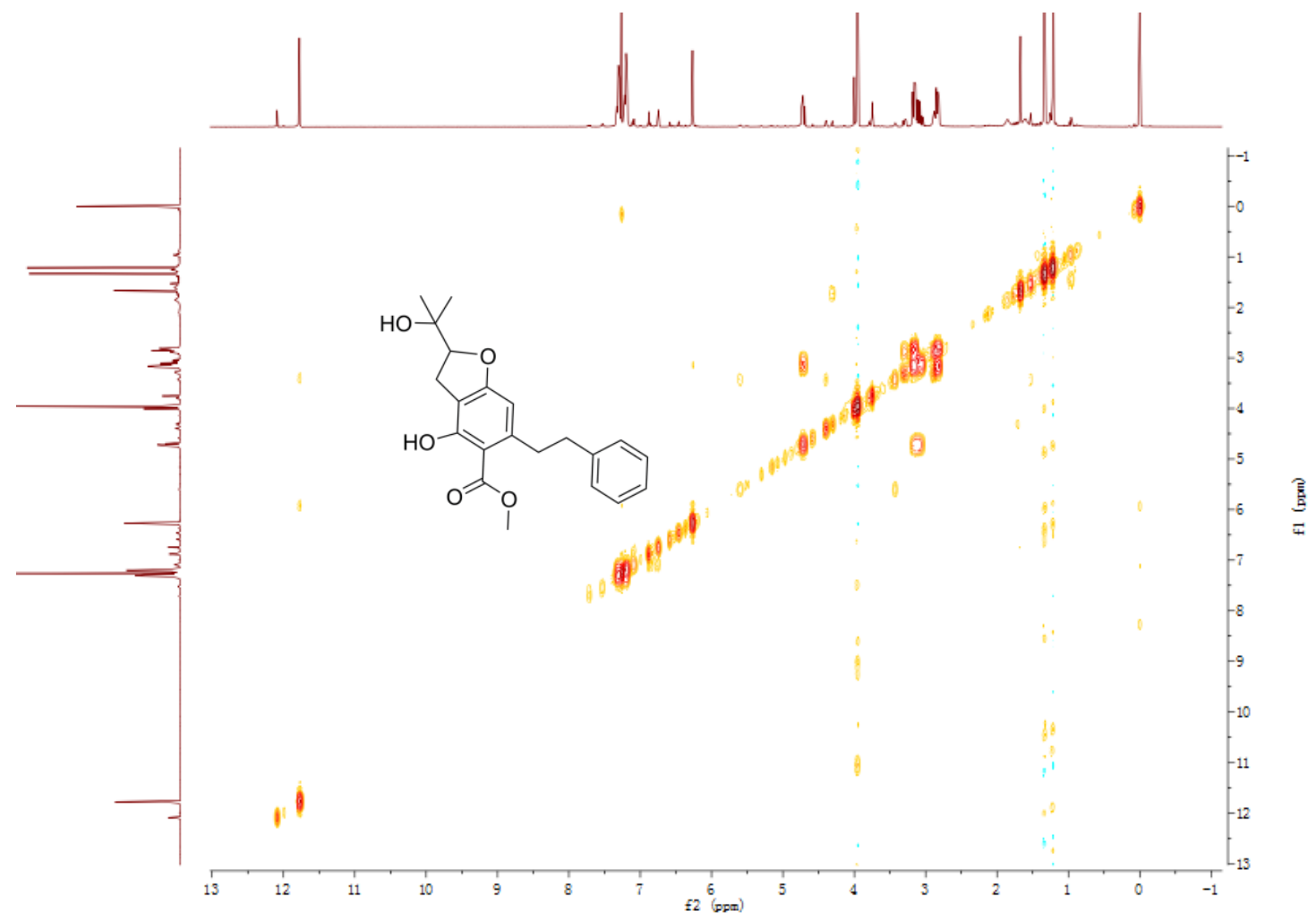


Figure S15. HMBC spectrum $(600 \mathrm{MHz})$ of 2 in $\mathrm{CDCl}_{3}$.

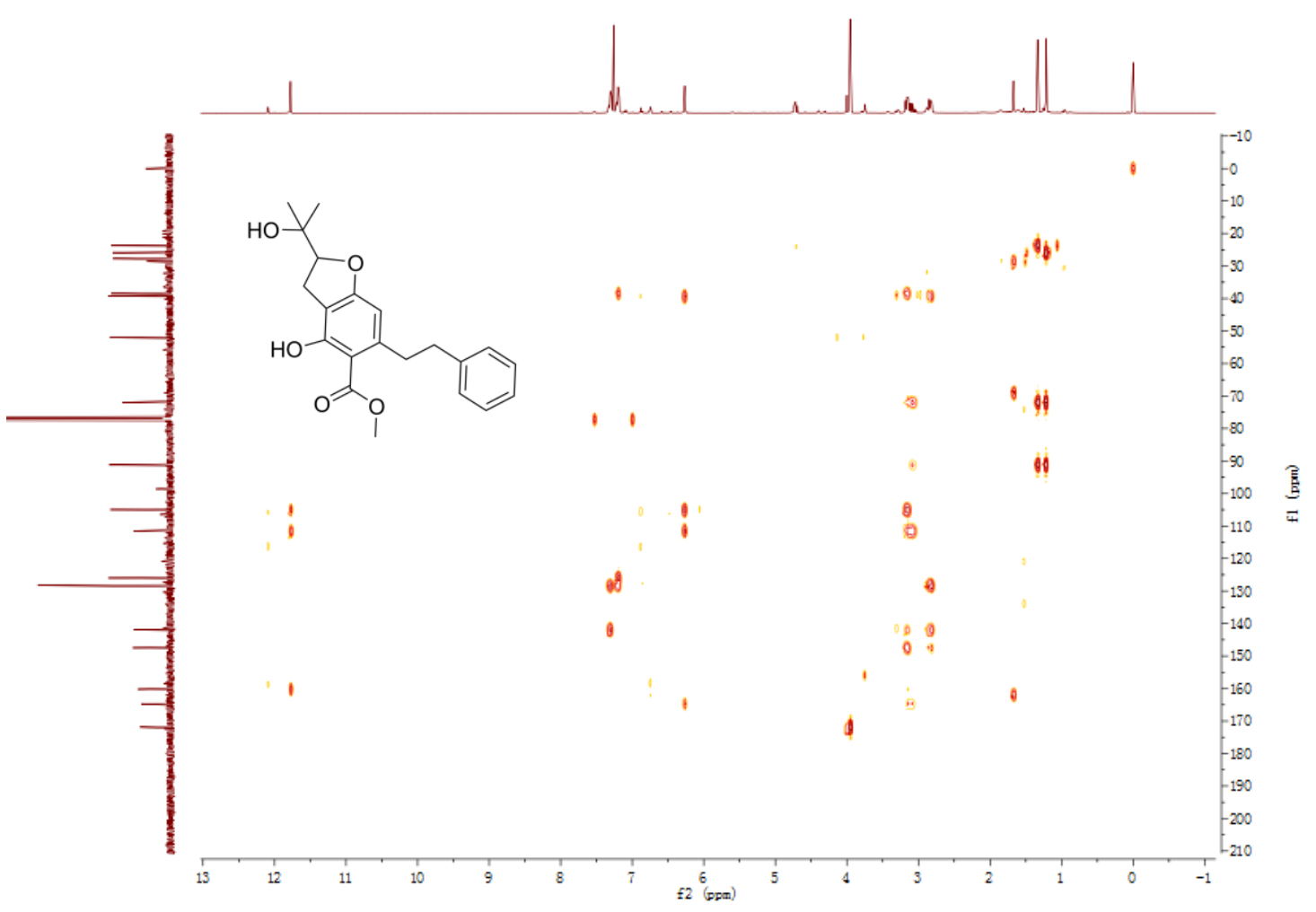

Figure S16. HRESIMS spectrum of 2.

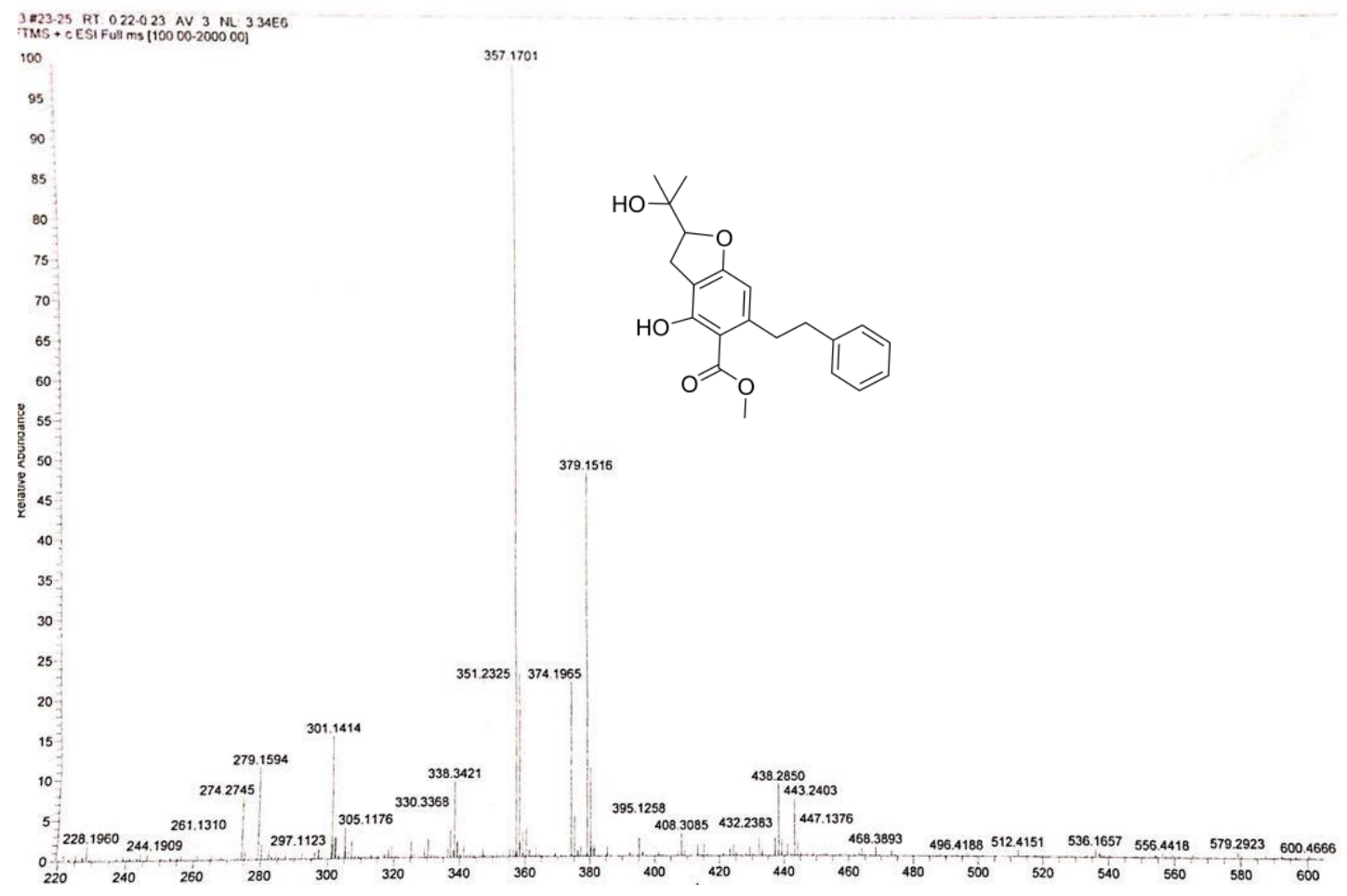


Figure S17. IR ( $\mathrm{KBr}$ disc) spectrum of 2.

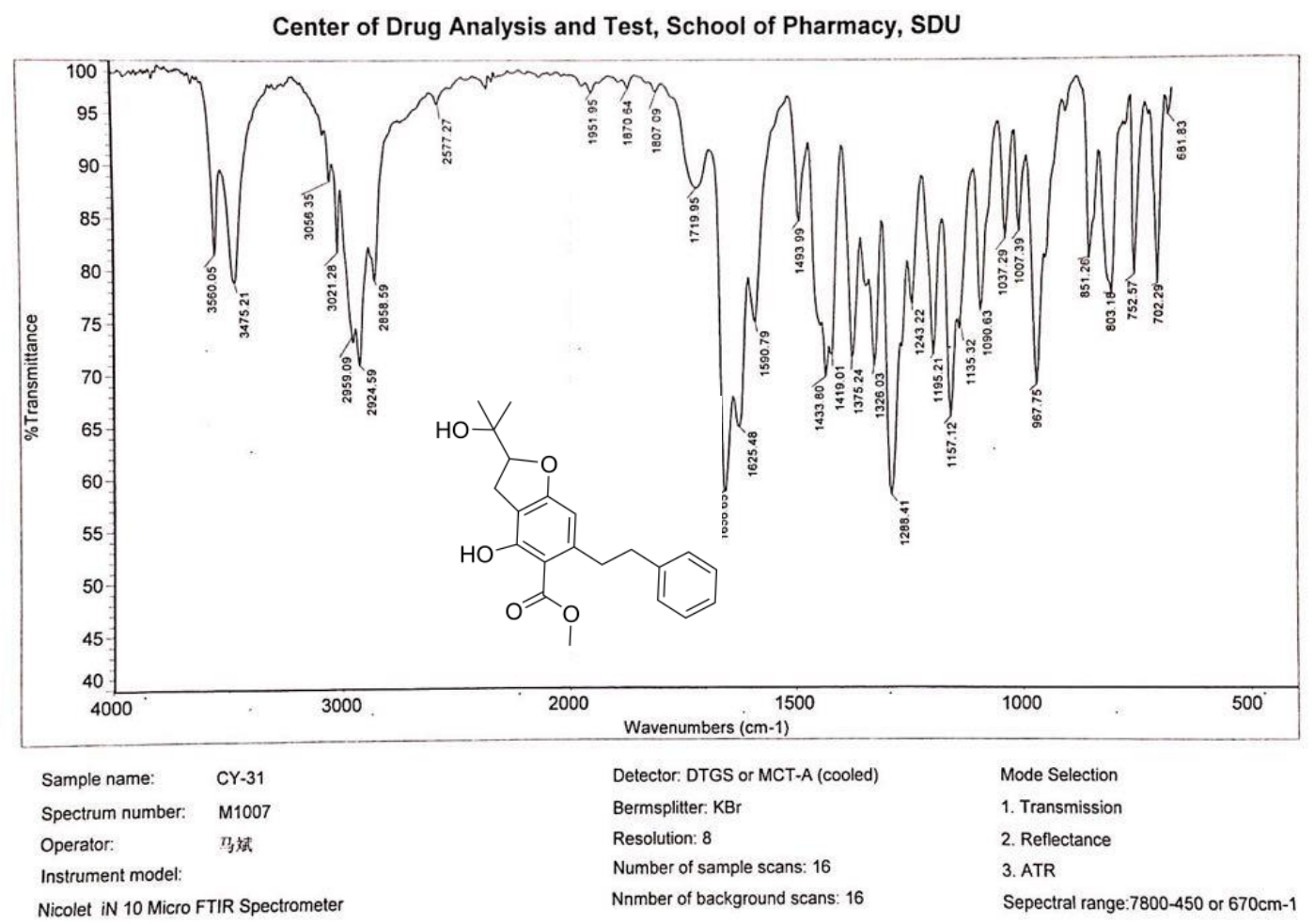

Figure S18. UV spectrum of 2.

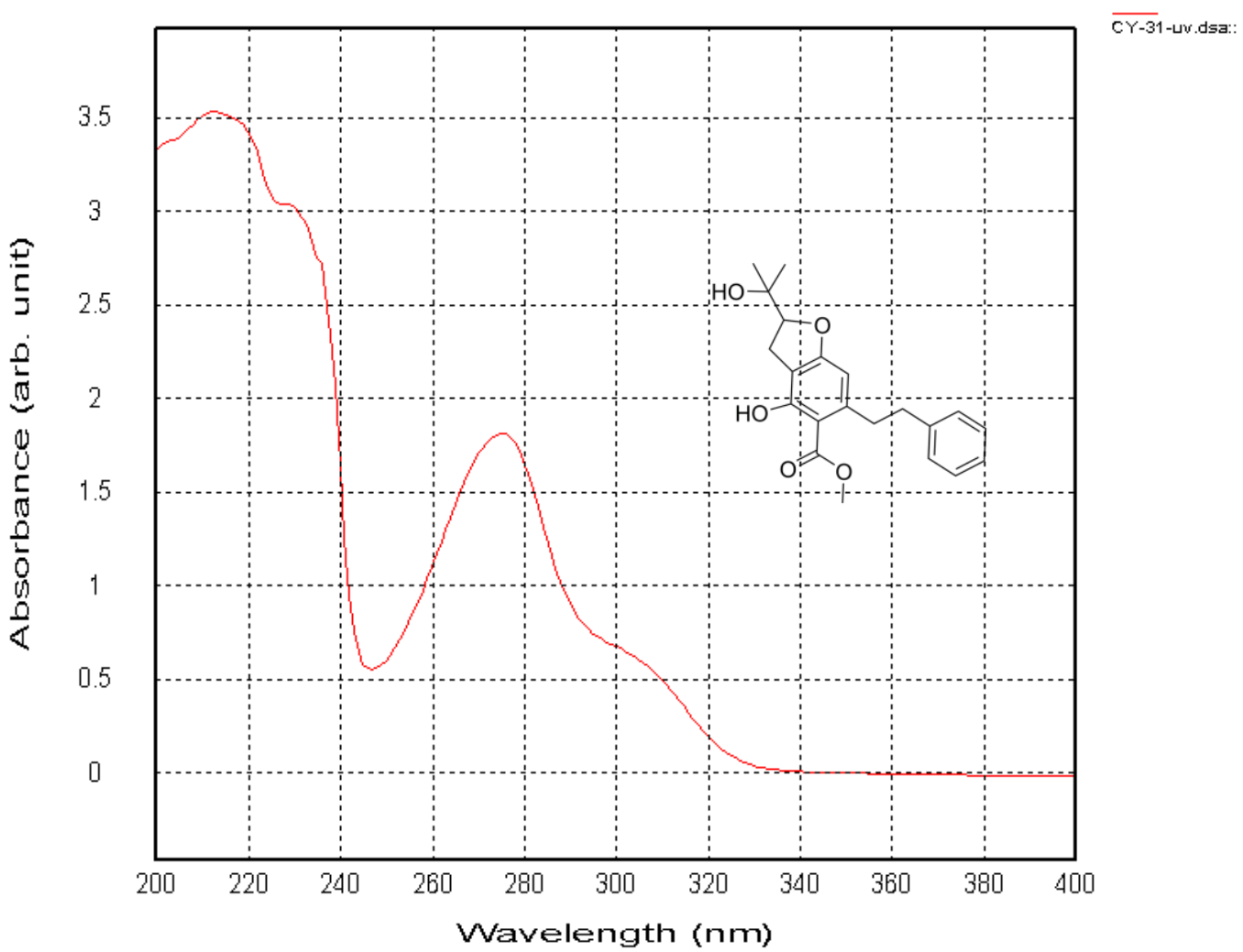


Figure S19. Chiral-phase HPLC analysis of 2.
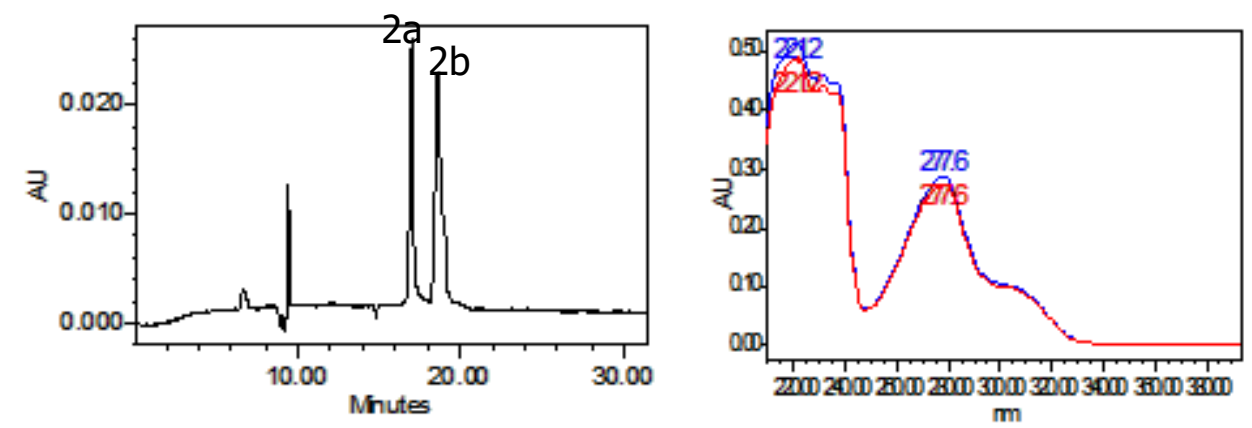

\begin{tabular}{cccccc}
\hline & Retention Time & Area & \% Area & Height & Int Type \\
\hline 1 & 16.962 & 593724 & 52.91 & 19710 & bb \\
2 & 18.613 & 528417 & 47.09 & 20630 & bb \\
\hline
\end{tabular}

Figure S20. Experimental ECD spectra of $\mathbf{2 a / 2} \mathbf{b}$ and calculated ECD spectrum of $\mathbf{2 a}$.

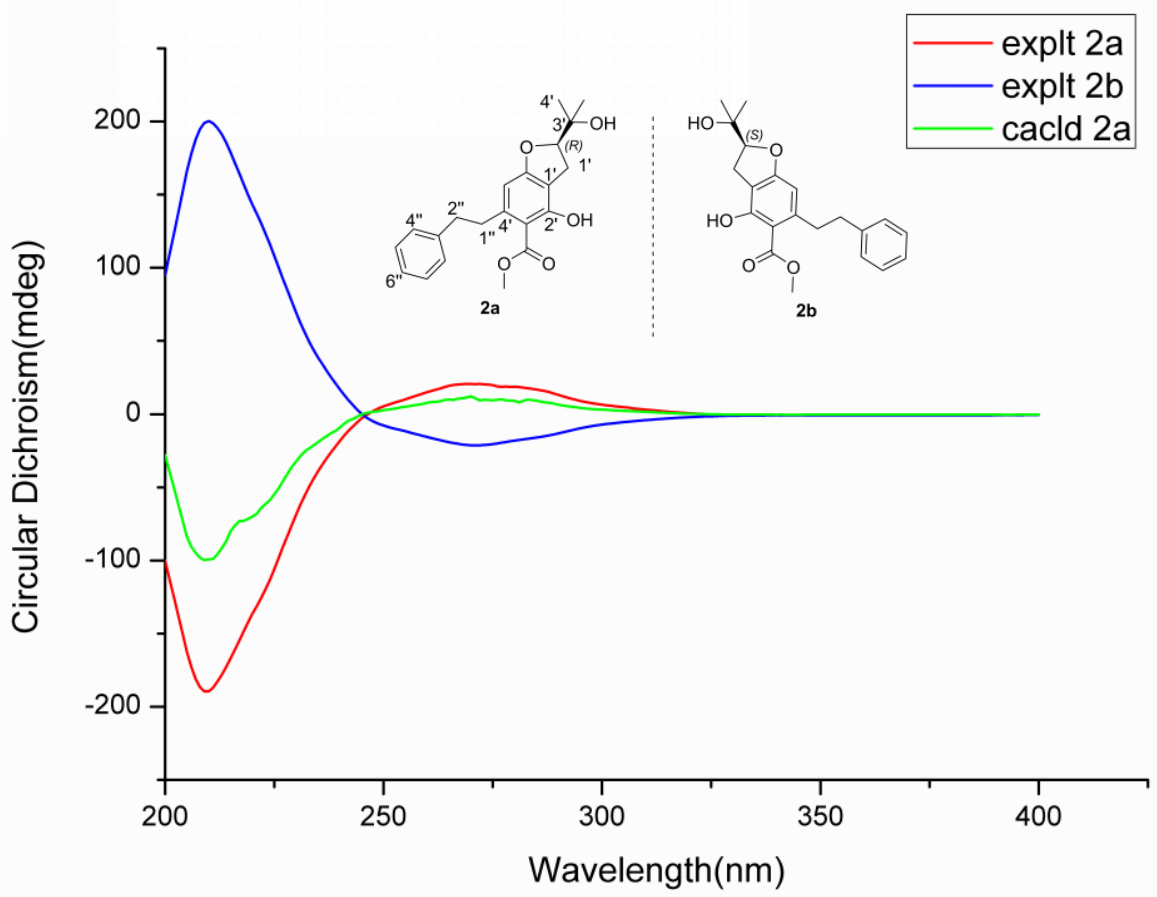


Figure S21. ${ }^{1} \mathrm{H}$ NMR spectrum $(400 \mathrm{MHz})$ of 3 in $\mathrm{CDCl}_{3}$.

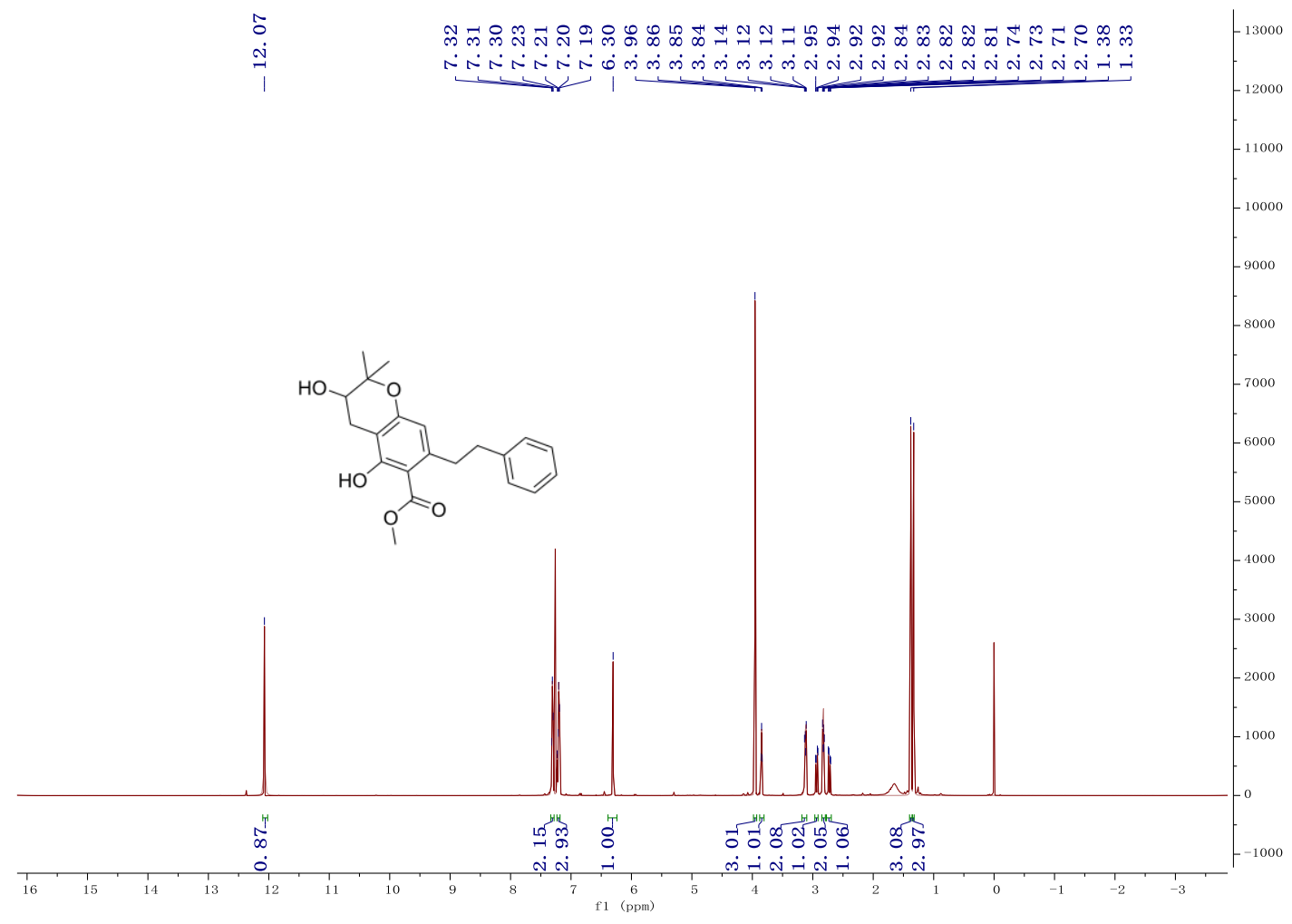

Figure S22. ${ }^{13} \mathrm{C}$ NMR spectrum $(100 \mathrm{MHz})$ of 3 in $\mathrm{CDCl}_{3}$.

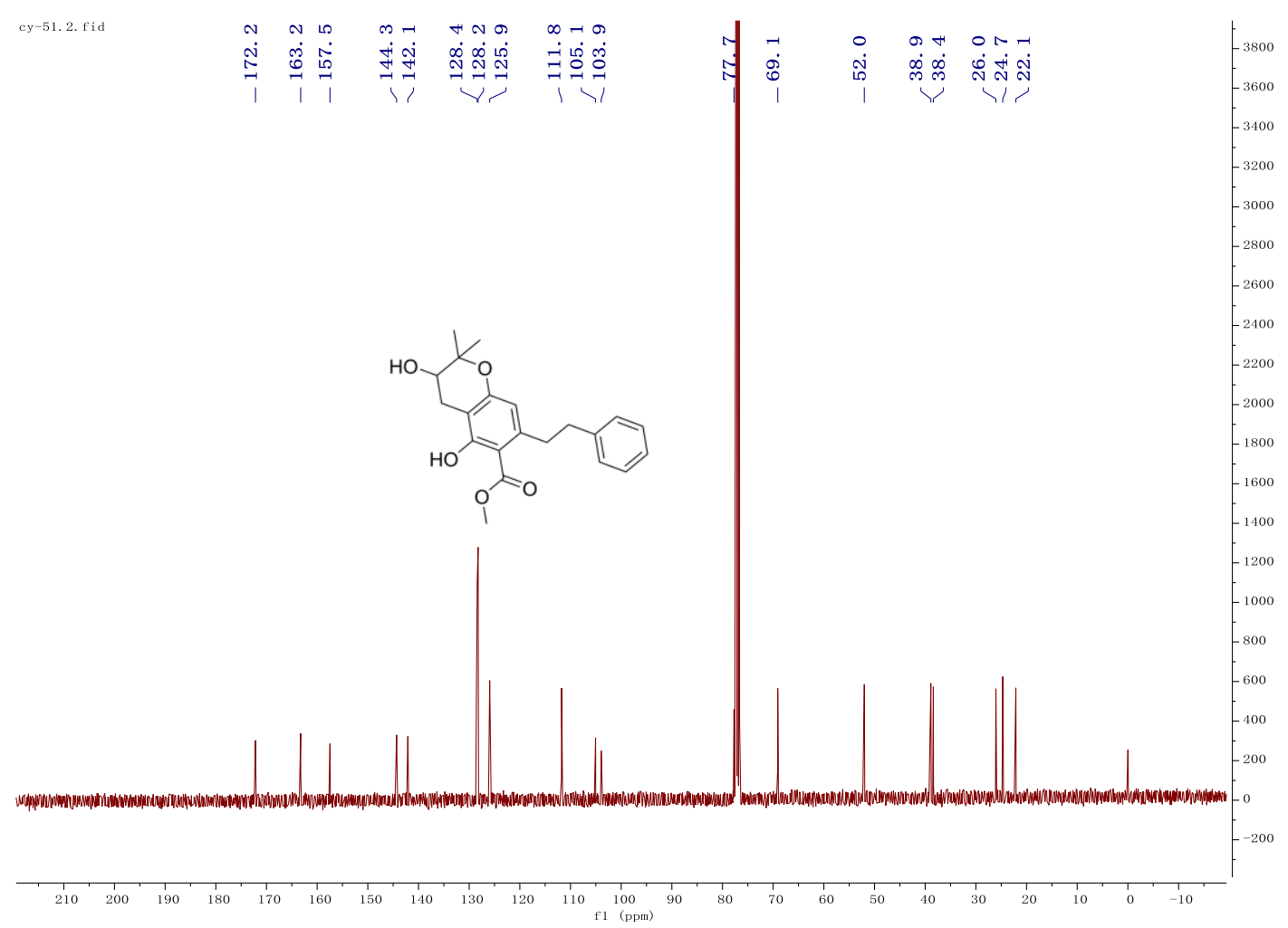


Figure S23. HMQC spectrum $(400 \mathrm{MHz})$ of 3 in $\mathrm{CDCl}_{3}$.

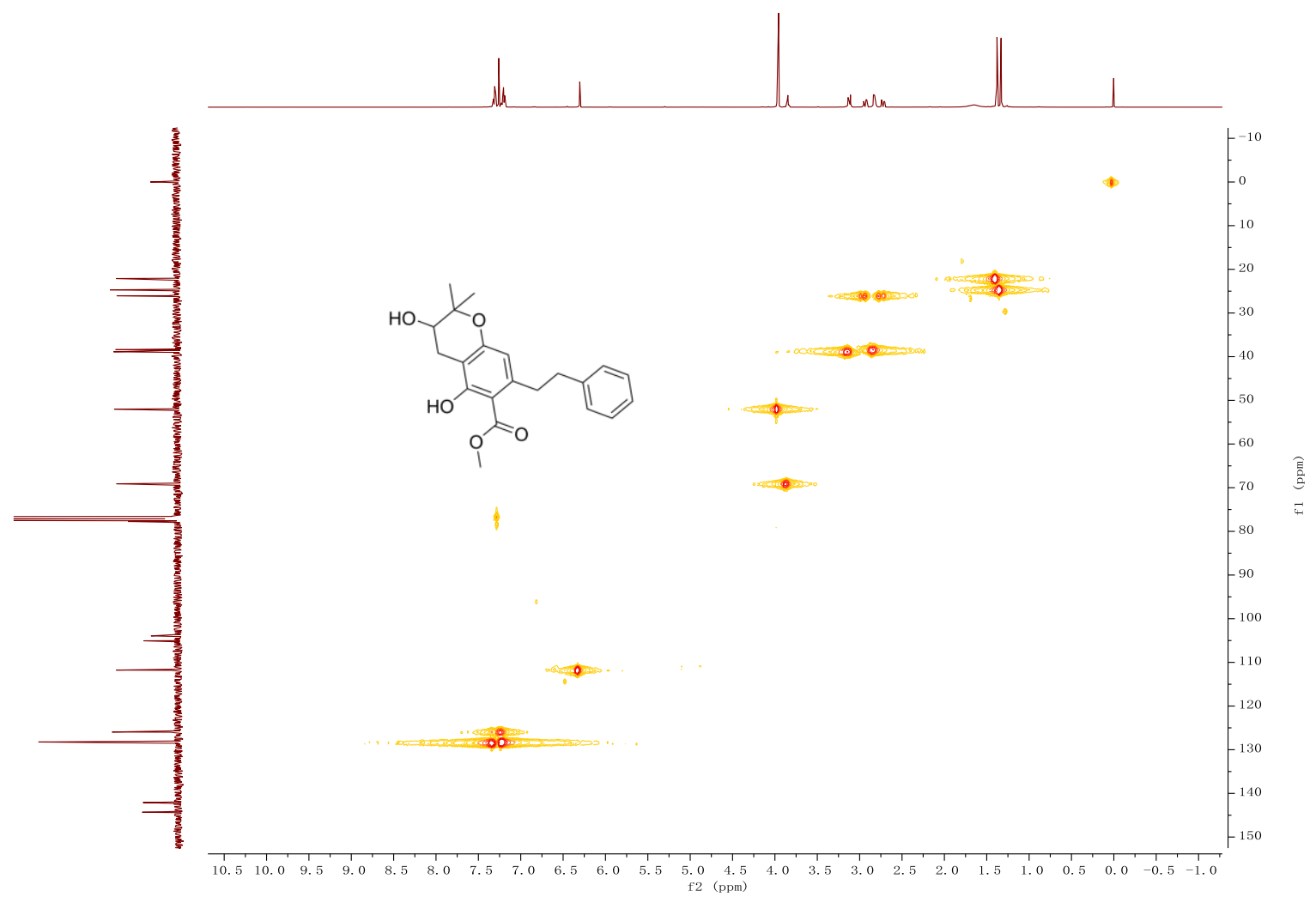

Figure S24. ${ }^{1} \mathrm{H}-1{ }^{1} \mathrm{H}$ spectrum $(400 \mathrm{MHz})$ of 3 in $\mathrm{CDCl}_{3}$.

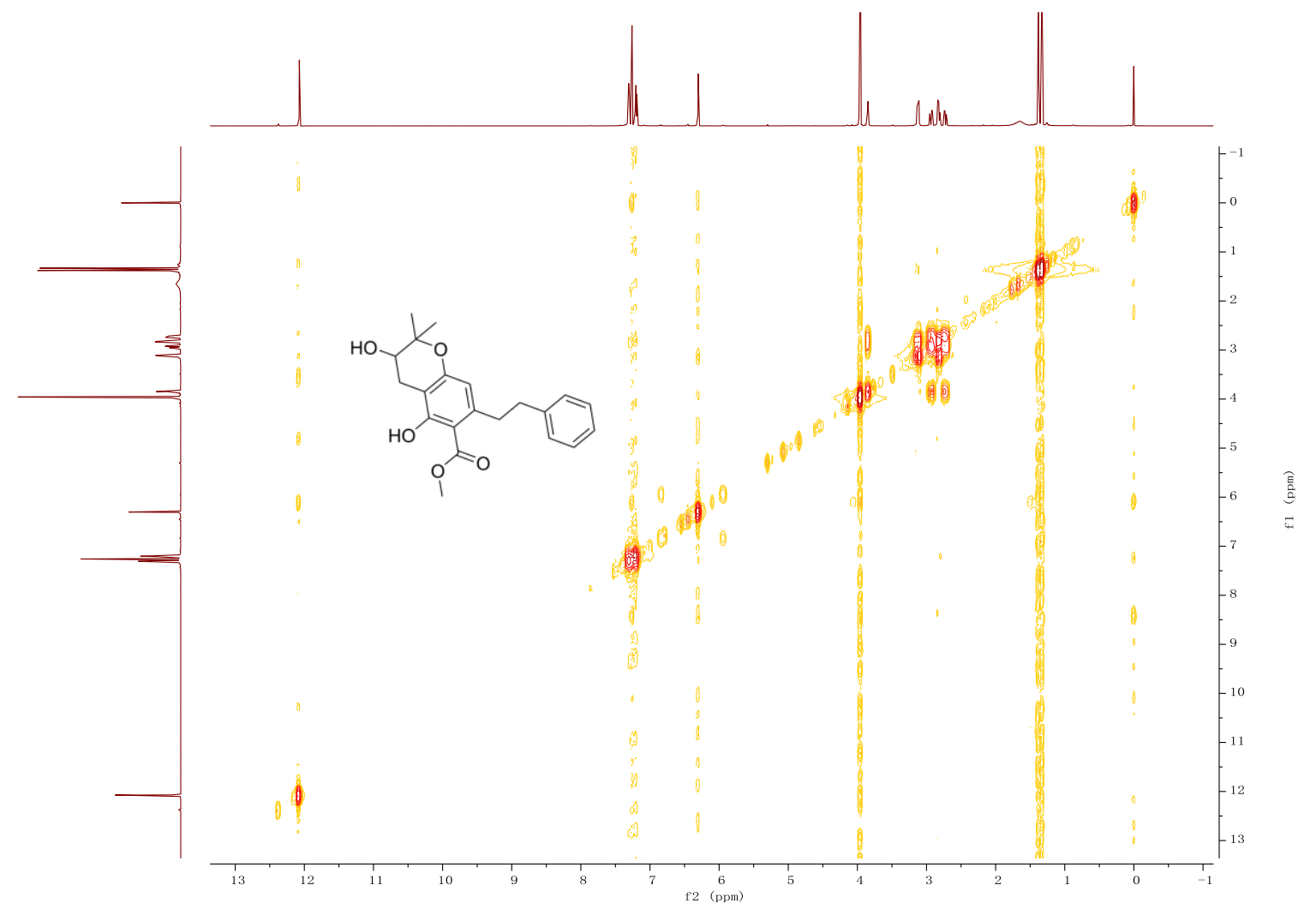


Figure S25. HMBC spectrum $(400 \mathrm{MHz})$ of $\mathbf{3}$ in $\mathrm{CDCl}_{3}$.

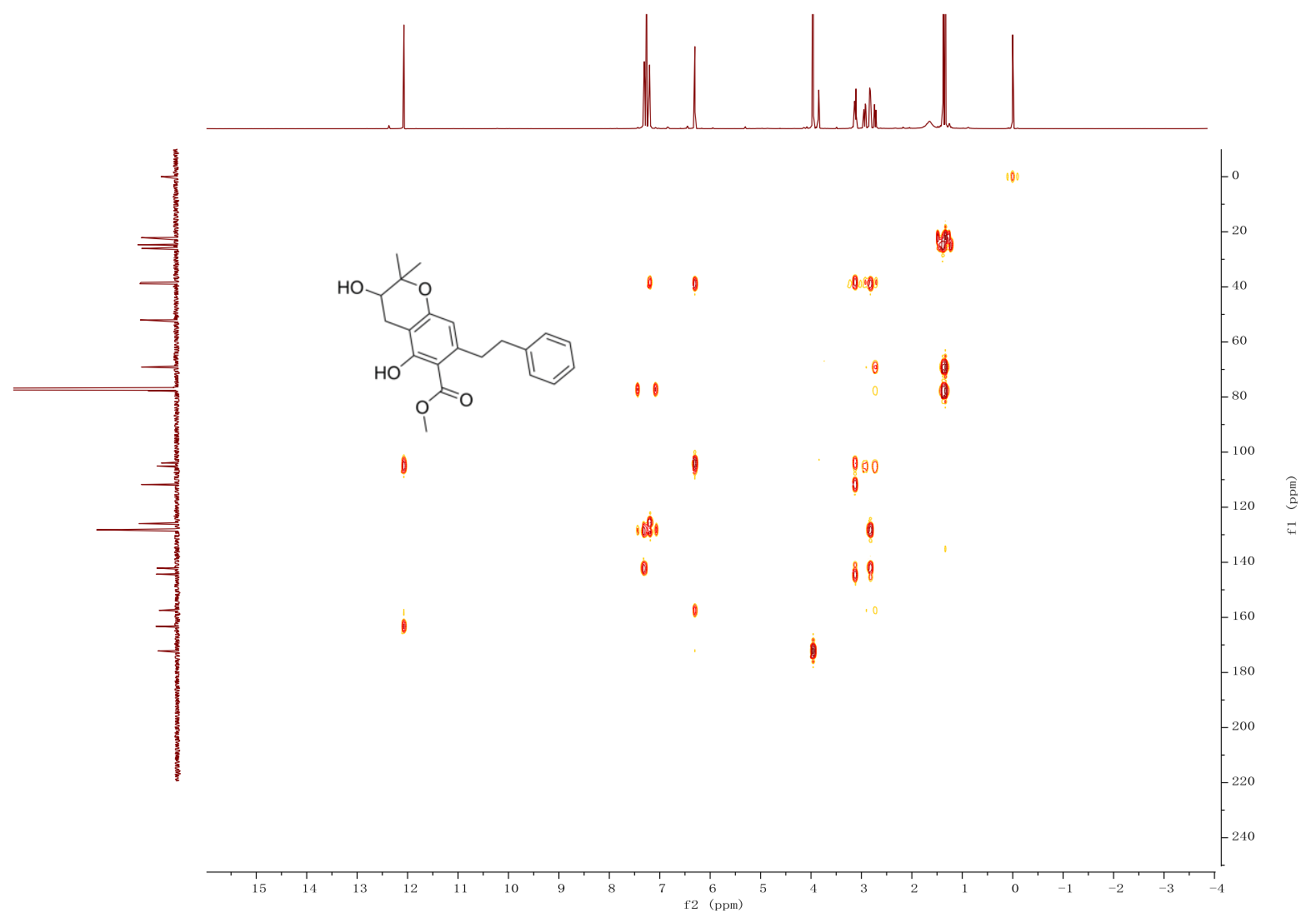

Figure S26. HRESIMS spectrum of $\mathbf{3}$.

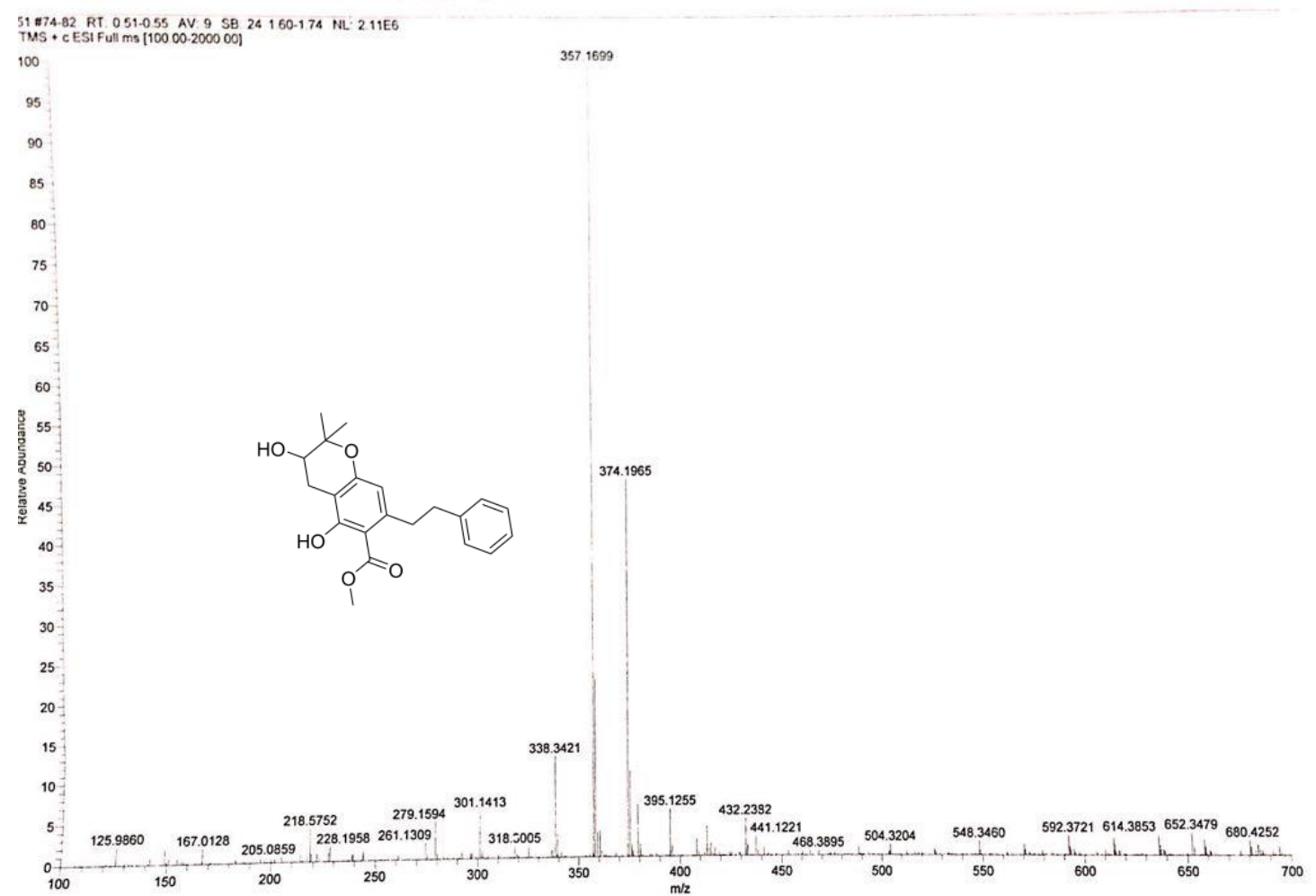


Figure S27. IR ( $\mathrm{KBr}$ disc) spectrum of 3.

Center of Drug Analysis and Test, School of Pharmacy, SDU

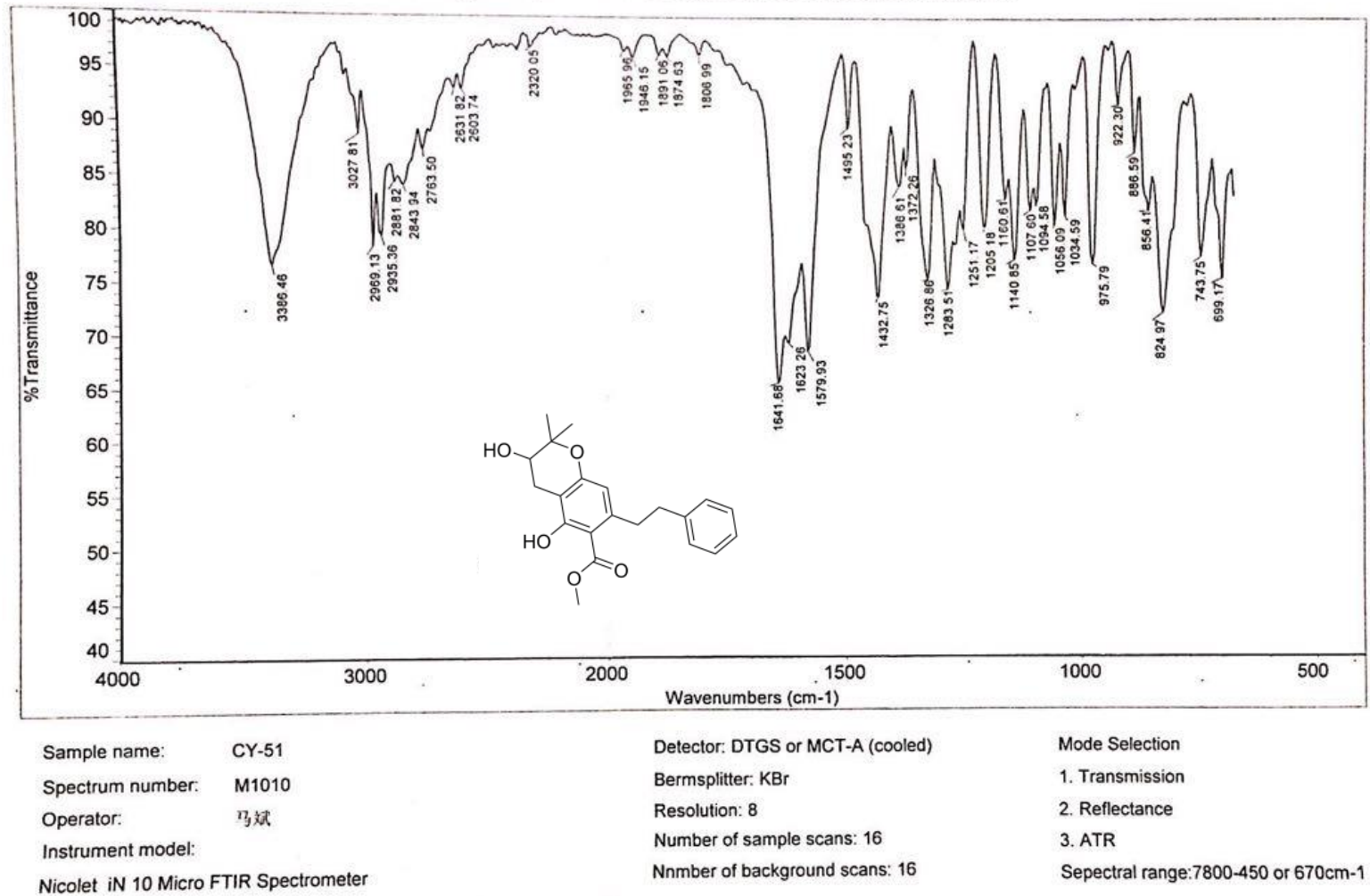

Figure S28. UV spectrum of $\mathbf{3}$.

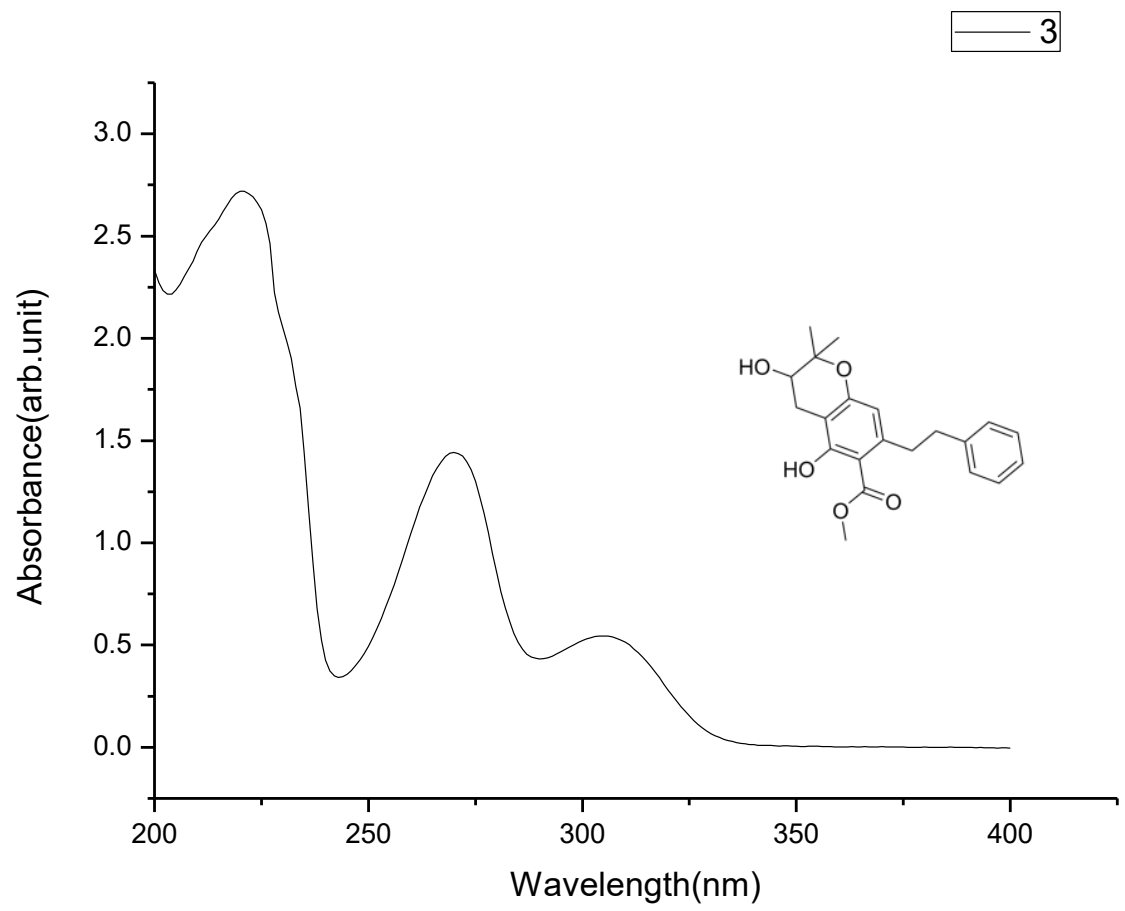


Figure S29. Chiral-phase HPLC analysis of 3.
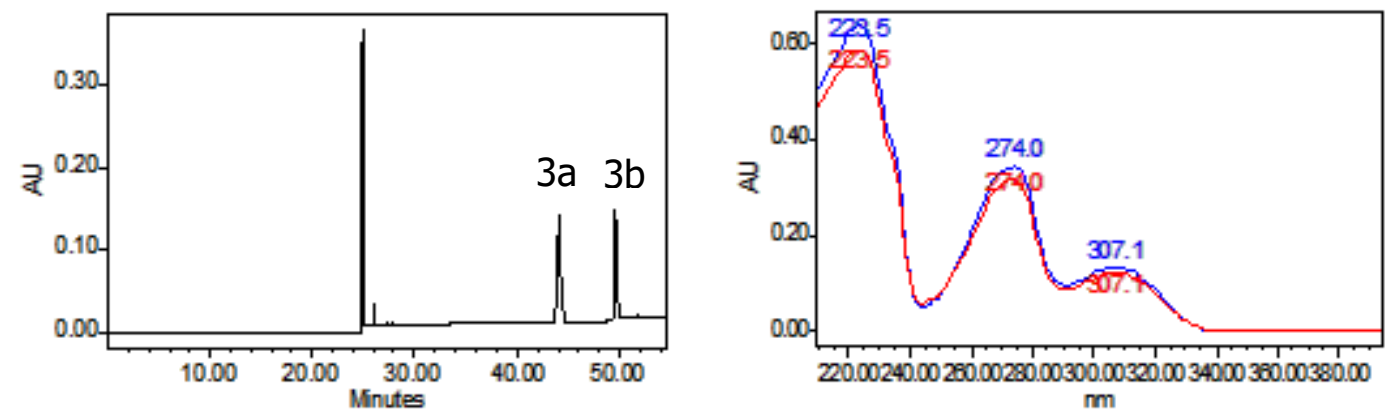

\begin{tabular}{cccccc}
\hline & Retention Time & Area & \% Area & Height & Int Type \\
\hline 1 & 44.1 & 3061649 & 50.81 & 119265 & bb \\
2 & 49.703 & 2964426 & 49.19 & 130699 & bb \\
\hline
\end{tabular}

Figure S30. Experimental ECD spectra of $\mathbf{3 a} / \mathbf{3 b}$ and calculated ECD spectrum of $\mathbf{3 a}$.

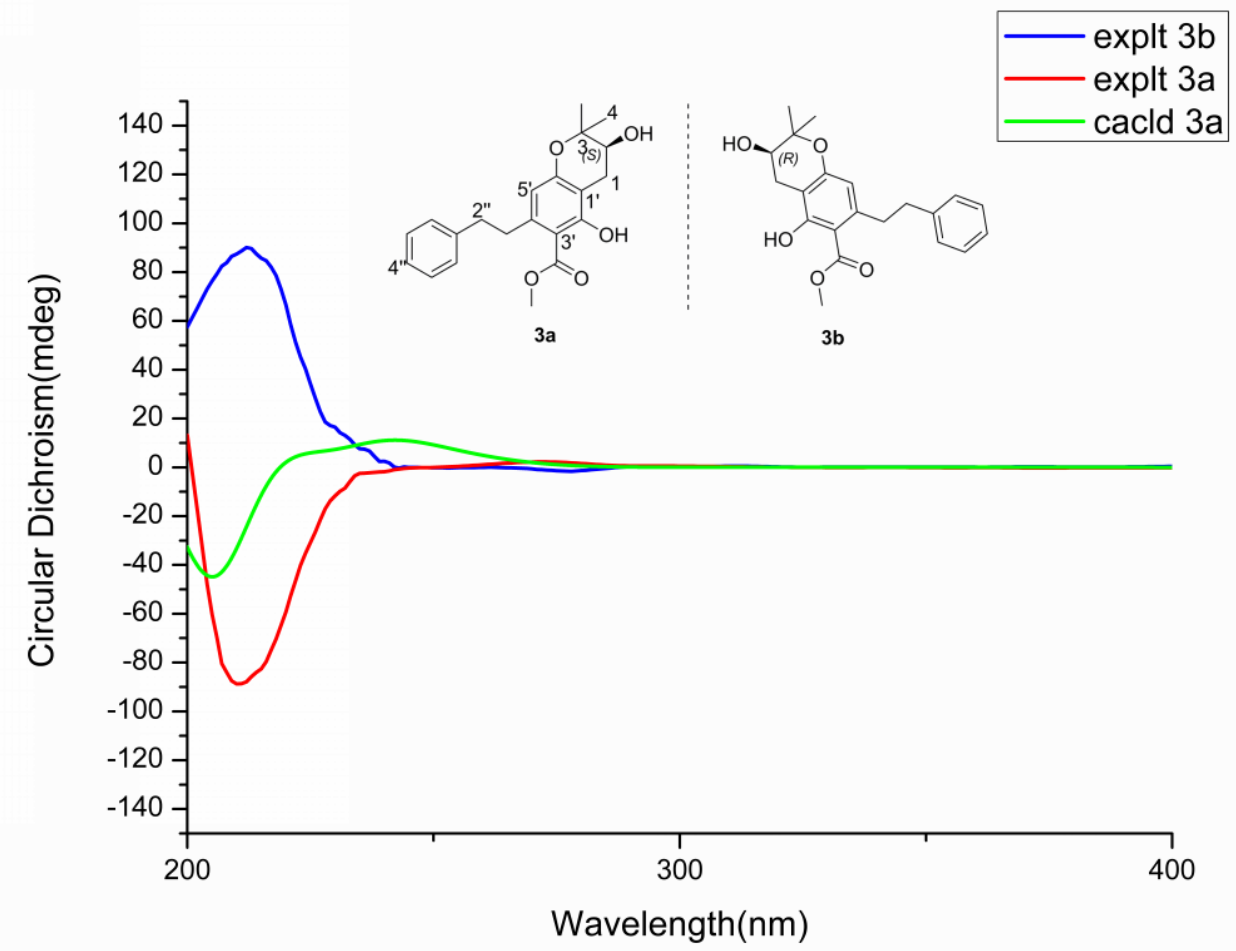


Figure S31. ${ }^{1} \mathrm{H}$ NMR spectrum $(600 \mathrm{MHz})$ of 4 in $\mathrm{CDCl}_{3}$.

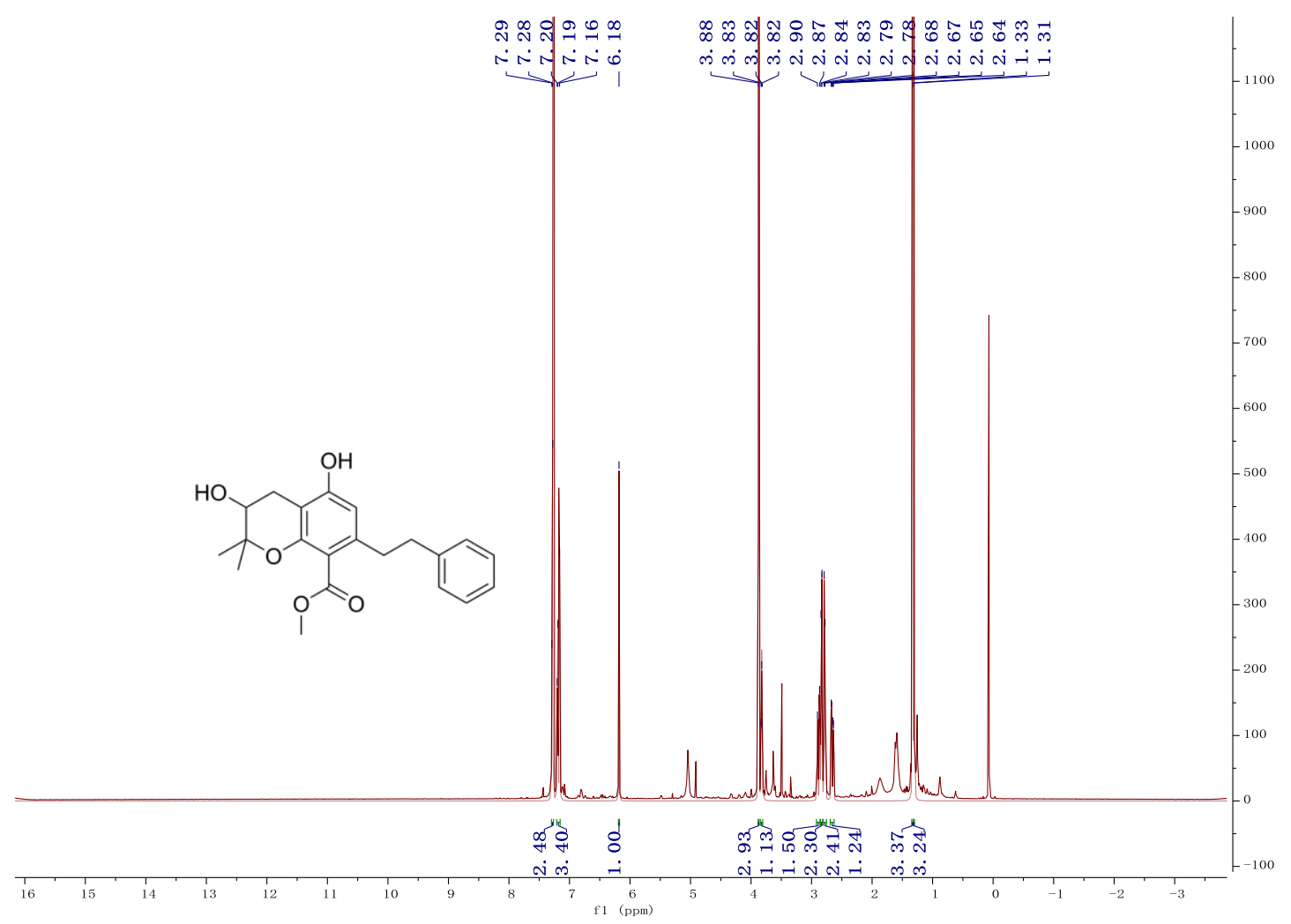

Figure S32. ${ }^{13} \mathrm{C}$ NMR spectrum $(150 \mathrm{MHz})$ of 4 in $\mathrm{CDCl}_{3}$.

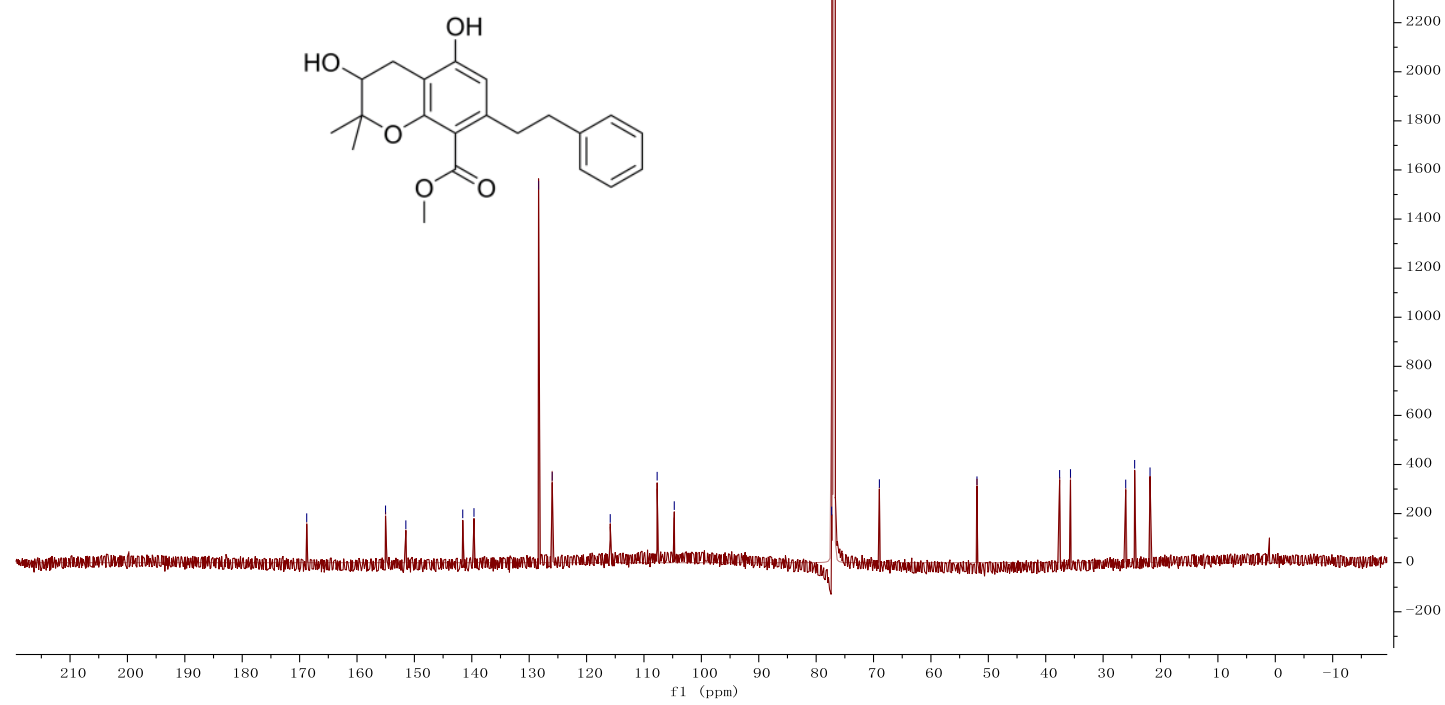


Figure S33. HSQC spectrum $(600 \mathrm{MHz})$ of 4 in $\mathrm{CDCl}_{3}$.

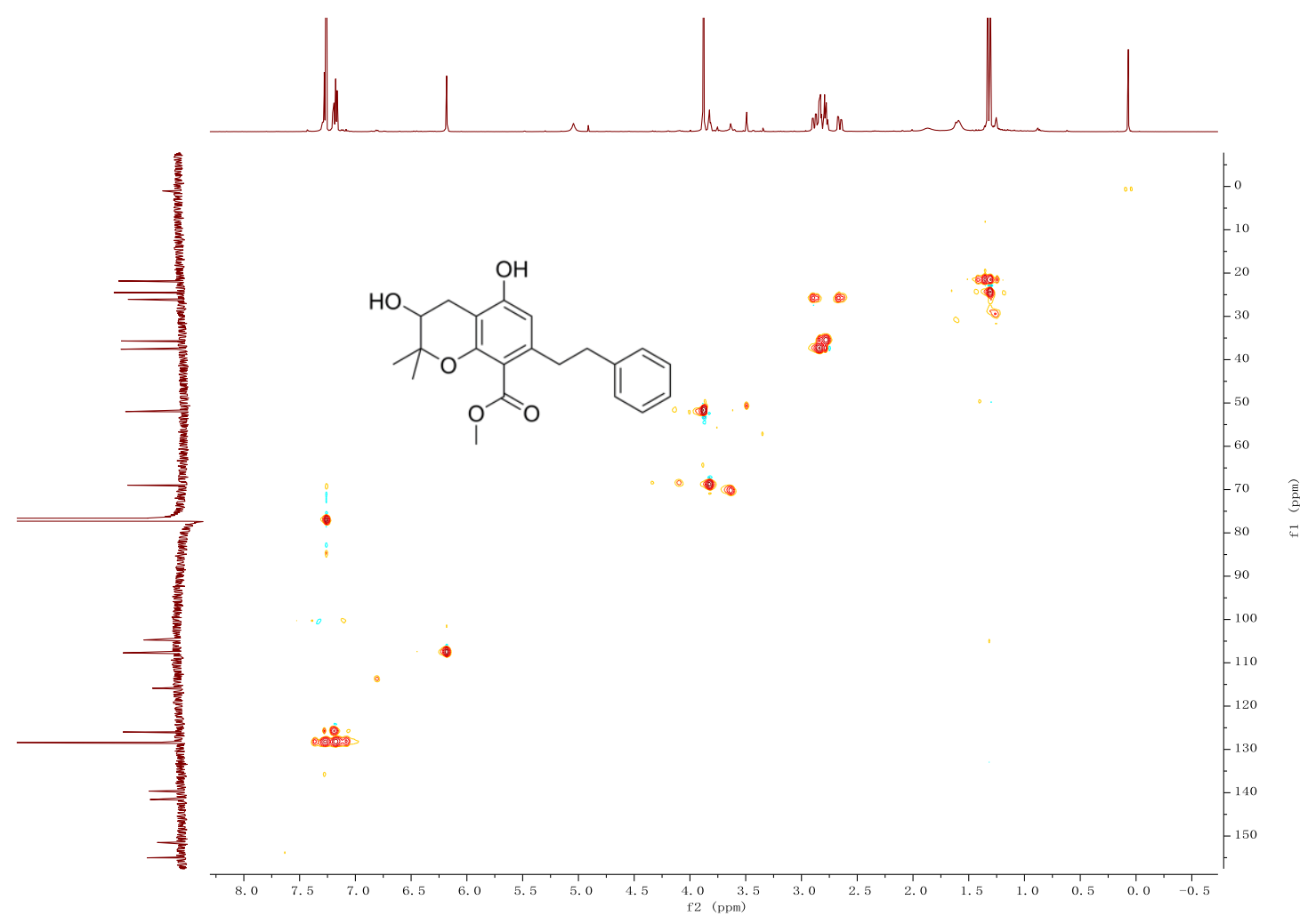

Figure S34. ${ }^{1} \mathrm{H}-{ }^{1} \mathrm{H}$ spectrum $(600 \mathrm{MHz})$ of 4 in $\mathrm{CDCl}_{3}$.

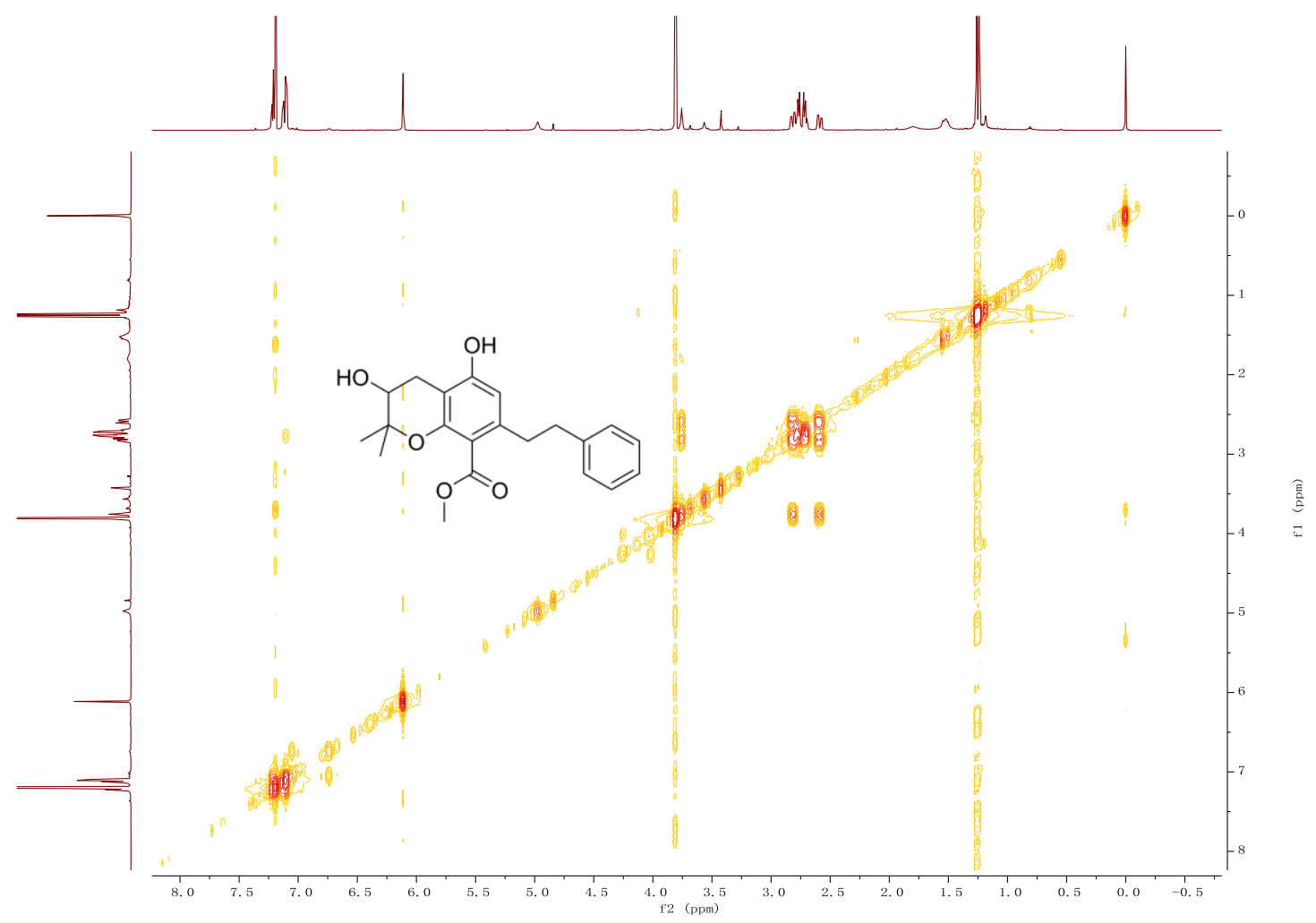


Figure S35. HMBC spectrum $(600 \mathrm{MHz})$ of 4 in $\mathrm{CDCl}_{3}$.

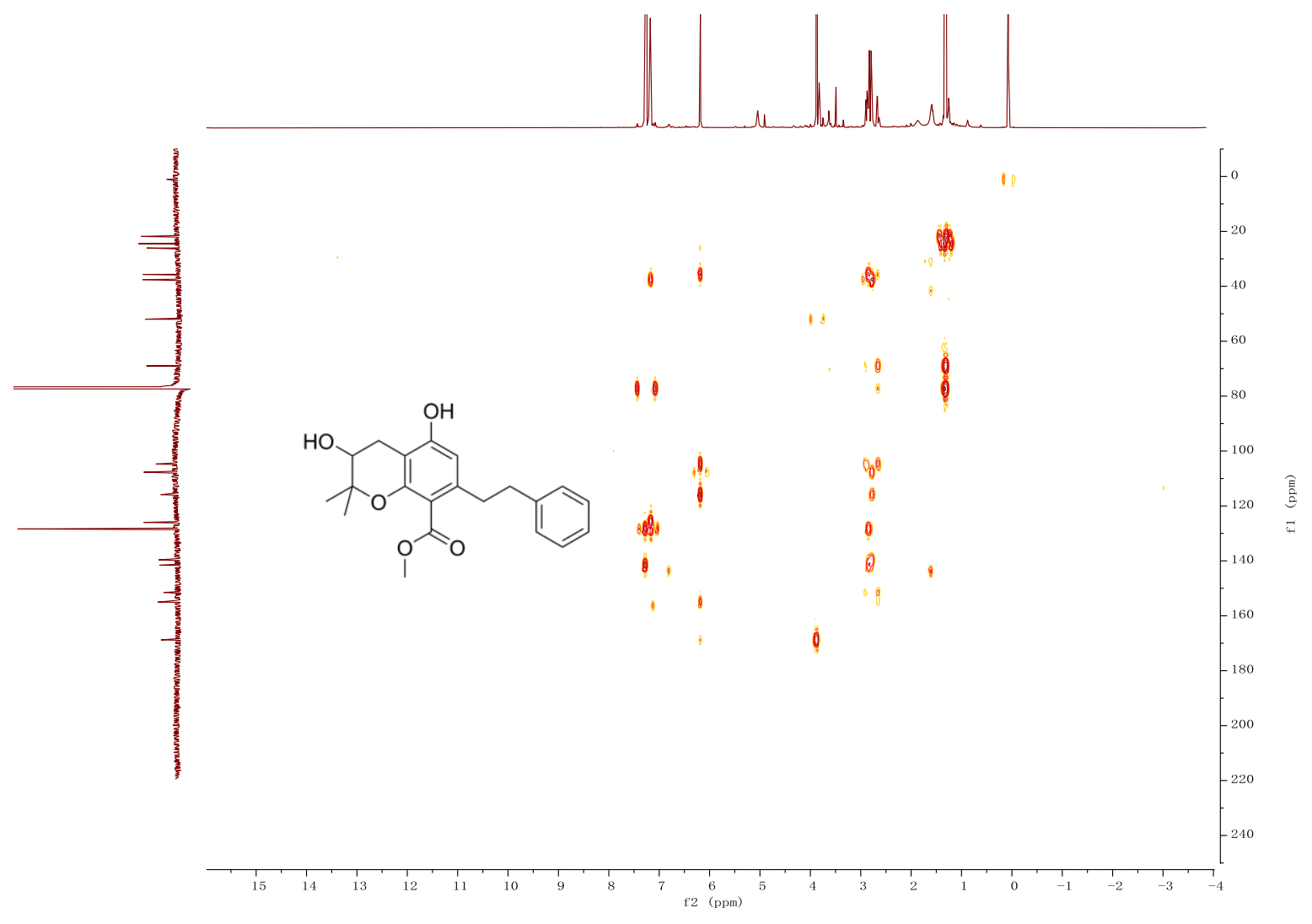

Figure S36. HRESIMS spectrum of 4.

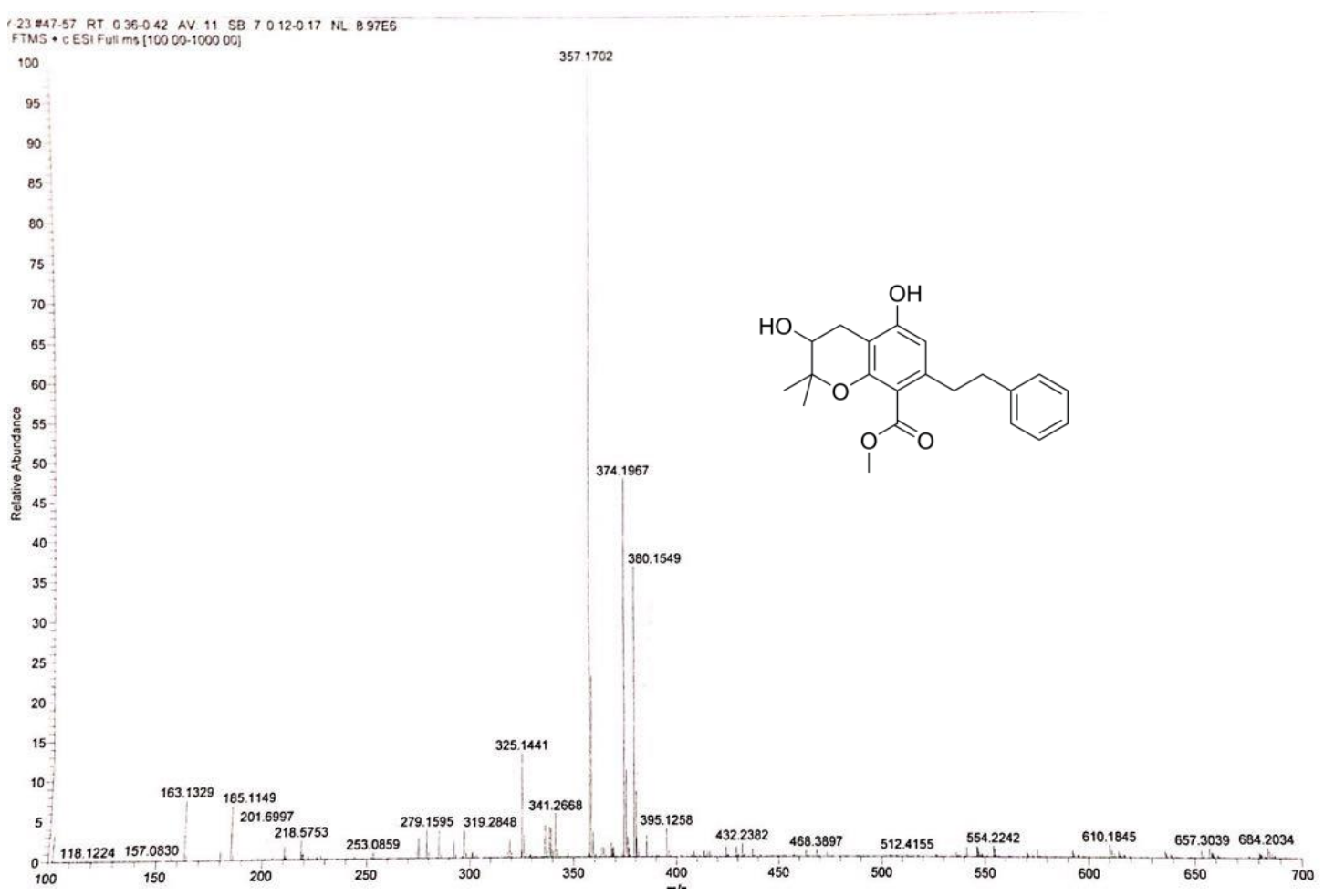


Figure S37. IR ( $\mathrm{KBr}$ disc) spectrum of 4.

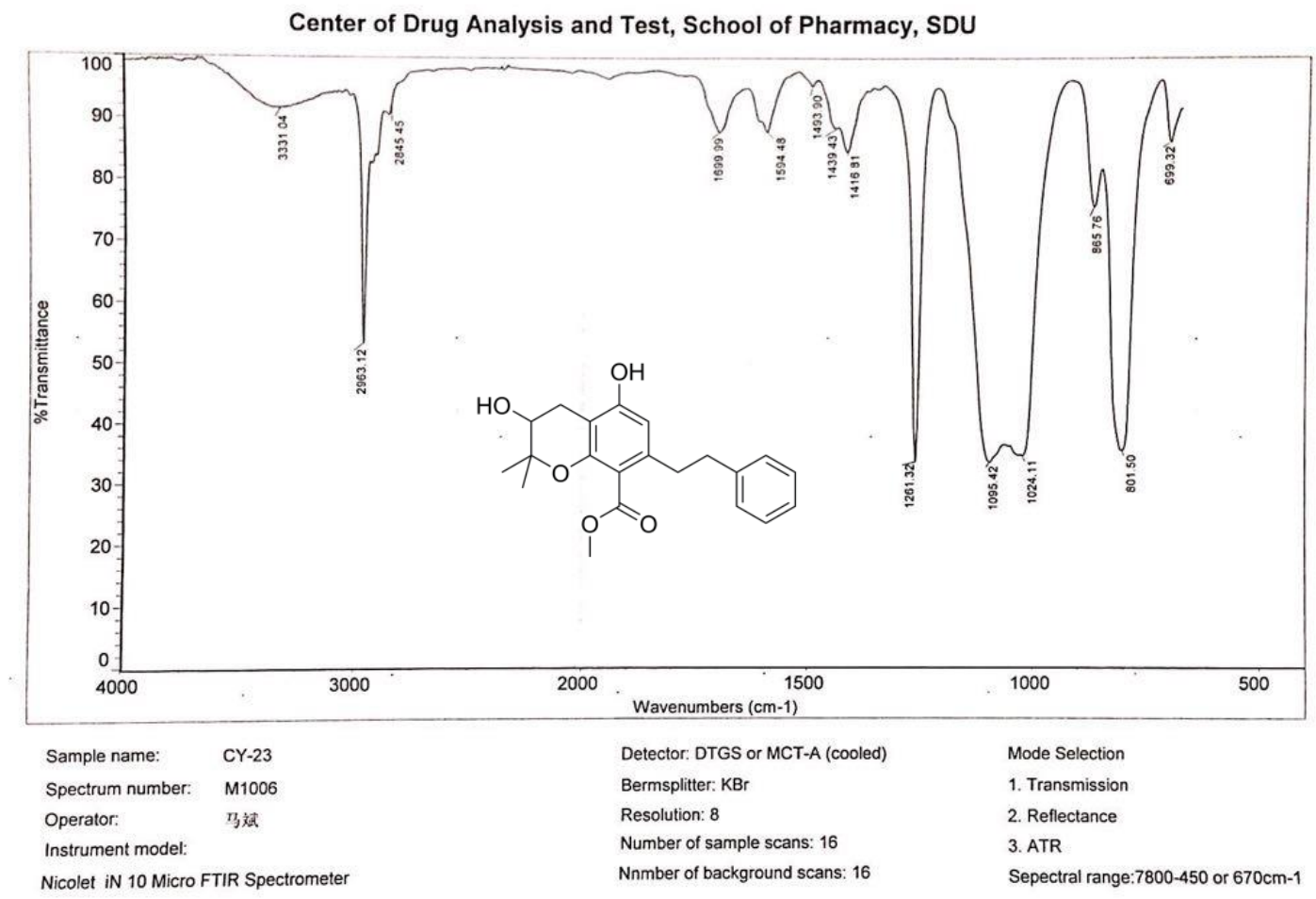

Figure S38. UV spectrum of 4.

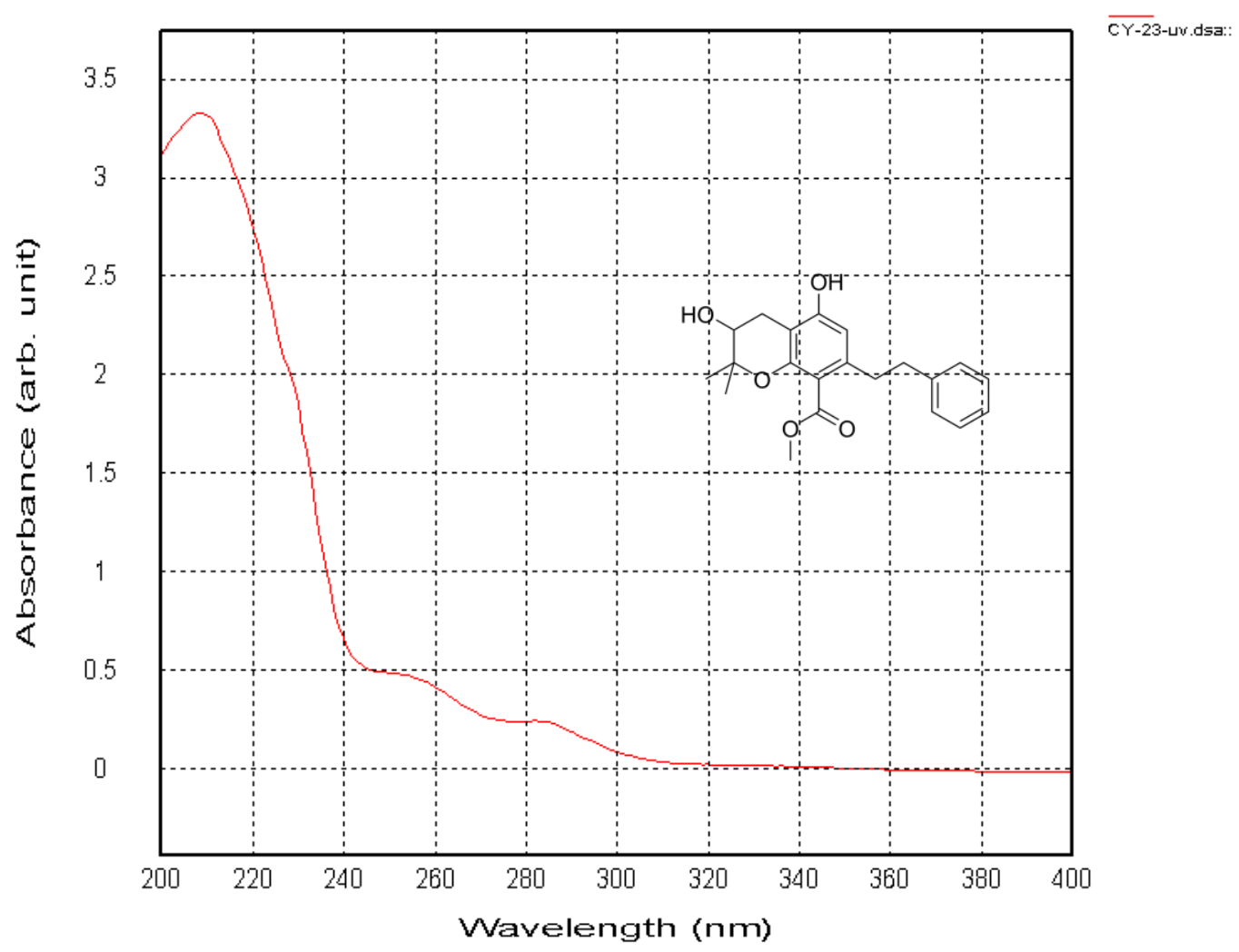


Figure S39. Chiral-phase HPLC analysis of 4.
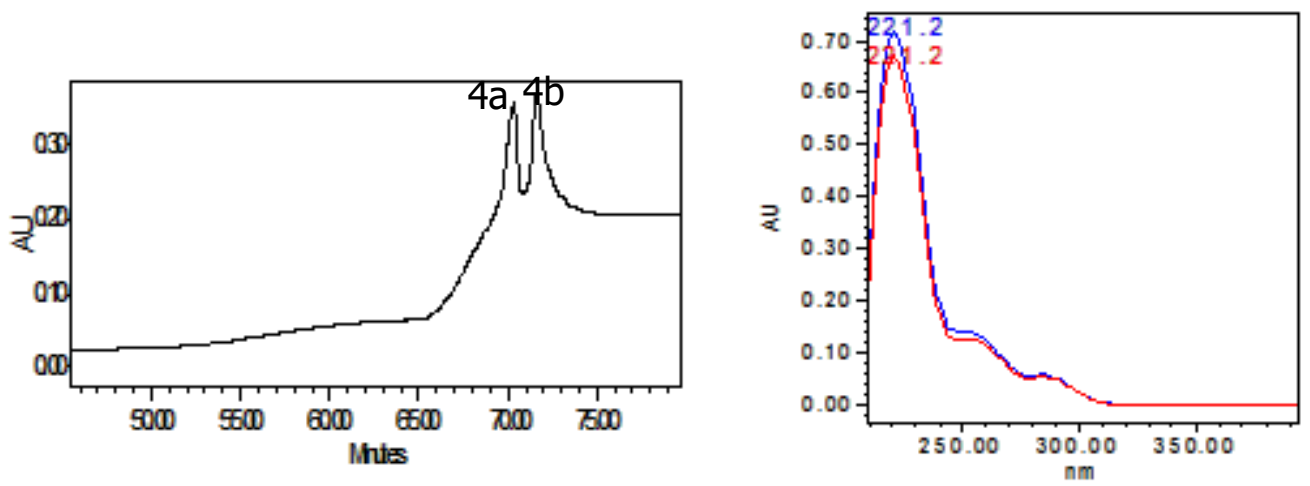

\begin{tabular}{cccccc}
\hline & Retention Time & Area & \% Area & Height & Int Type \\
\hline 1 & 70.313 & 6350491 & 49.31 & 125887 & bb \\
2 & 71.624 & 6527727 & 50.69 & 137766 & bb \\
\hline
\end{tabular}

Figure S40. Experimental ECD spectra of $\mathbf{4 a} / \mathbf{4 b}$ and calculated ECD spectrum of $\mathbf{4 b}$.

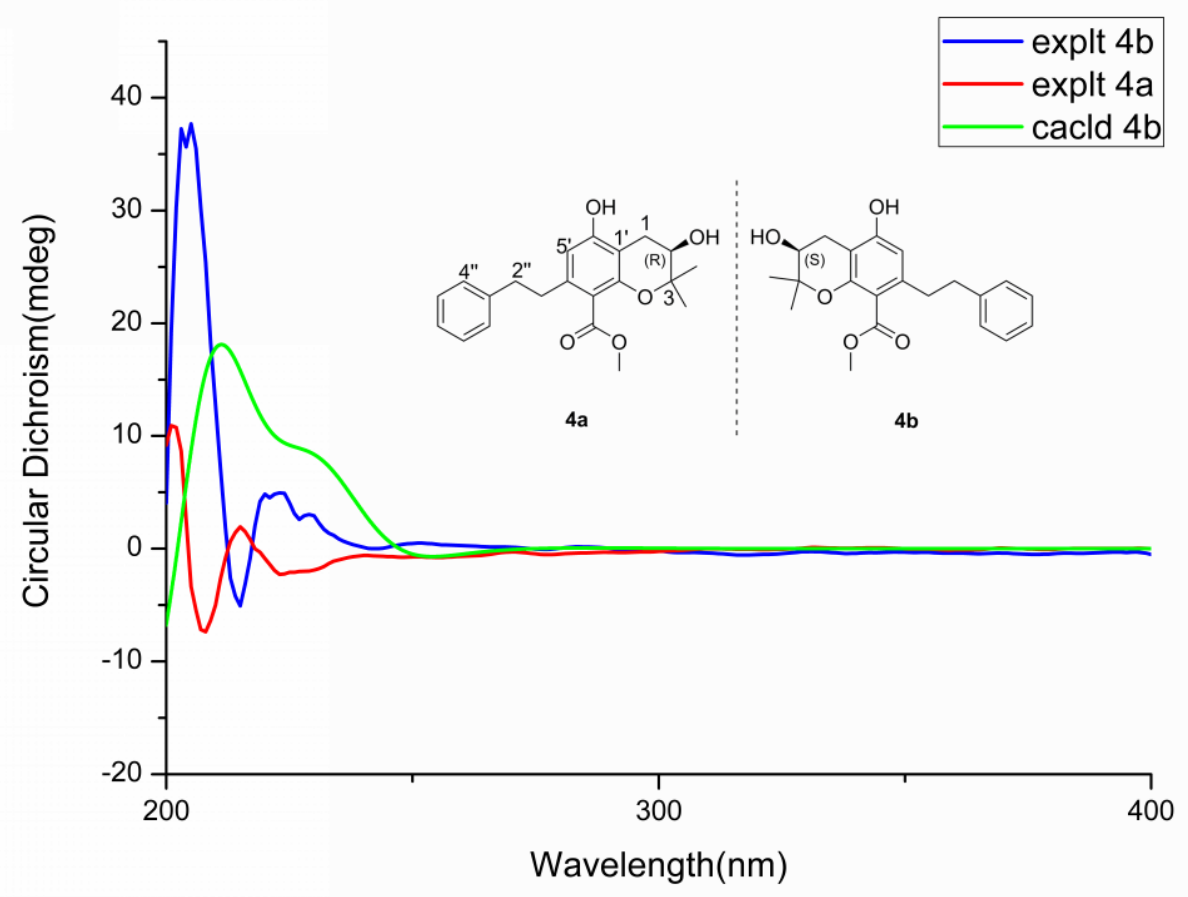


Figure S41. ${ }^{1} \mathrm{H}$ NMR spectrum $(400 \mathrm{MHz})$ of 5 in $\mathrm{CDCl}_{3}$.

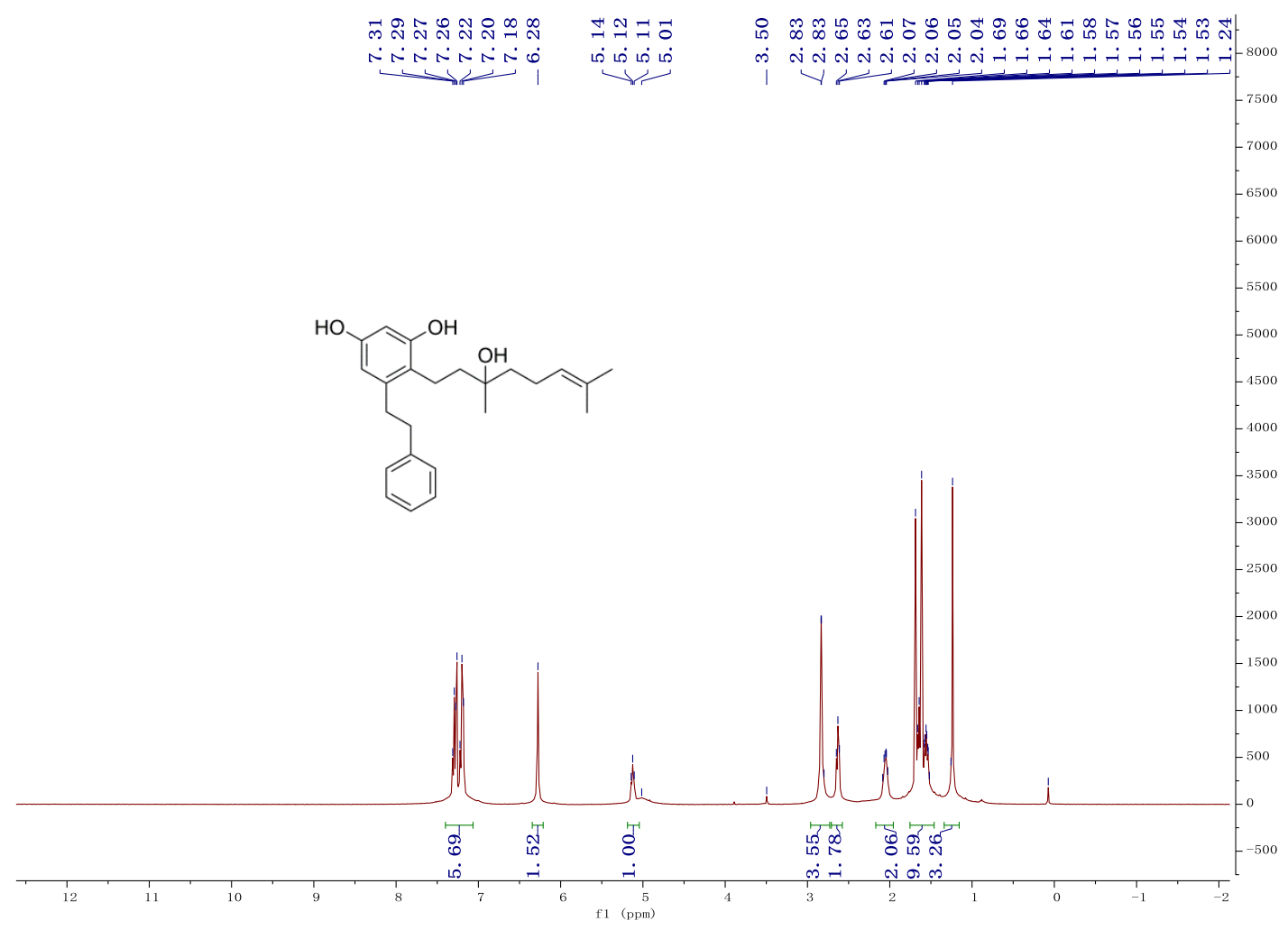

Figure $\mathbf{S 4 2} .{ }^{13} \mathrm{C}$ NMR spectrum $(100 \mathrm{MHz})$ of 5 in $\mathrm{CDCl}_{3}$.

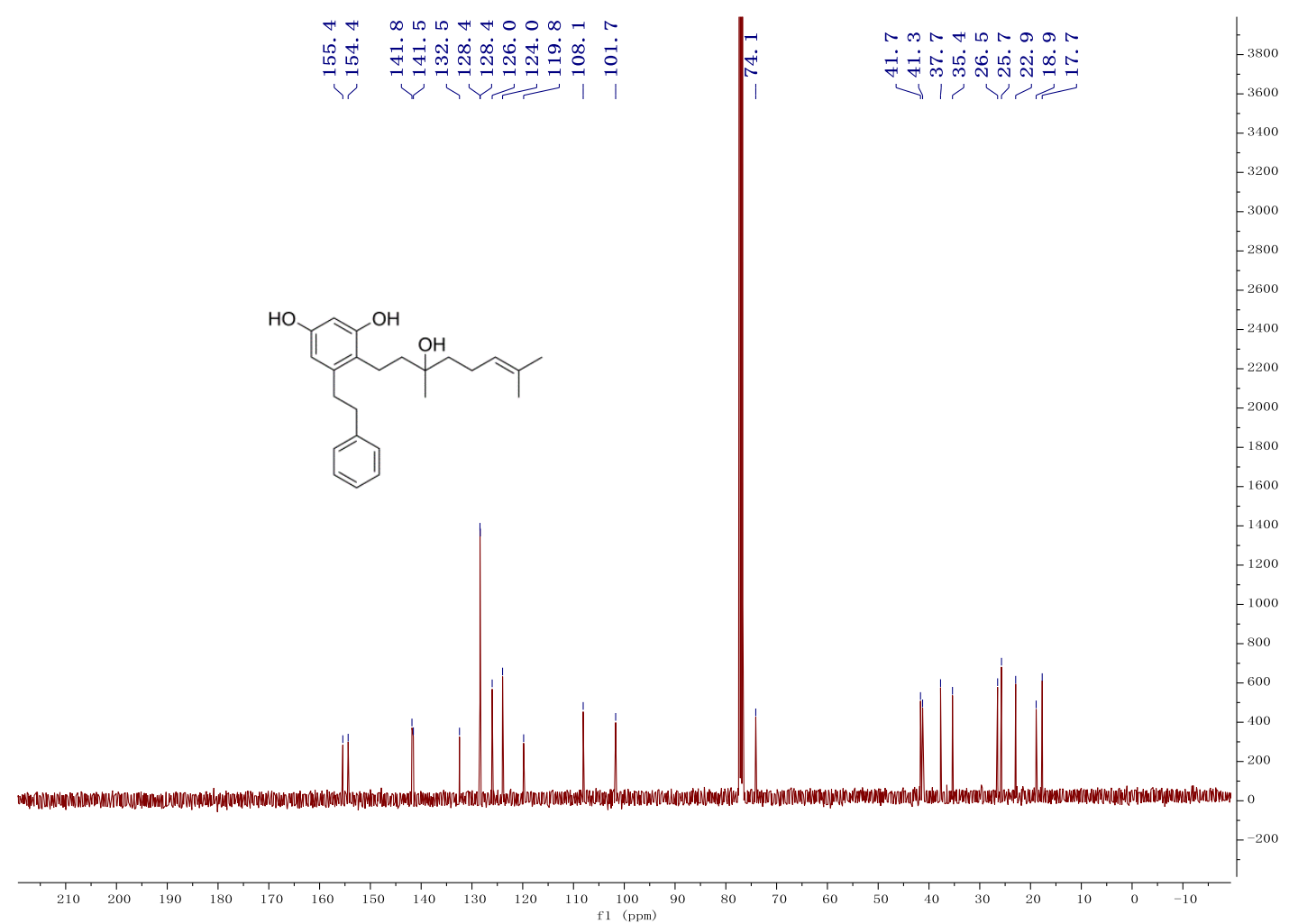


Figure S43. HSQC spectrum $(400 \mathrm{MHz})$ of 5 in $\mathrm{CDCl}_{3}$.

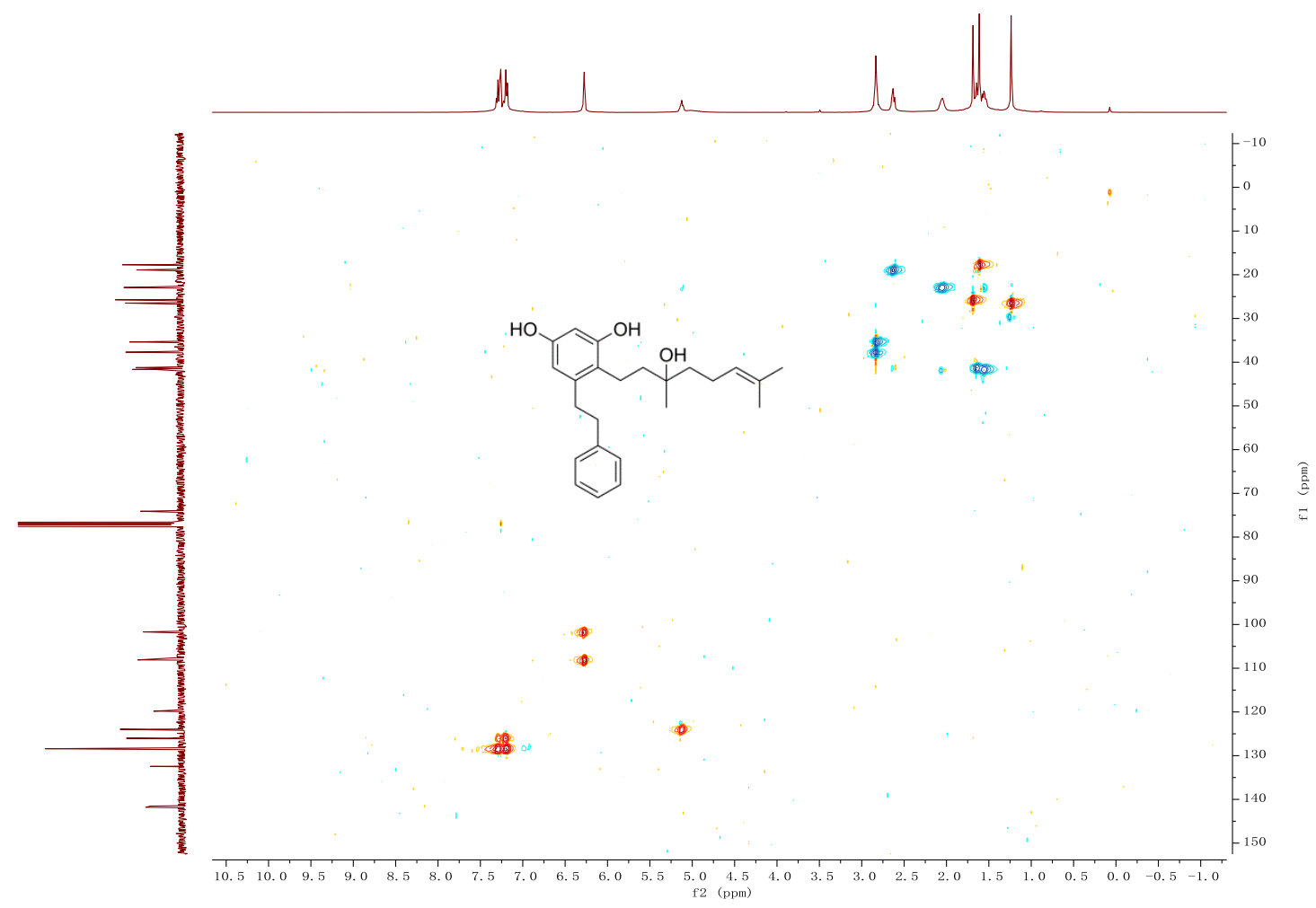

Figure S44. ${ }^{1} \mathrm{H}-{ }^{1} \mathrm{H}$ spectrum $(400 \mathrm{MHz})$ of 5 in $\mathrm{CDCl}_{3}$.

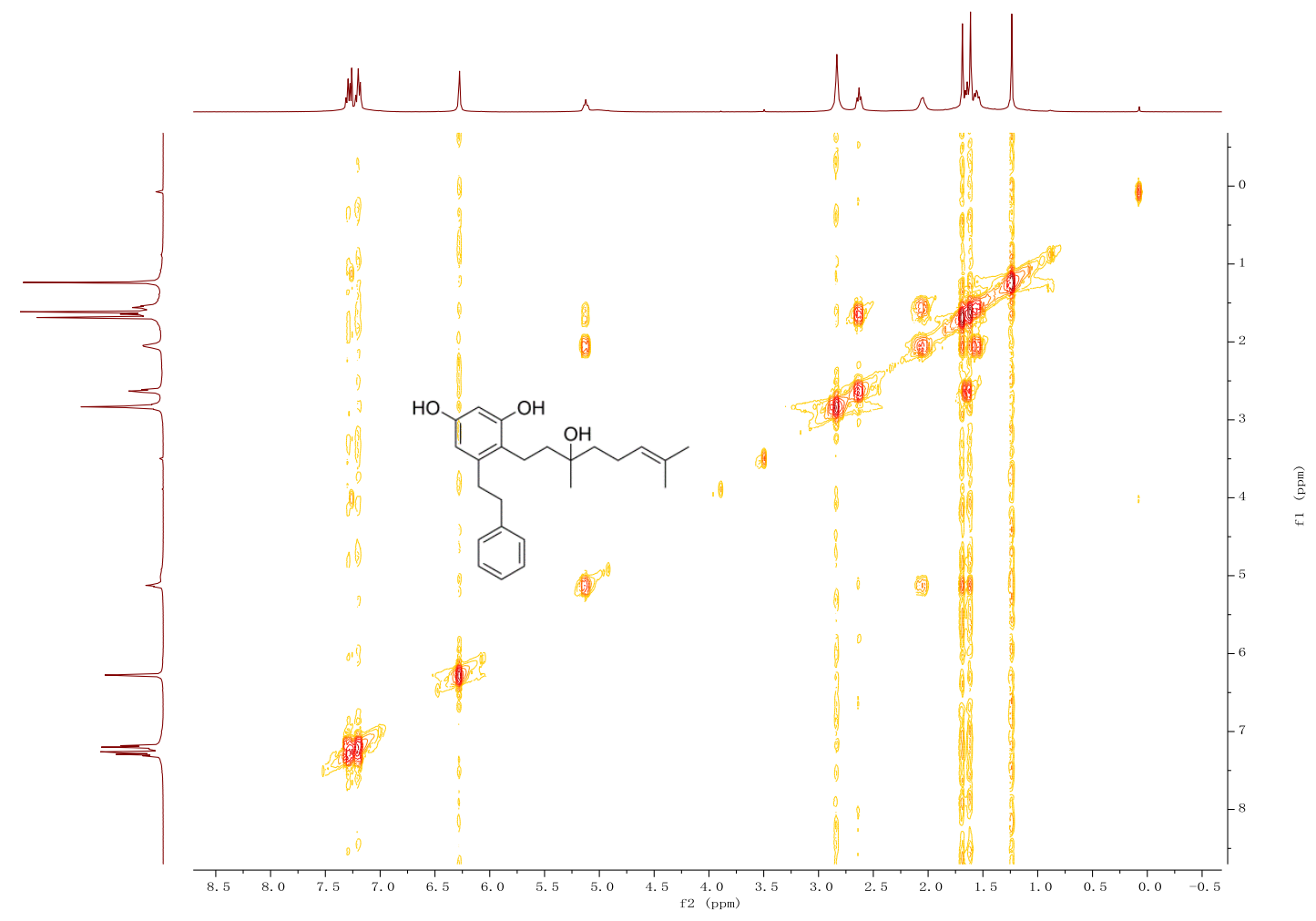


Figure S45. HMBC spectrum (400 MHz) of 5 in $\mathrm{CDCl}_{3}$.

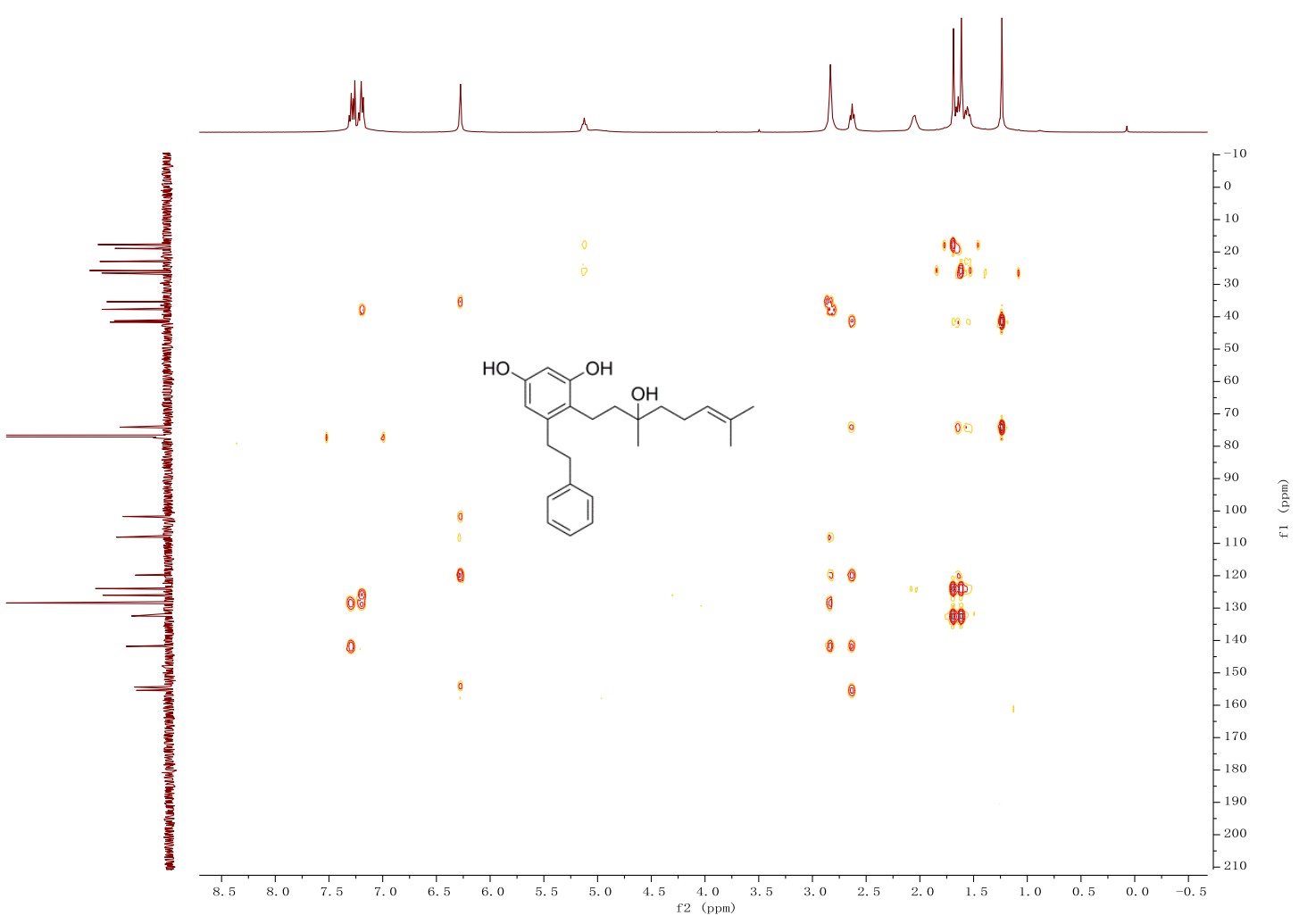

Figure S46. HRESIMS spectrum of 5.

$Y .20=242.45$ RT 0.37 .040 AV . 4 NL. $2.75 E 6$
FTMS + CESI Full ms $[10000-200000]$

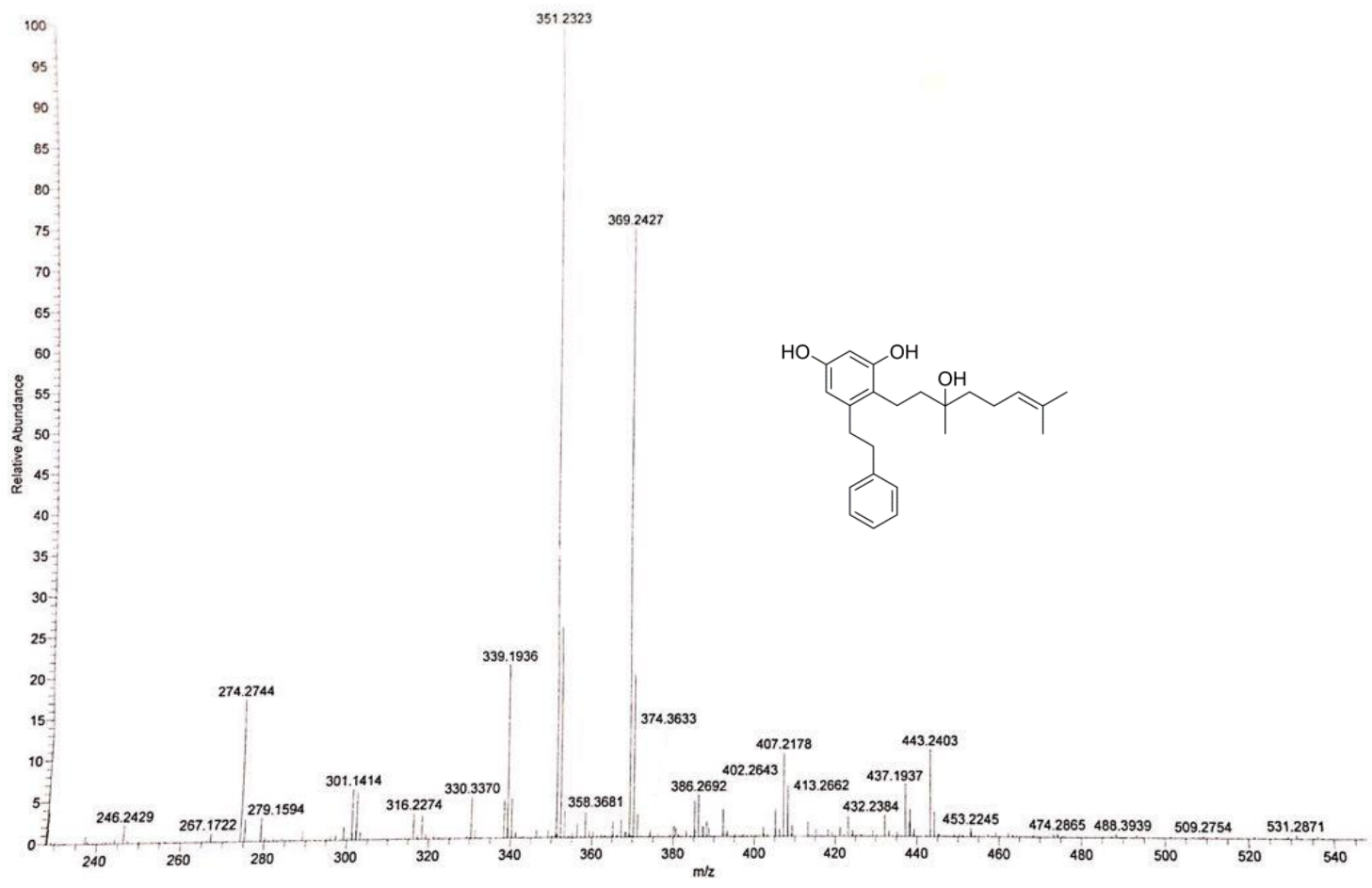


Figure S47. IR ( $\mathrm{KBr}$ disc) spectrum of 5.

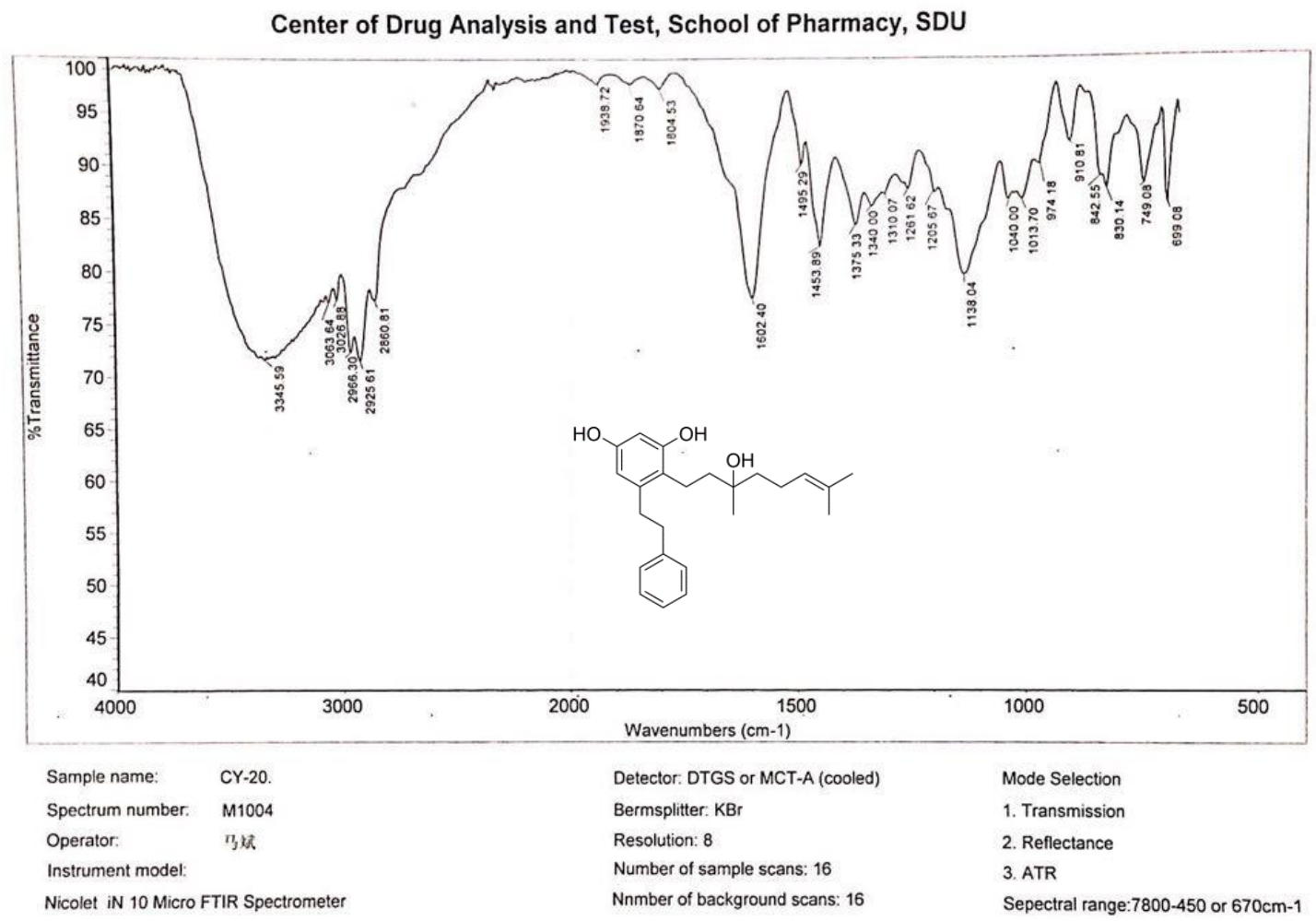

Figure S48. UV spectrum of 5.

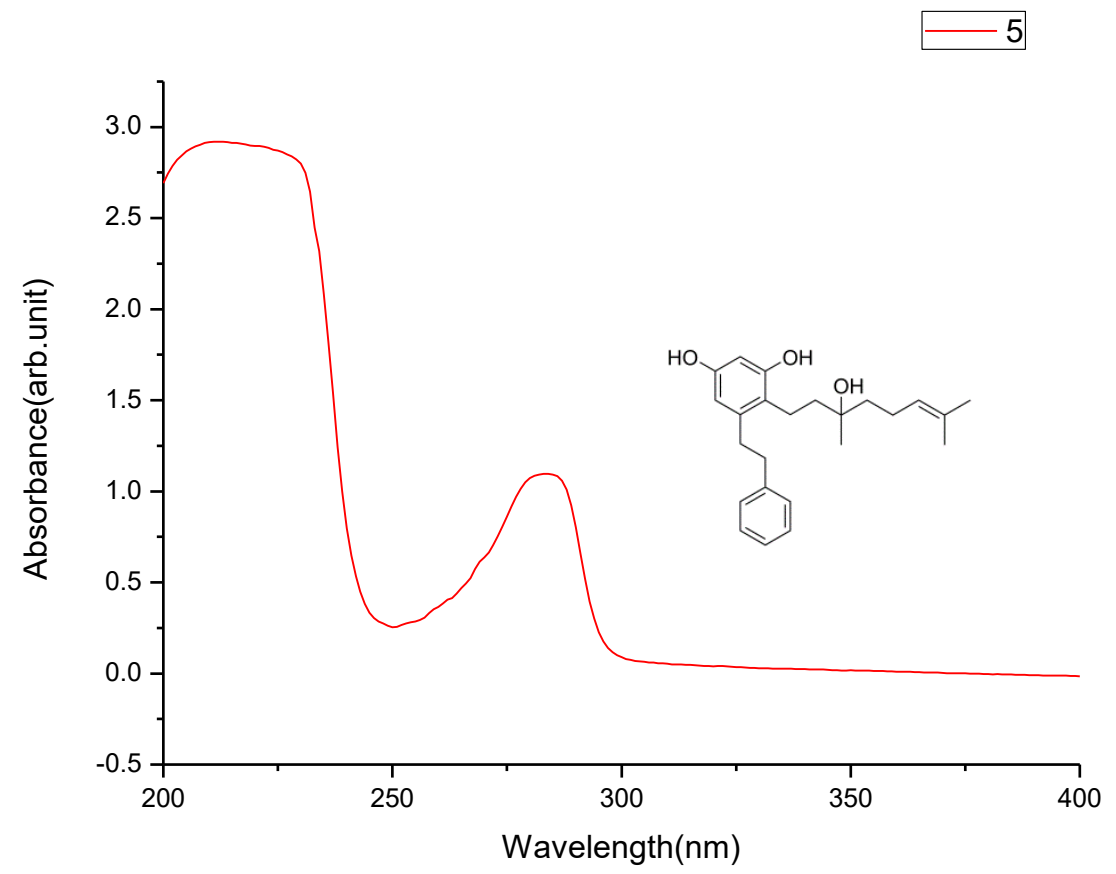


Figure S49. Chiral-phase HPLC analysis of 5.
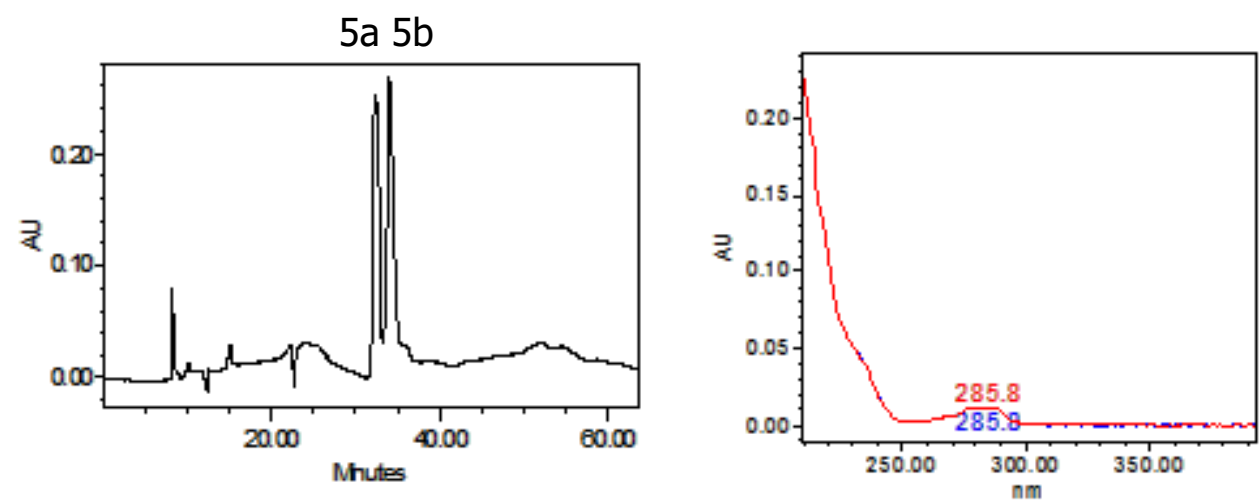

\begin{tabular}{cccccc}
\hline & Retention Time & Area & \% Area & Height & Int Type \\
\hline 1 & 32.488 & 10759089 & 48.91 & 230645 & bb \\
2 & 34.189 & 11237919 & 51.09 & 229510 & bb \\
\hline
\end{tabular}

Figure S50. Experimental ECD spectra of 5a/5b and calculated ECD spectrum of $\mathbf{5 a}$.

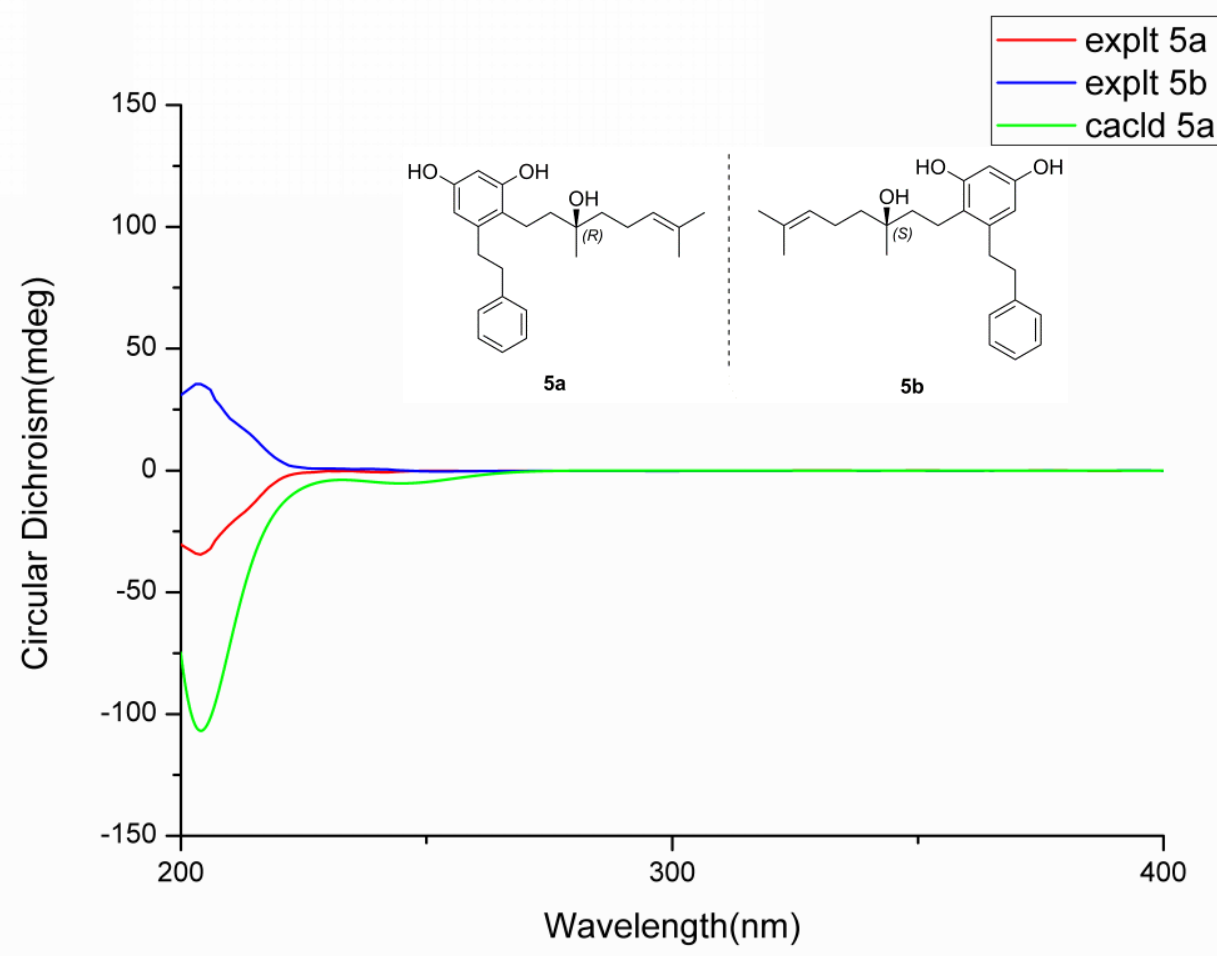


Figure S51. ${ }^{1} \mathrm{H}$ NMR spectrum $(600 \mathrm{MHz})$ of 6 in $\mathrm{CDCl}_{3}$.

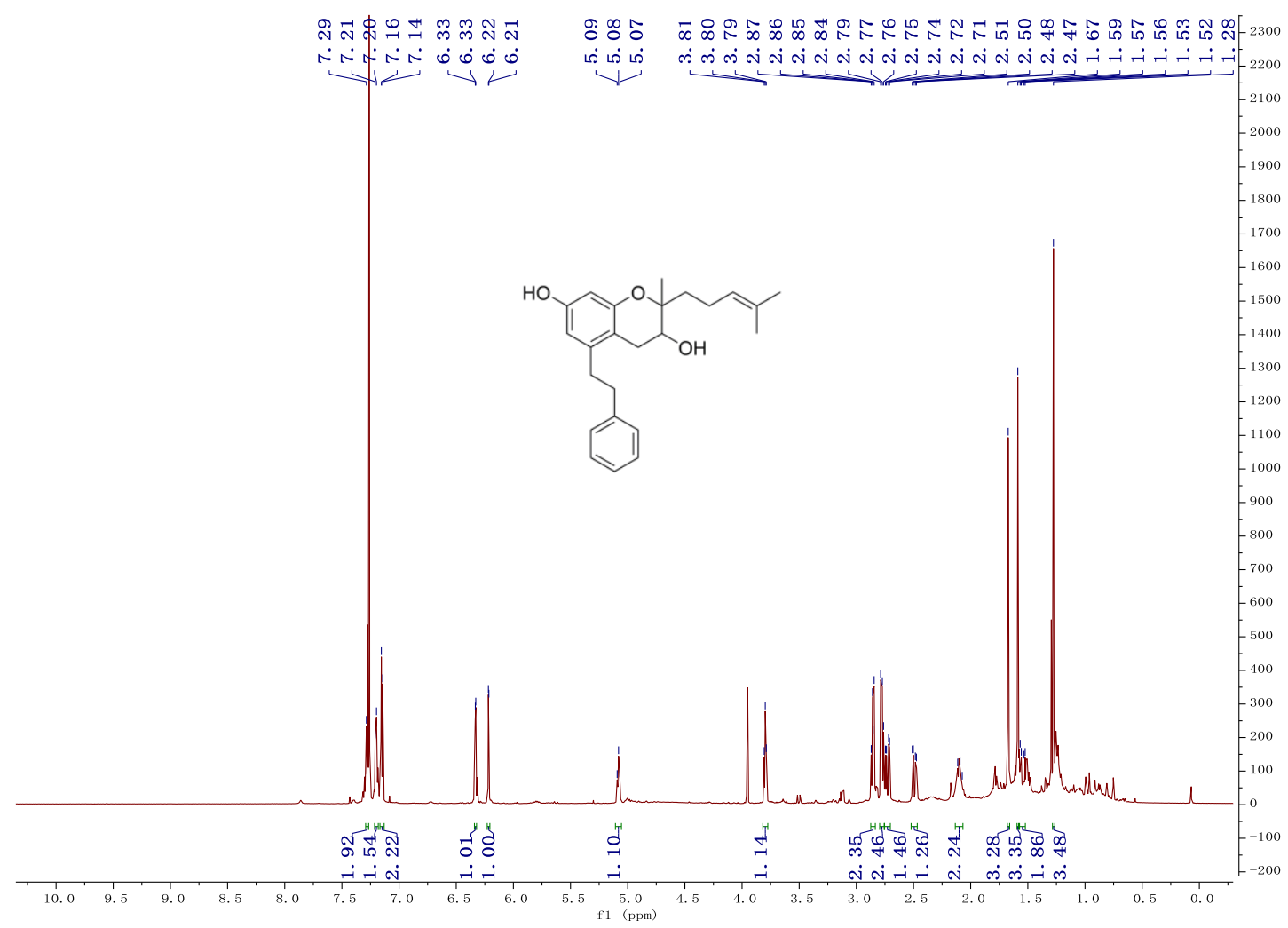

Figure S52. ${ }^{13} \mathrm{C}$ NMR spectrum $(150 \mathrm{MHz})$ of 6 in $\mathrm{CDCl}_{3}$.

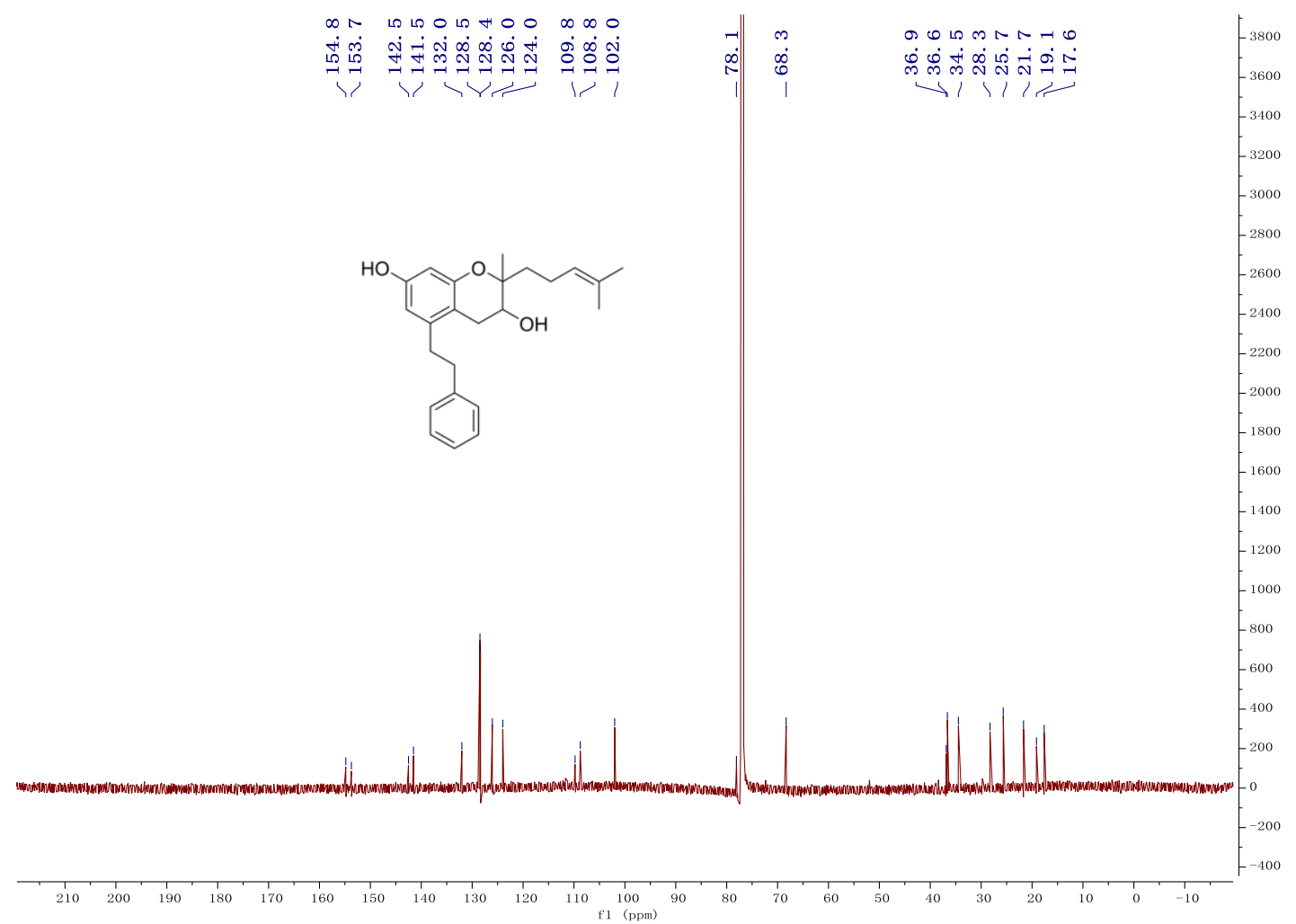


Figure S53. HSQC spectrum $(600 \mathrm{MHz})$ of 6 in $\mathrm{CDCl}_{3}$.

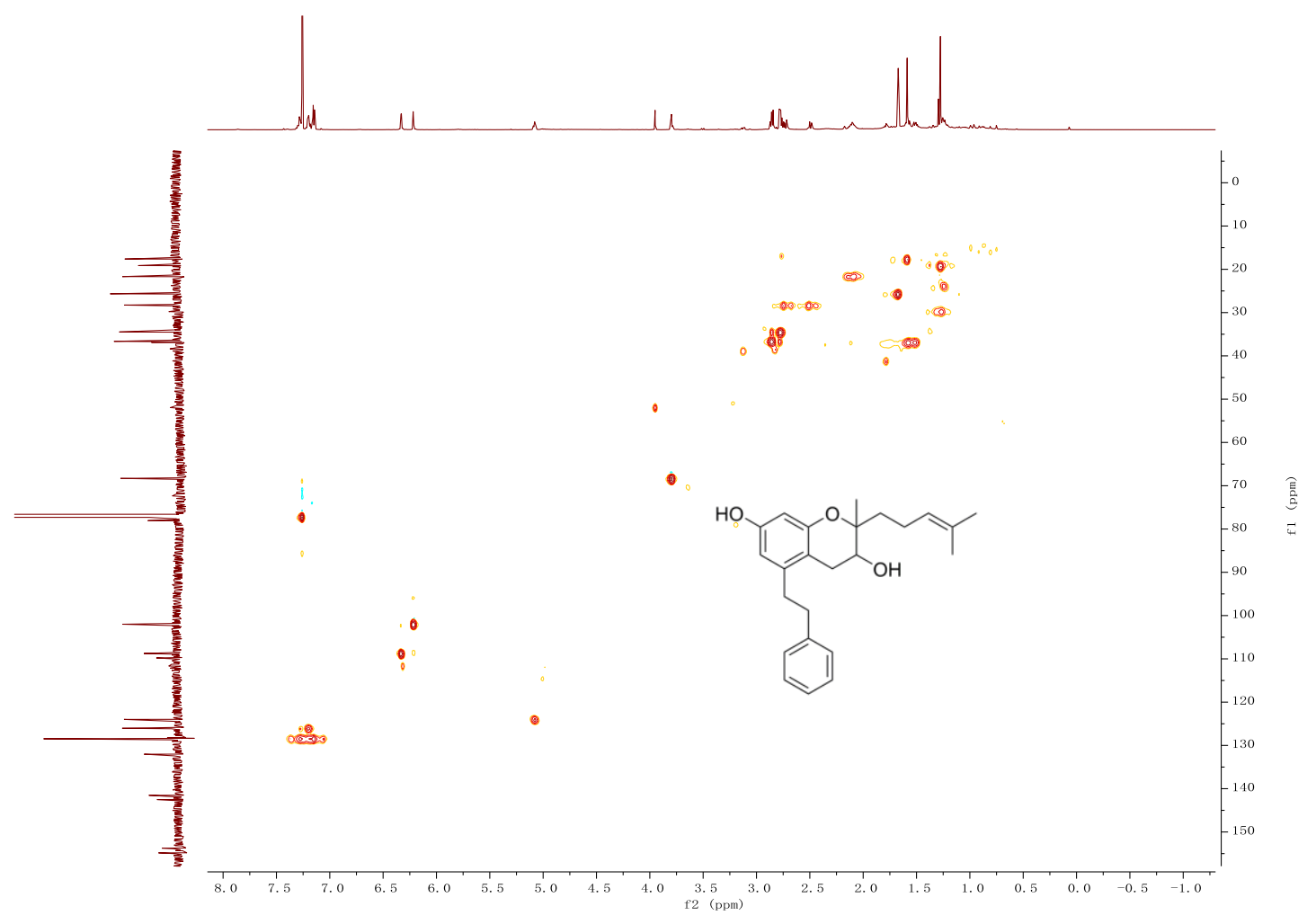

Figure S54. ${ }^{1} \mathrm{H}-{ }^{1} \mathrm{H}$ Spectrum $(600 \mathrm{MHz})$ of 6 in $\mathrm{CDCl}_{3}$.

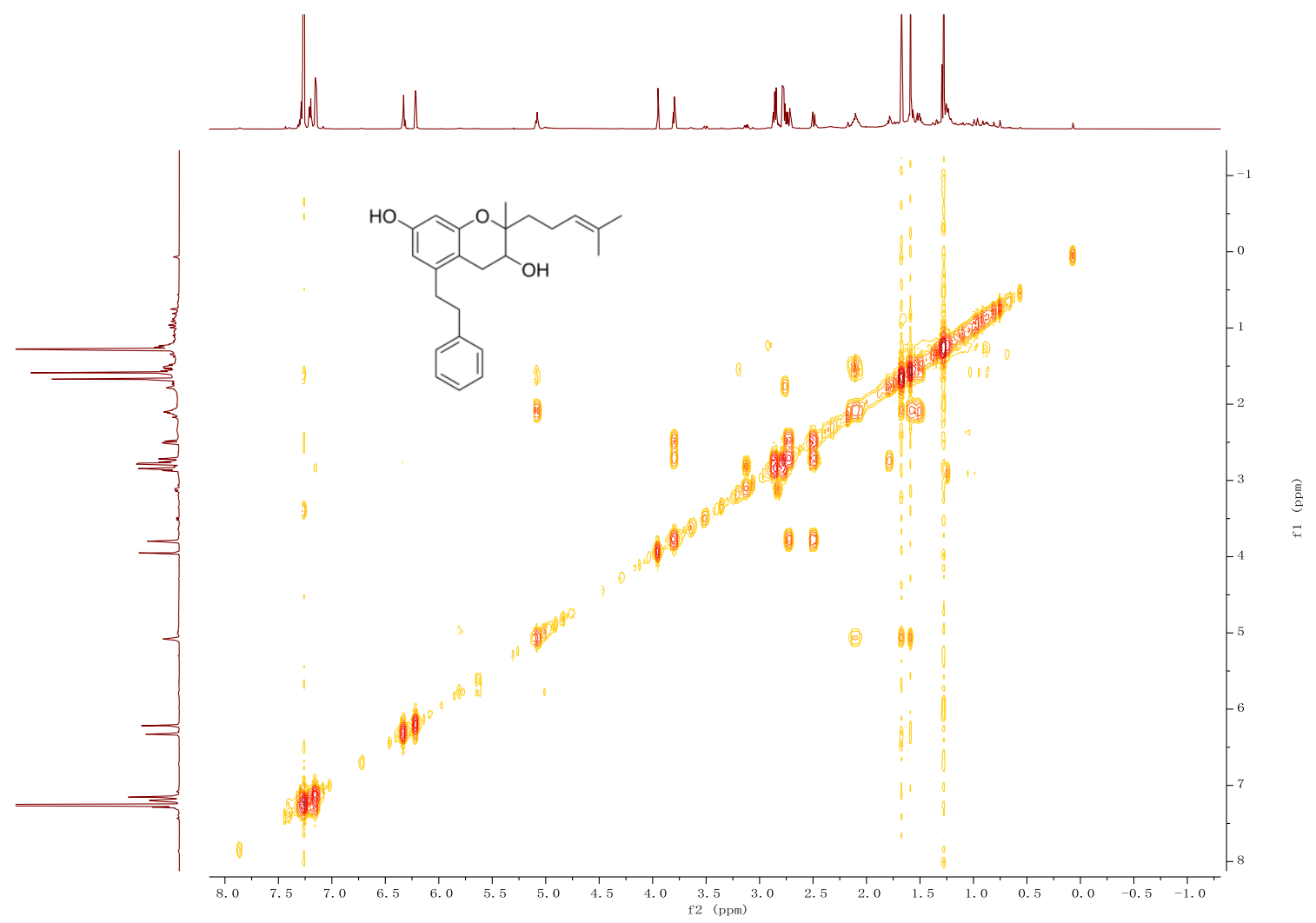


Figure S55. HMBC spectrum $(600 \mathrm{MHz})$ of 6 in $\mathrm{CDCl}_{3}$.

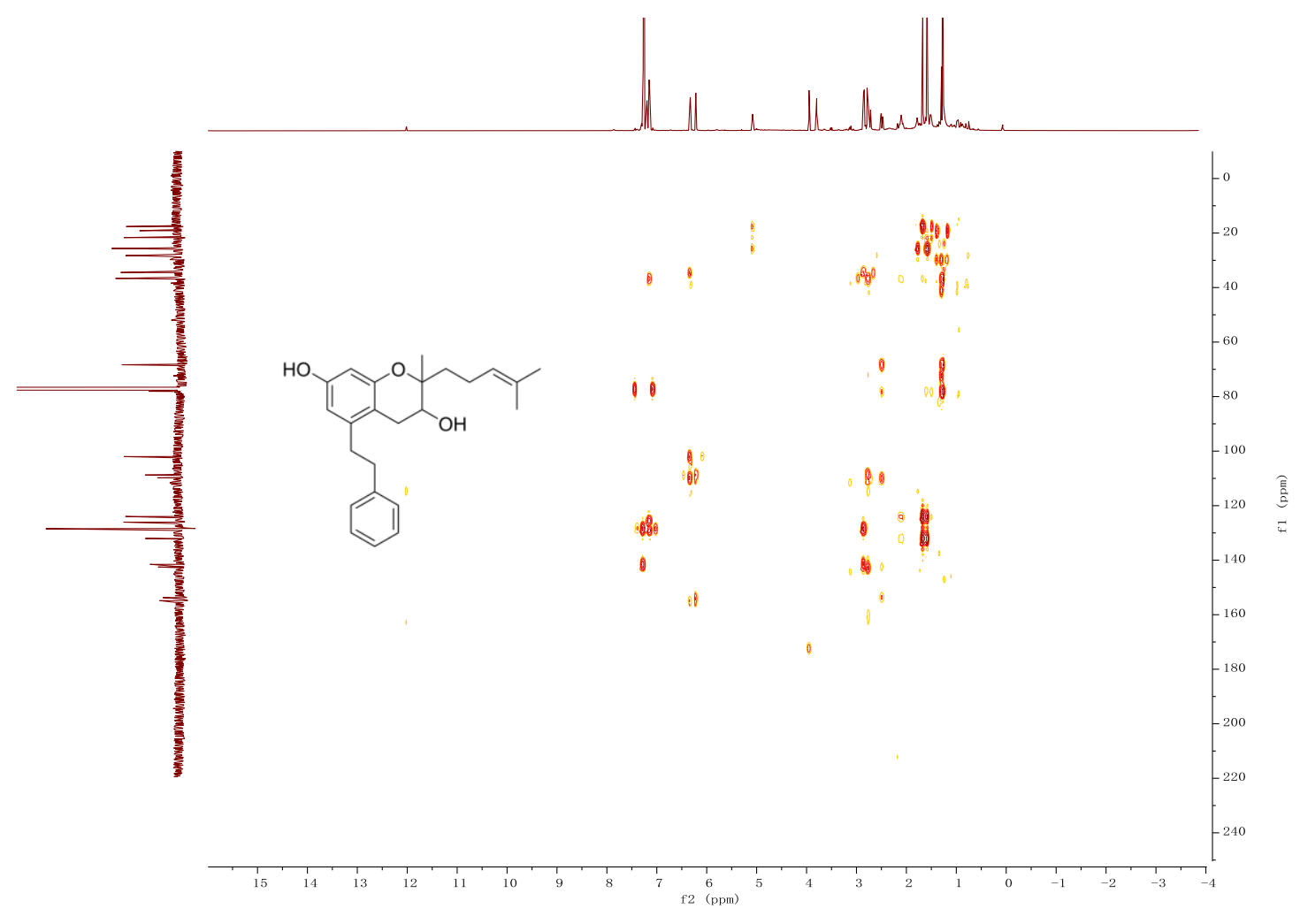

Figure S56. NOESY spectrum $(600 \mathrm{MHz})$ of 6 in $\mathrm{CDCl}_{3}$.

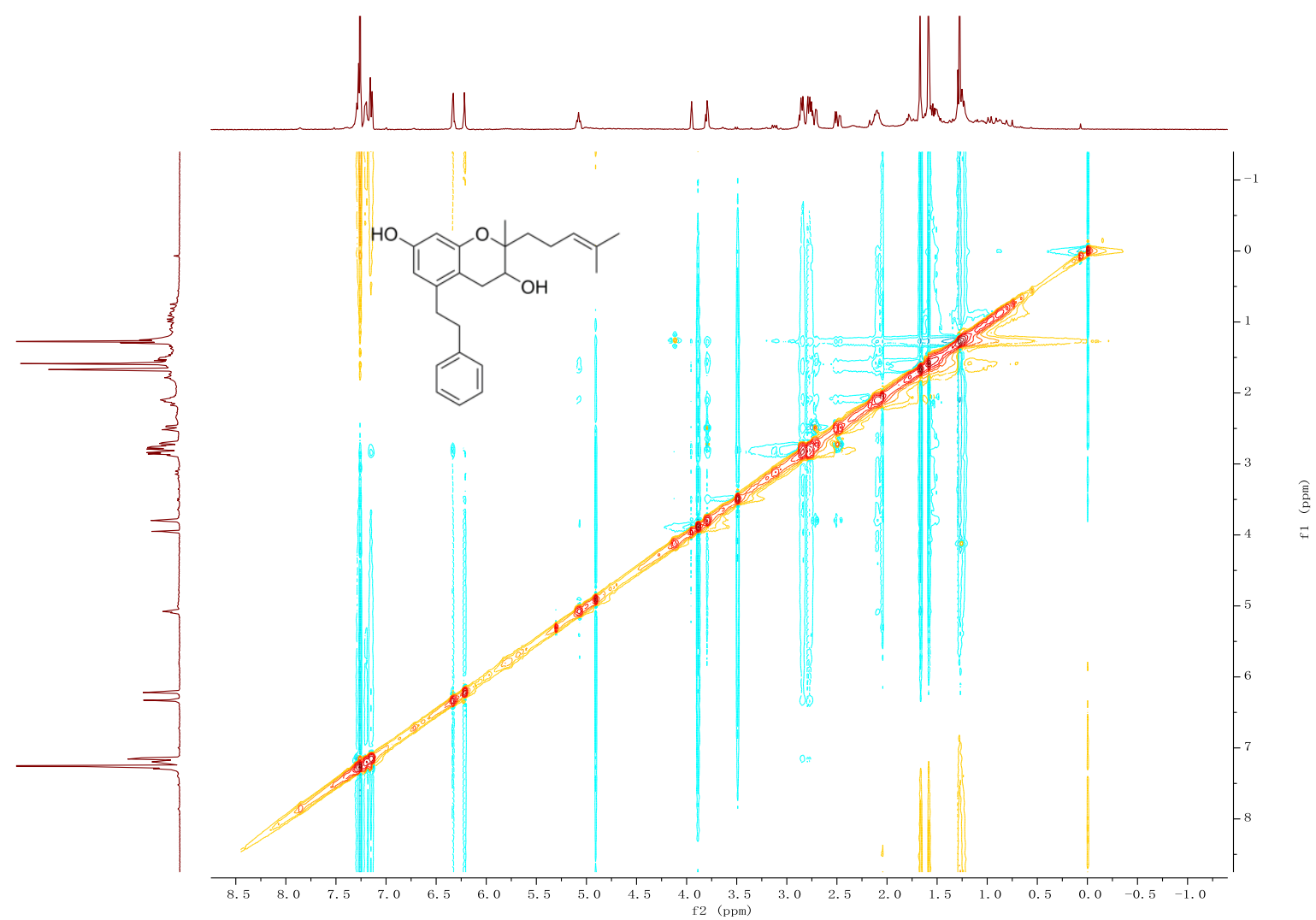


Figure S57. HRESIMS spectrum of 6.

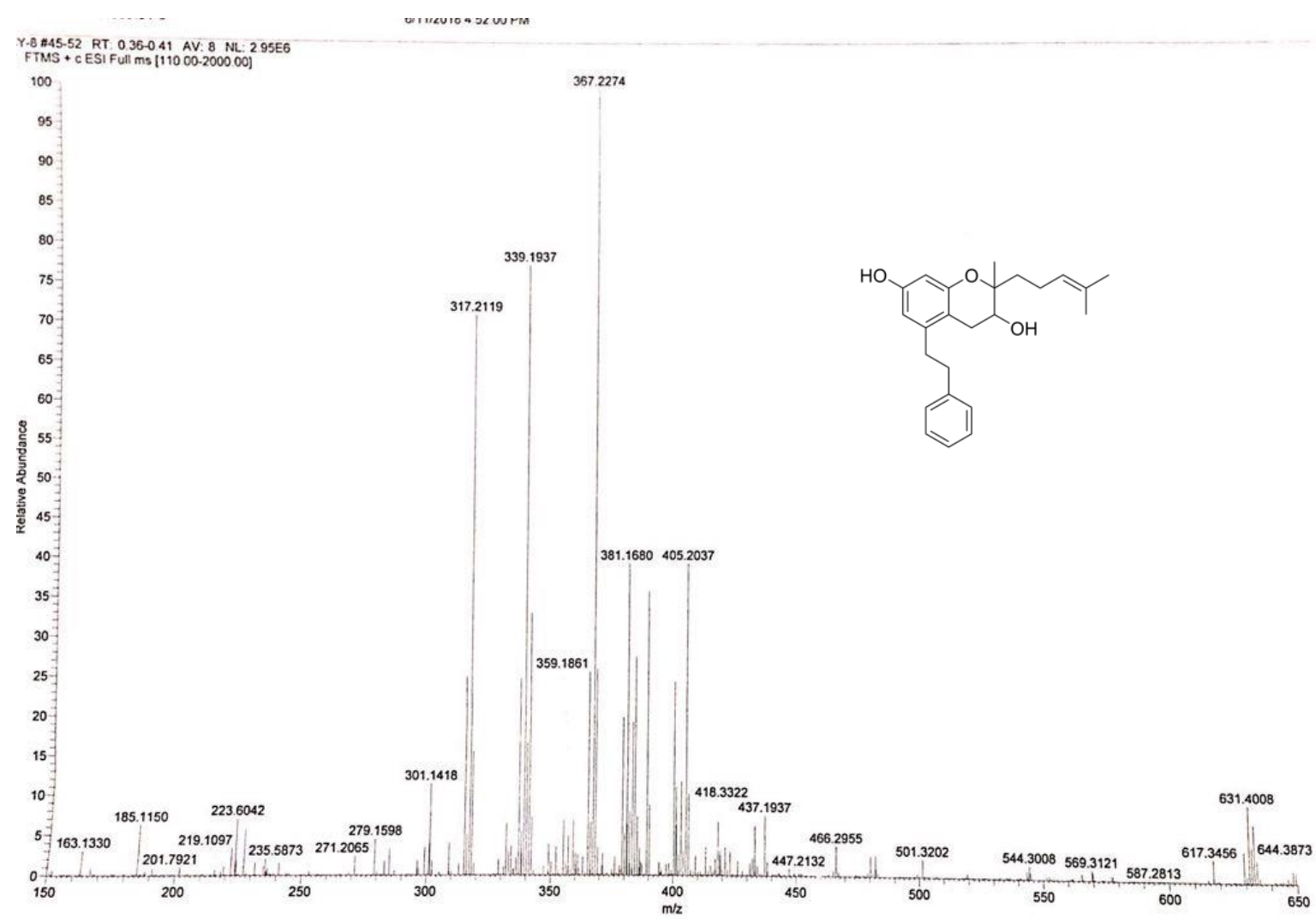

Figure S58. IR ( $\mathrm{KBr}$ disc) spectrum of 6.

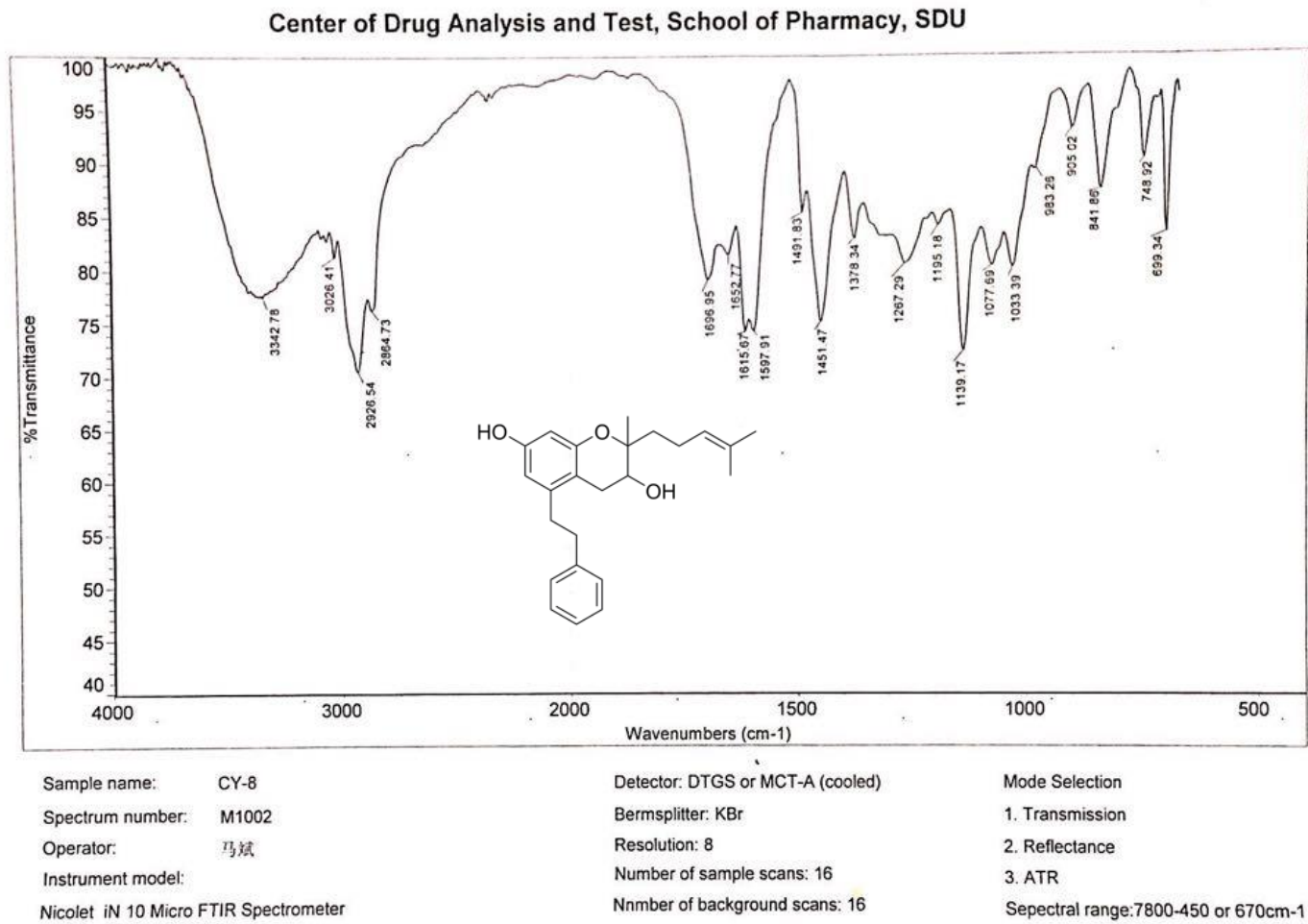


Figure S59. UV spectrum of 6.

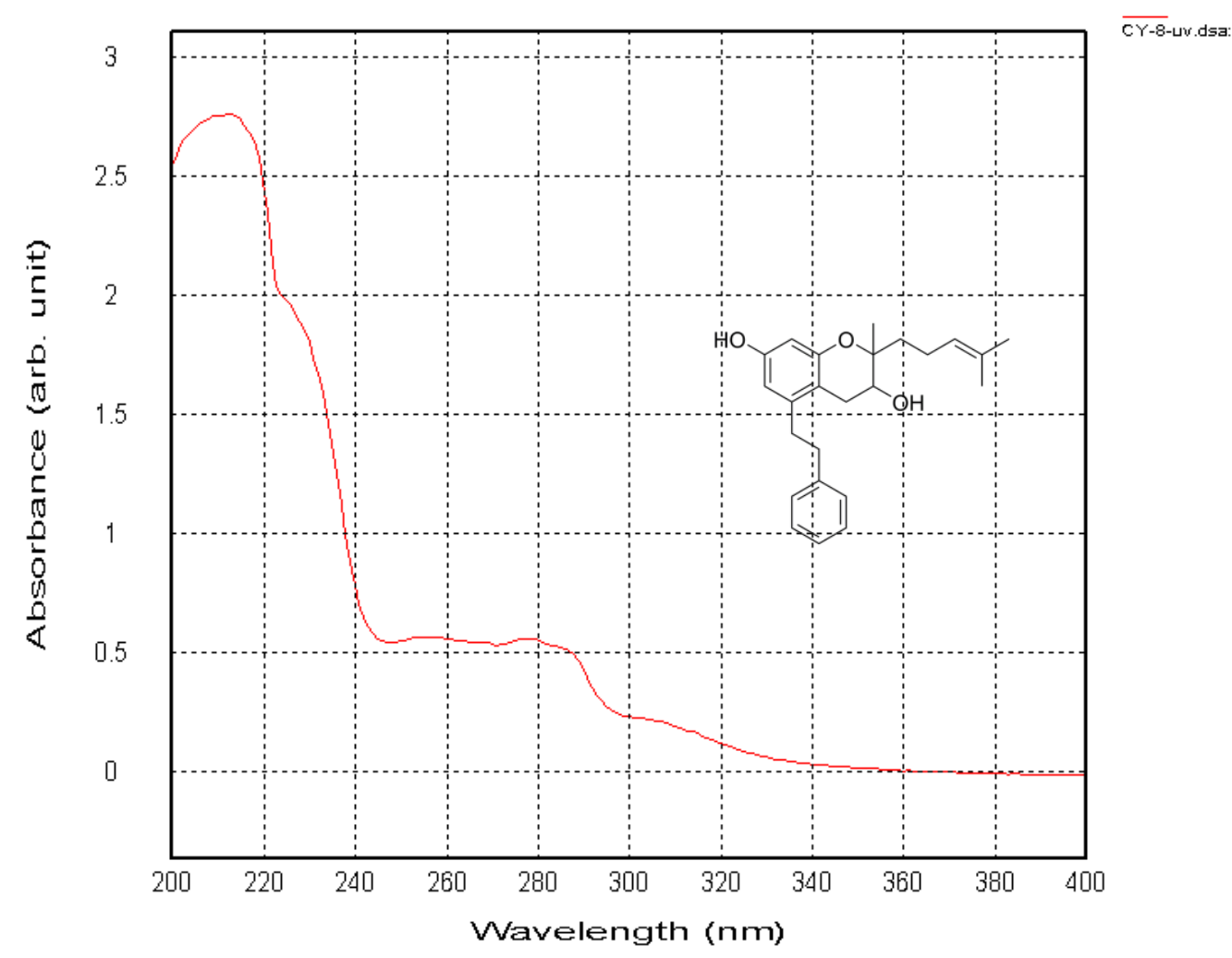

Figure S60. Chiral-phase HPLC analysis of 6.
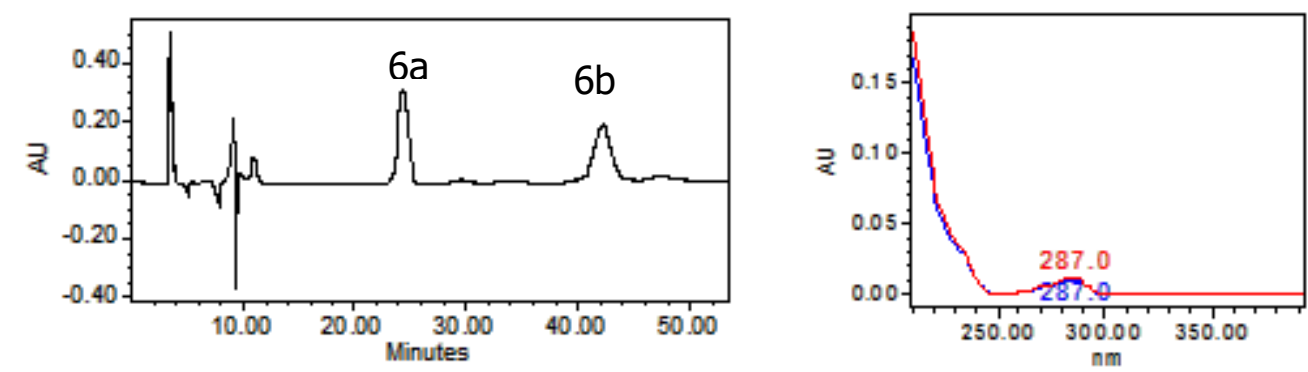

\begin{tabular}{cccccc}
\hline & Retention Time & Area & \% Area & Height & Int Type \\
\hline 1 & 24.314 & 15129104 & 49.12 & 272278 & bb \\
2 & 42.167 & 15673025 & 50.88 & 164819 & bb \\
\hline
\end{tabular}


Figure S61. Experimental ECD spectra of $\mathbf{6 a} / \mathbf{6 b}$ and calculated ECD spectrum of $\mathbf{6 a}$.

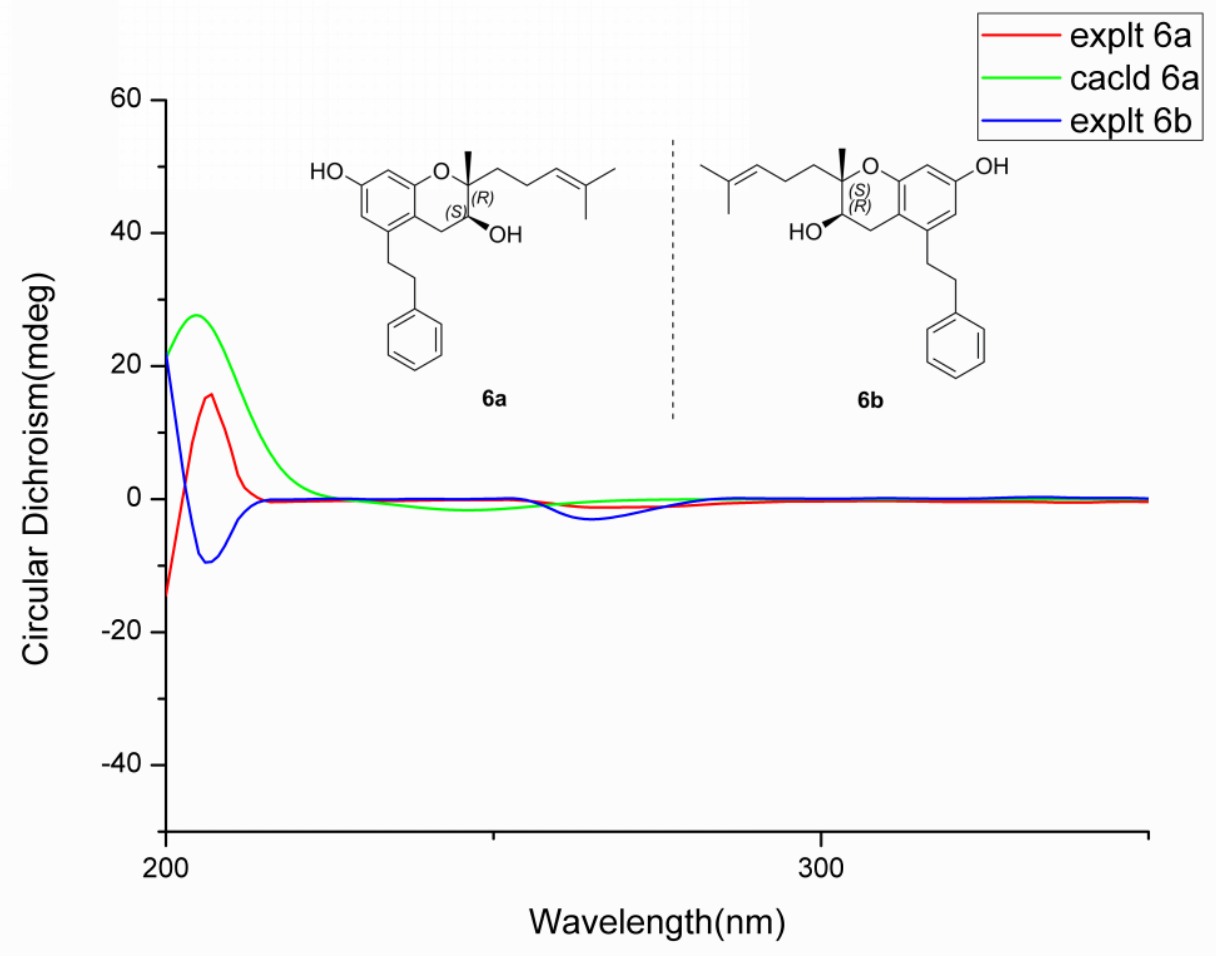

Figure S62. ${ }^{1} \mathrm{H}$ NMR spectrum $(600 \mathrm{MHz})$ of 7 in $\mathrm{CDCl}_{3}$.

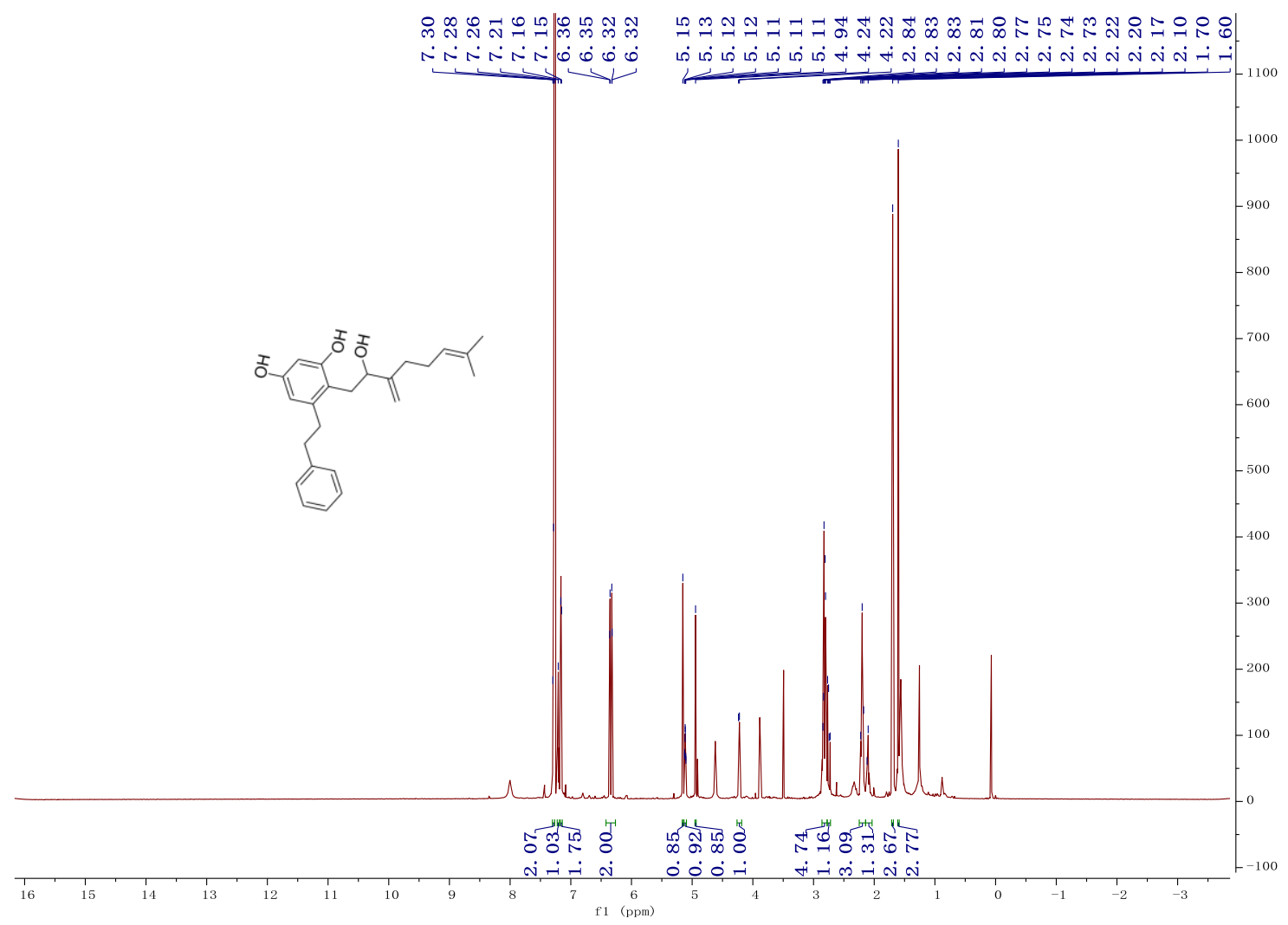


Figure S63. ${ }^{13} \mathrm{C}$ NMR spectrum $(150 \mathrm{MHz})$ of 7 in $\mathrm{CDCl}_{3}$.

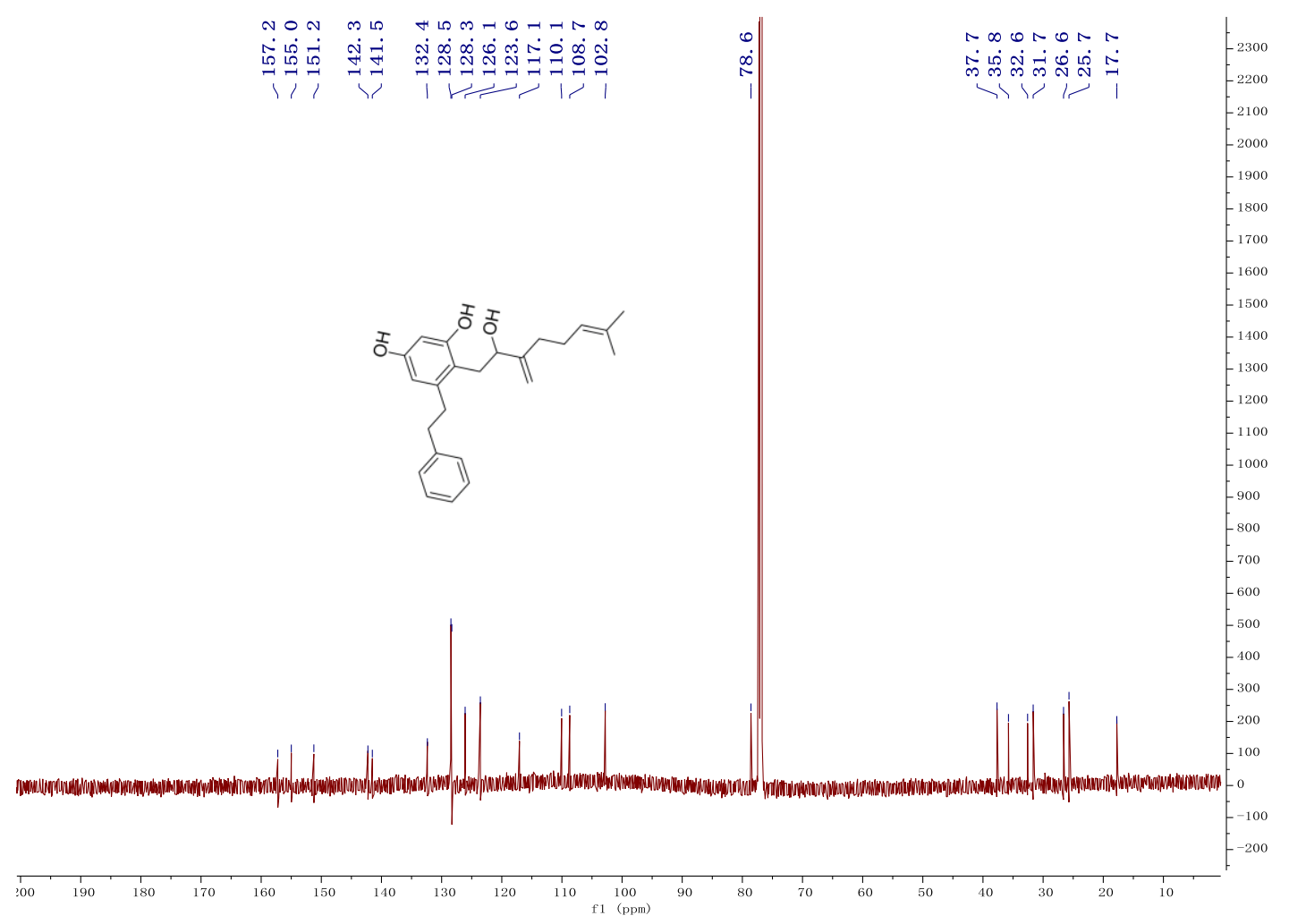

Figure S64. HSQC spectrum $(600 \mathrm{MHz})$ of 7 in $\mathrm{CDCl}_{3}$.

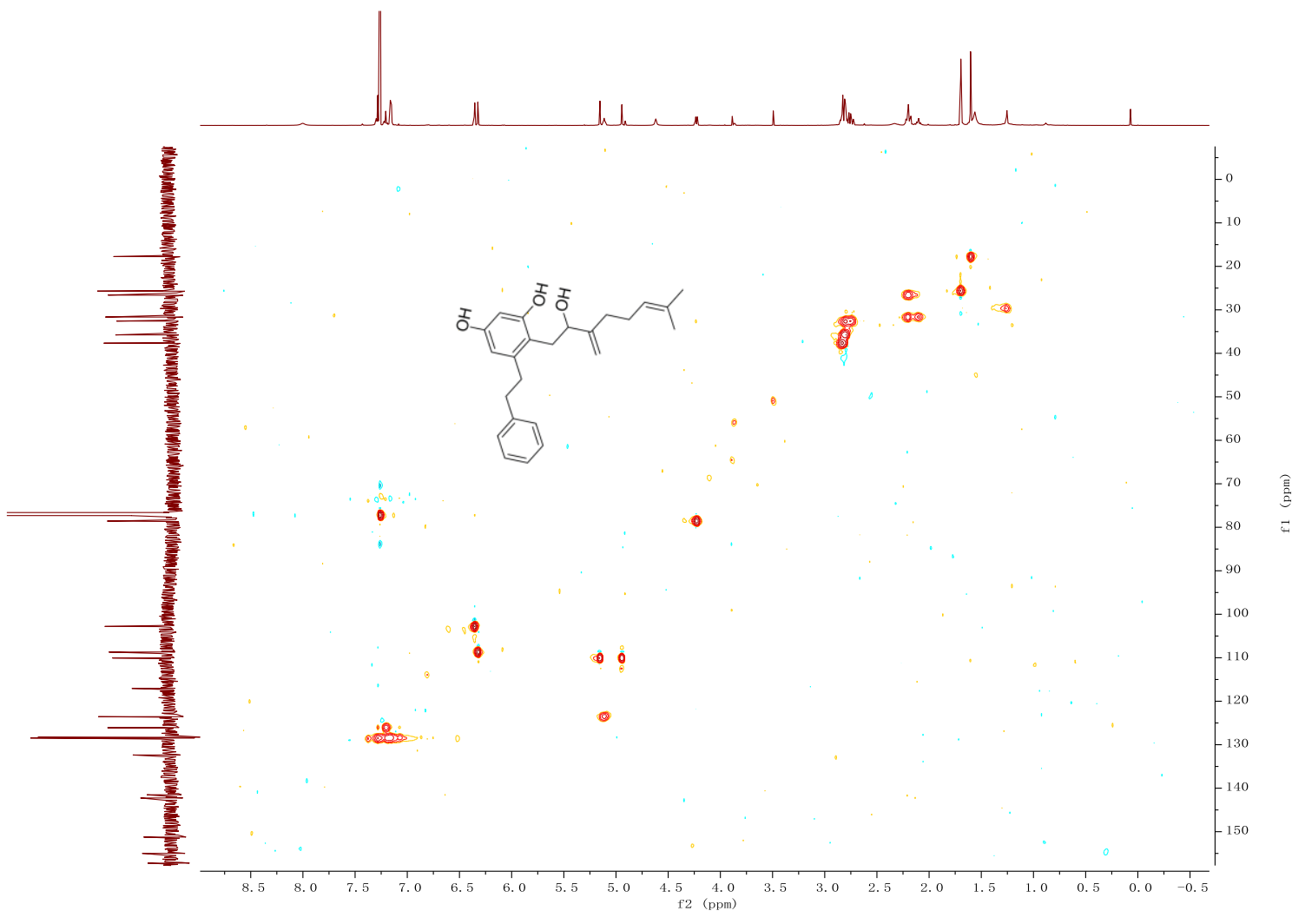


Figure S65. ${ }^{1} \mathrm{H}-{ }^{1} \mathrm{H}$ spectrum $(600 \mathrm{MHz})$ of 7 in $\mathrm{CDCl}_{3}$.

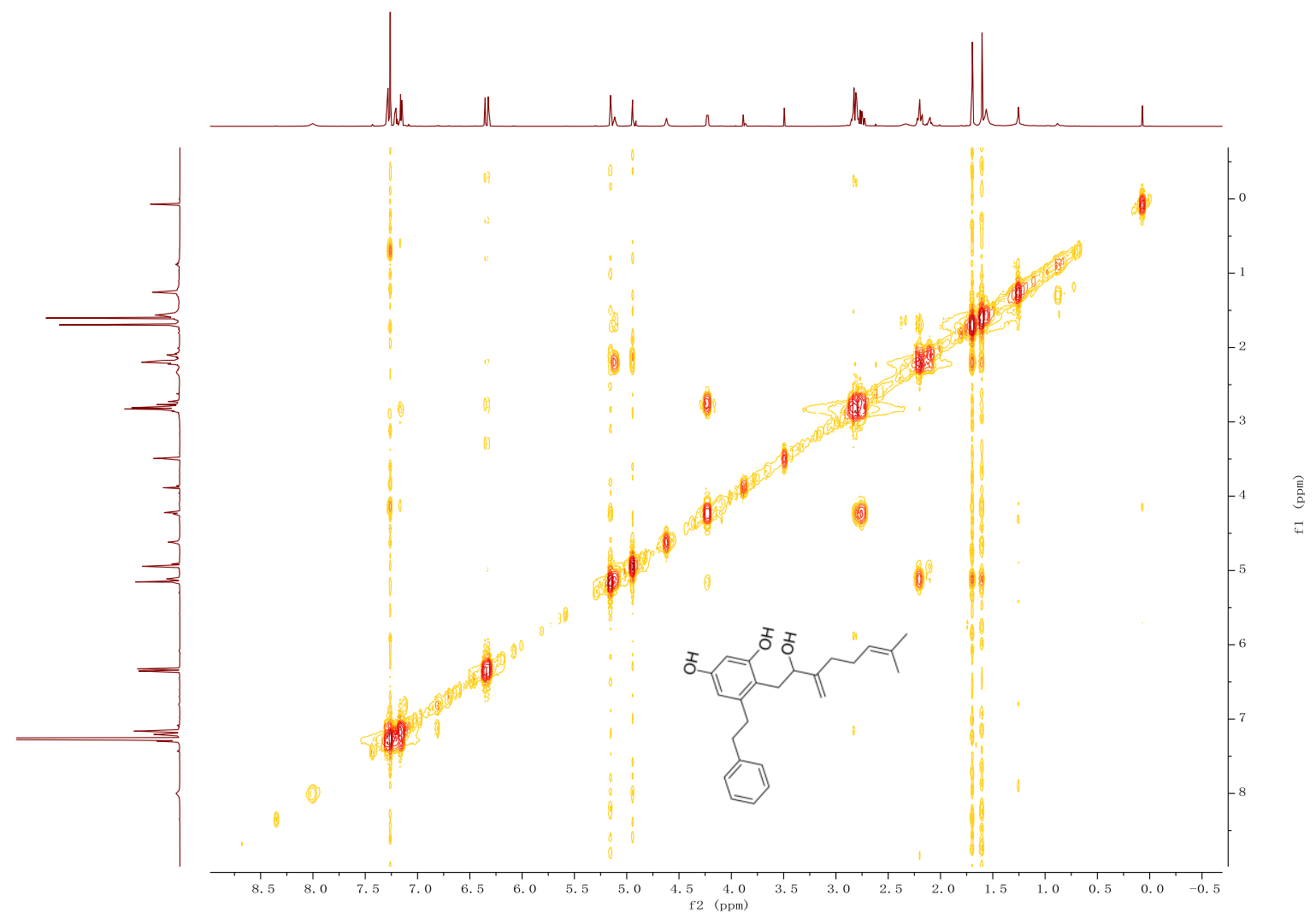

Figure S66. $\mathrm{HMBC}$ spectrum $(600 \mathrm{MHz})$ of 7 in $\mathrm{CDCl}_{3}$.

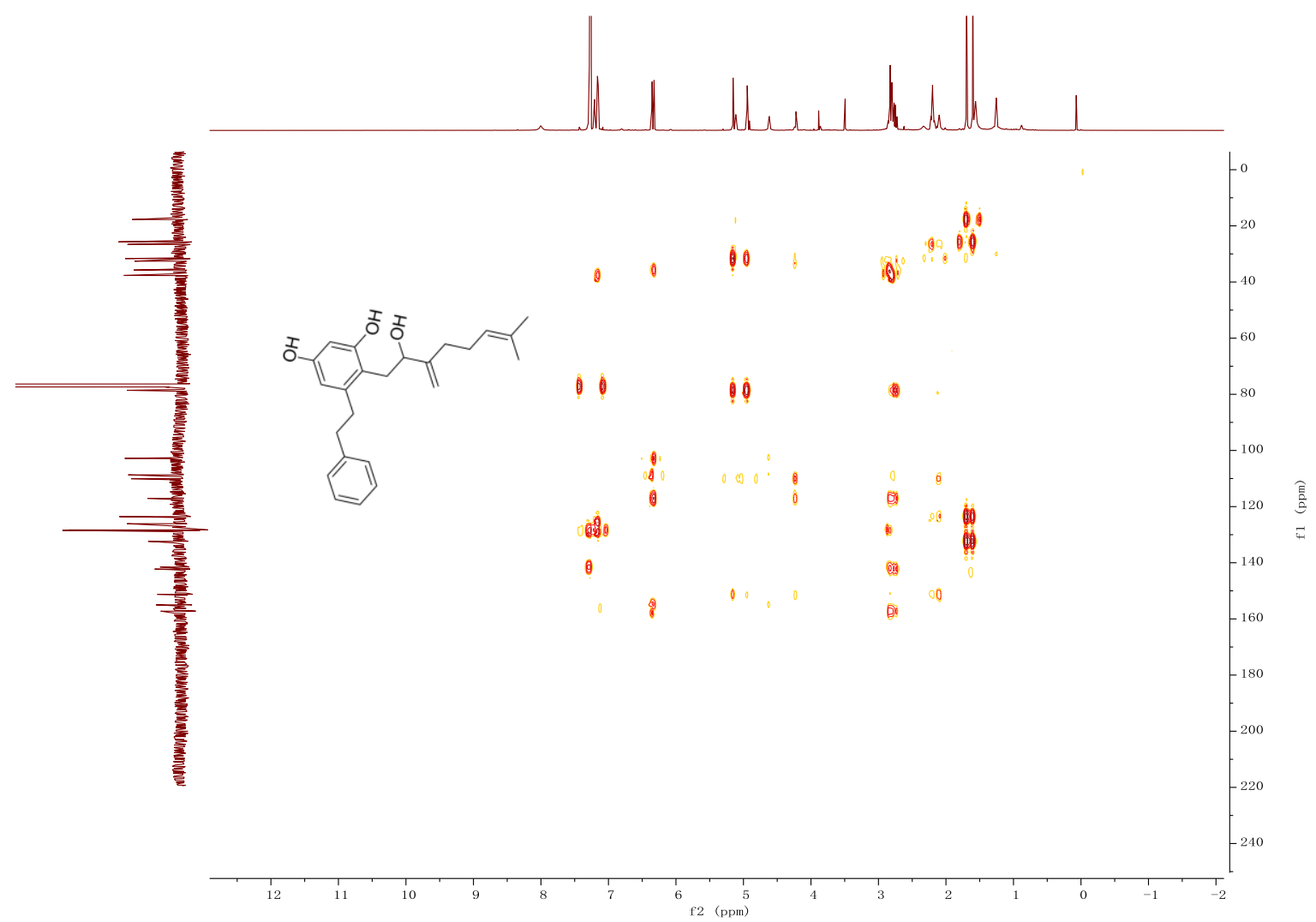


Figure S67. HRESIMS spectrum of 7.

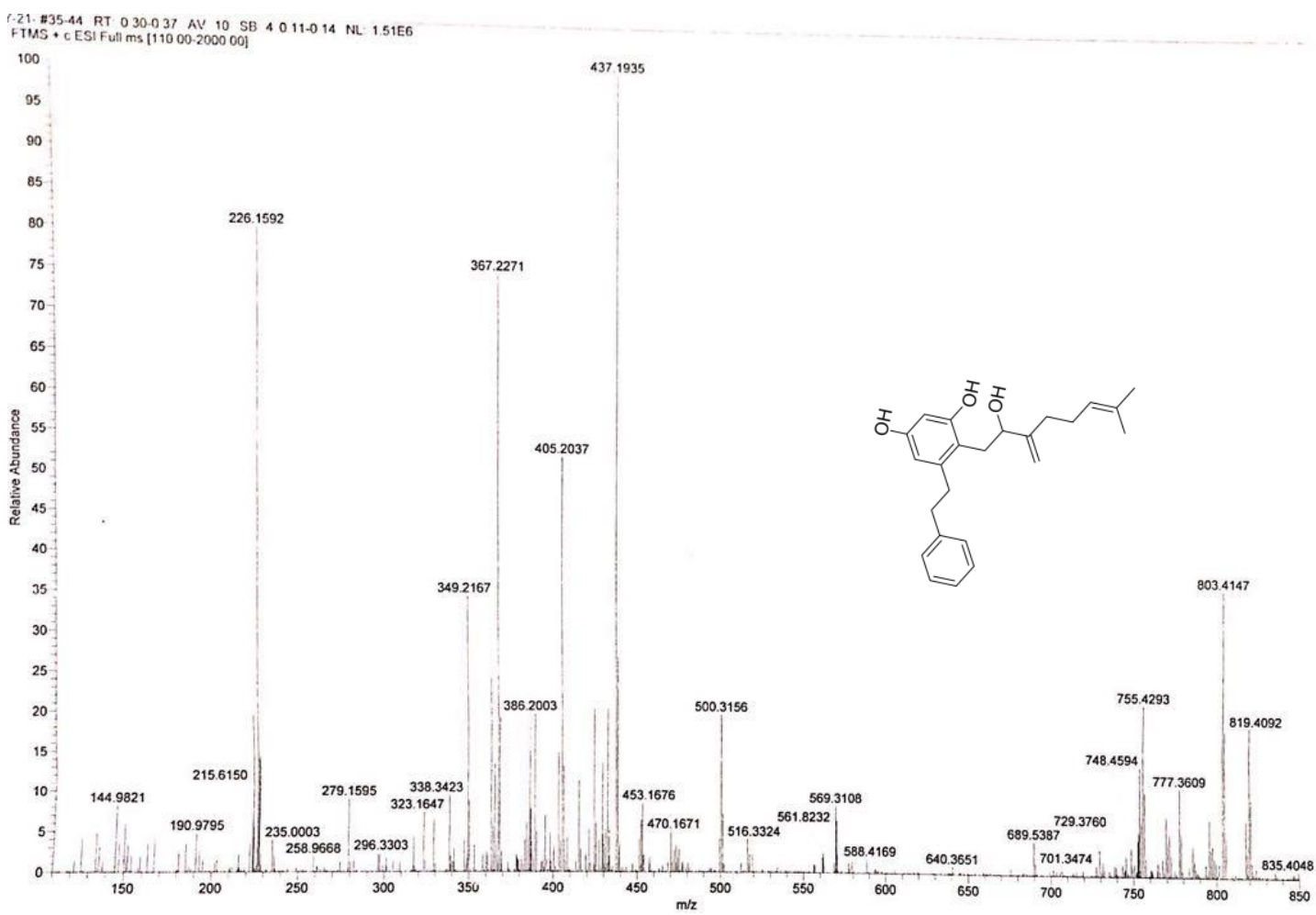

Figure S68. IR ( $\mathrm{KBr}$ disc) spectrum of 7.

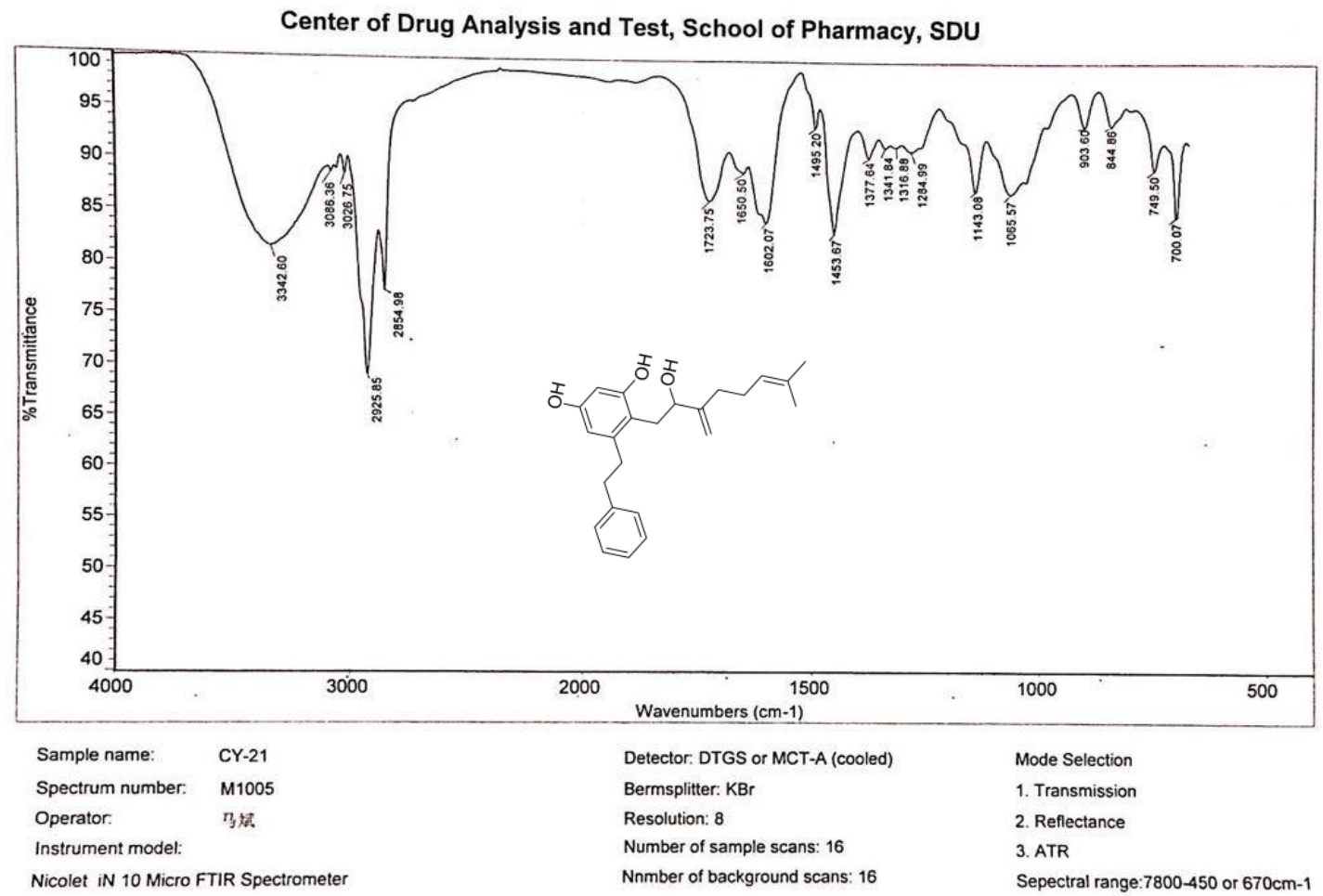


Figure S69. UV spectrum of 7.

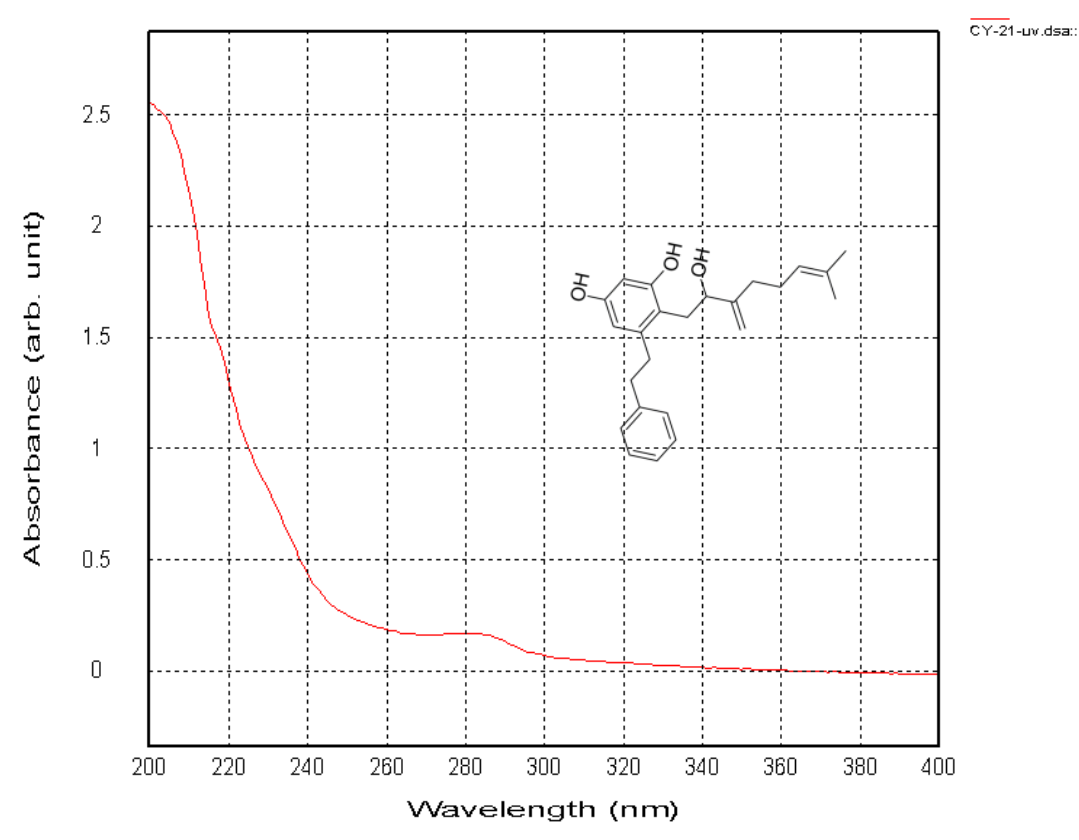

Figure S70. Chiral-phase HPLC analysis of 7.
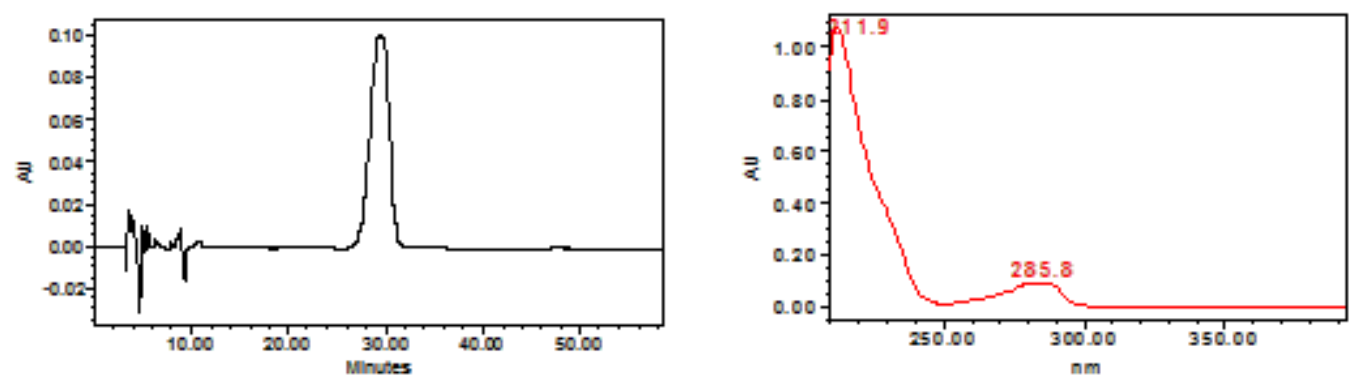

Figure S71. Experimental ECD spectra of 7.

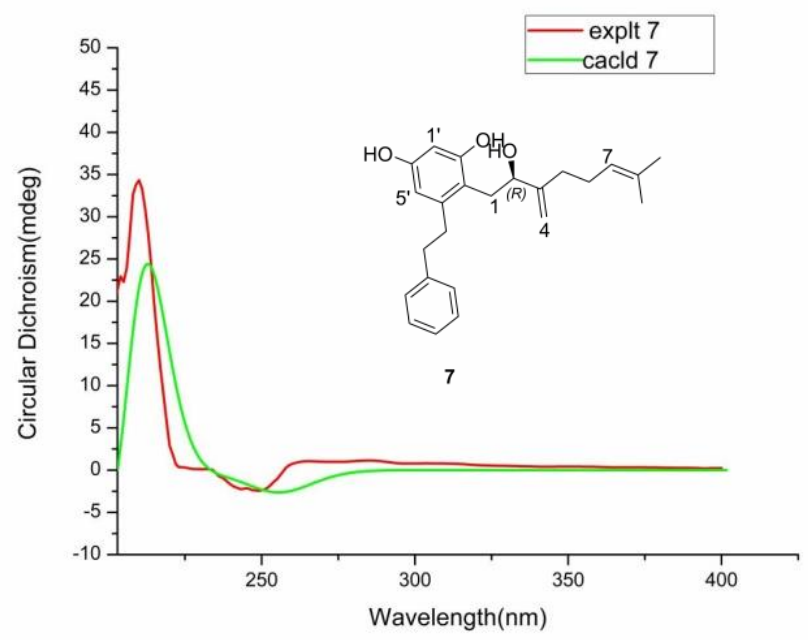


Figure S72. ${ }^{1} \mathrm{H}$ NMR spectrum $(600 \mathrm{MHz})$ of 8 in $\mathrm{CDCl}_{3}$.

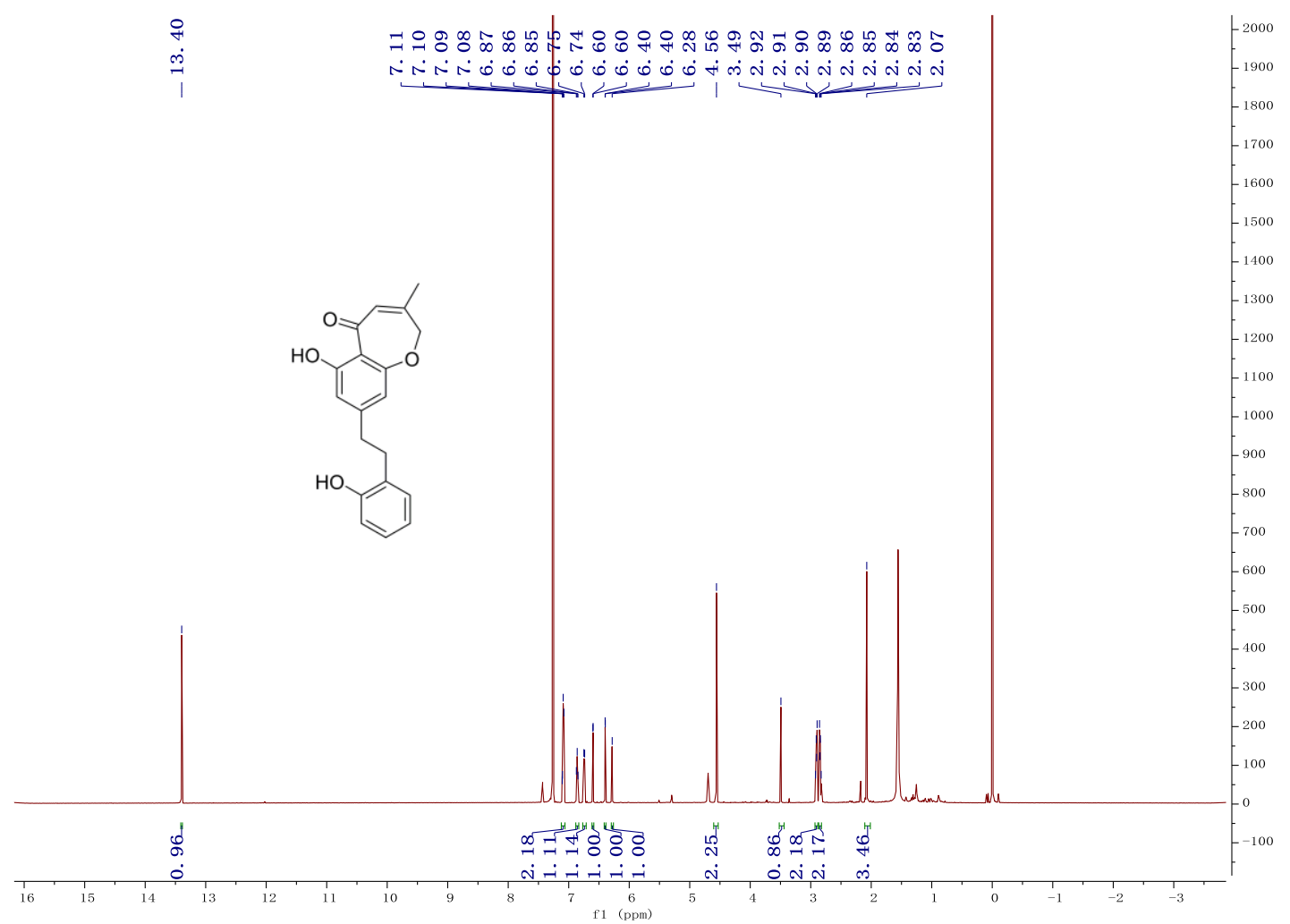

Figure S73. ${ }^{13} \mathrm{C}$ NMR spectrum $(150 \mathrm{MHz})$ of $\mathbf{8}$ in $\mathrm{CDCl}_{3}$.

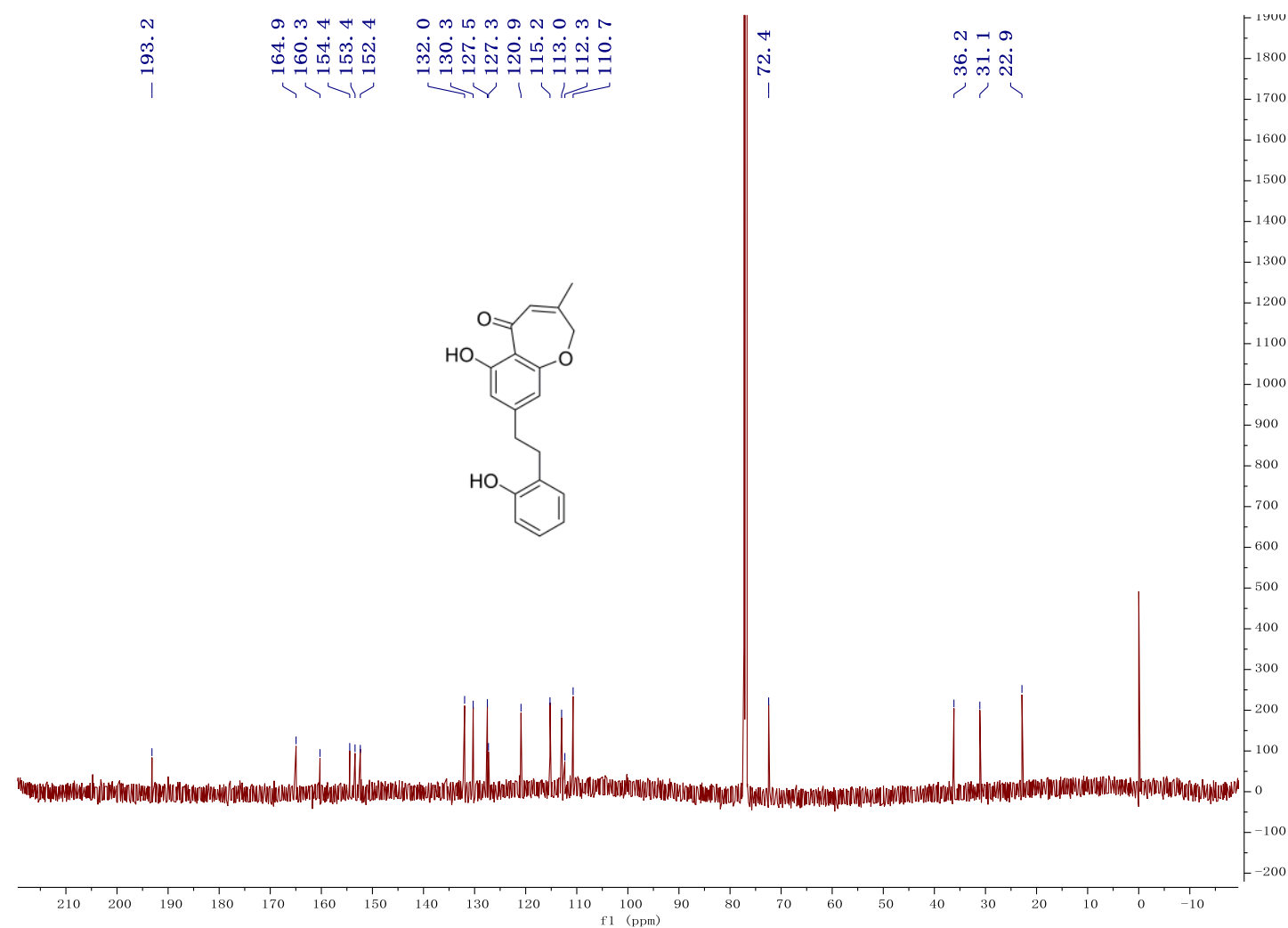


Figure S74. HSQC spectrum (600 MHz) of 8 in $\mathrm{CDCl}_{3}$.

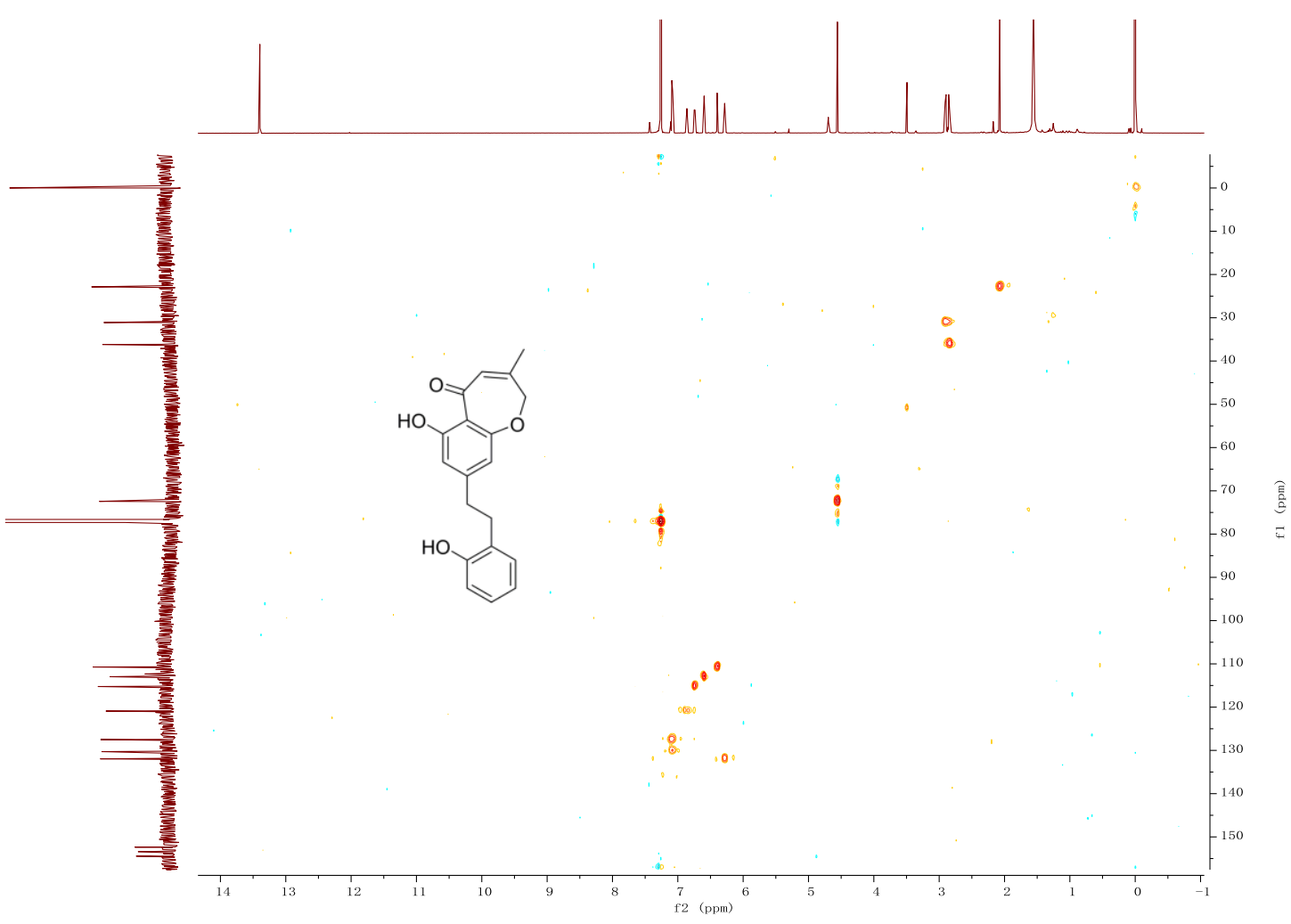

Figure S75. ${ }^{1} \mathrm{H}-{ }^{1} \mathrm{H}$ spectrum $(600 \mathrm{MHz})$ of 8 in $\mathrm{CDCl}_{3}$.

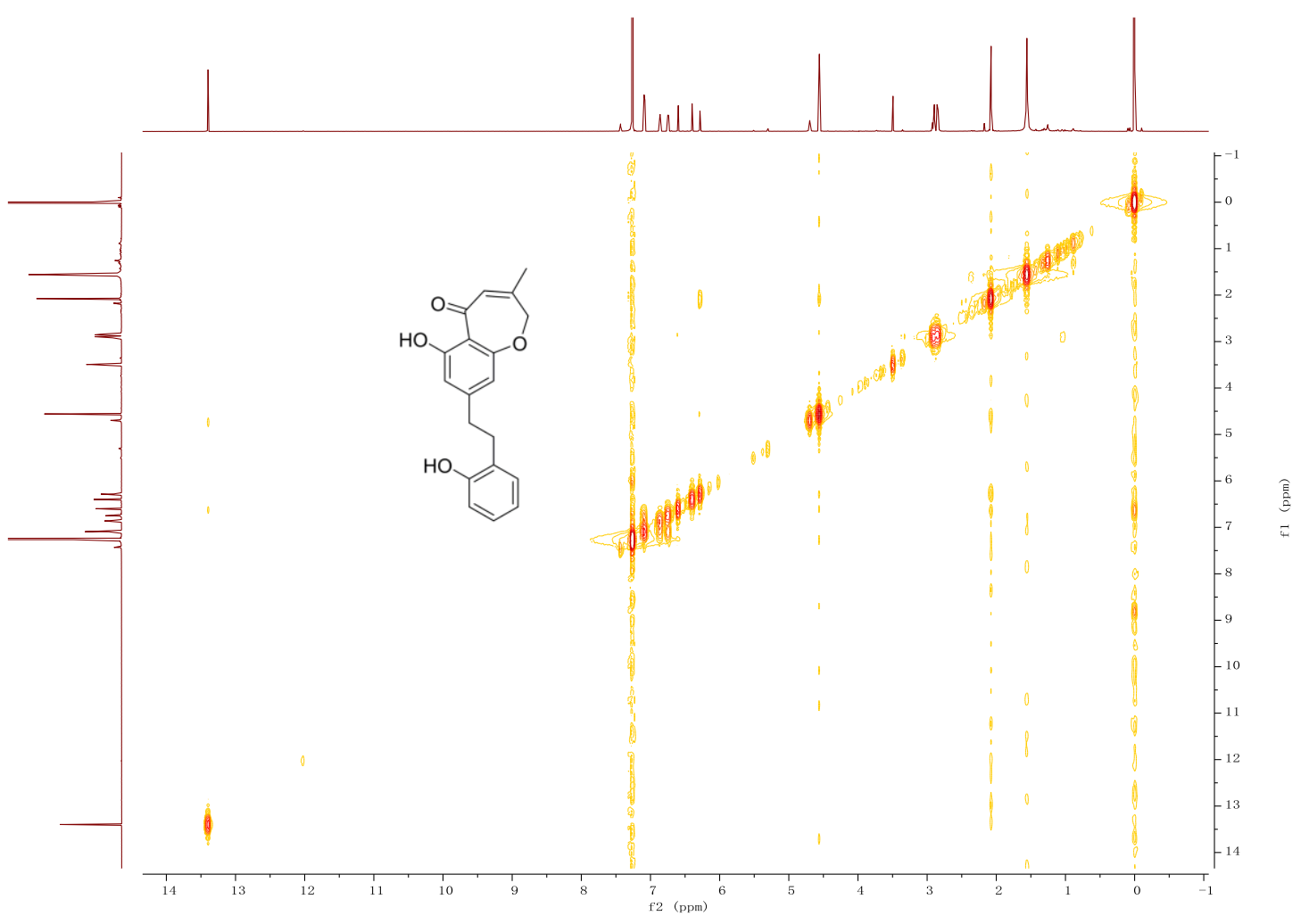


Figure S76. $\mathrm{HMBC}$ spectrum $(600 \mathrm{MHz})$ of $\mathbf{8}$ in $\mathrm{CDCl}_{3}$.

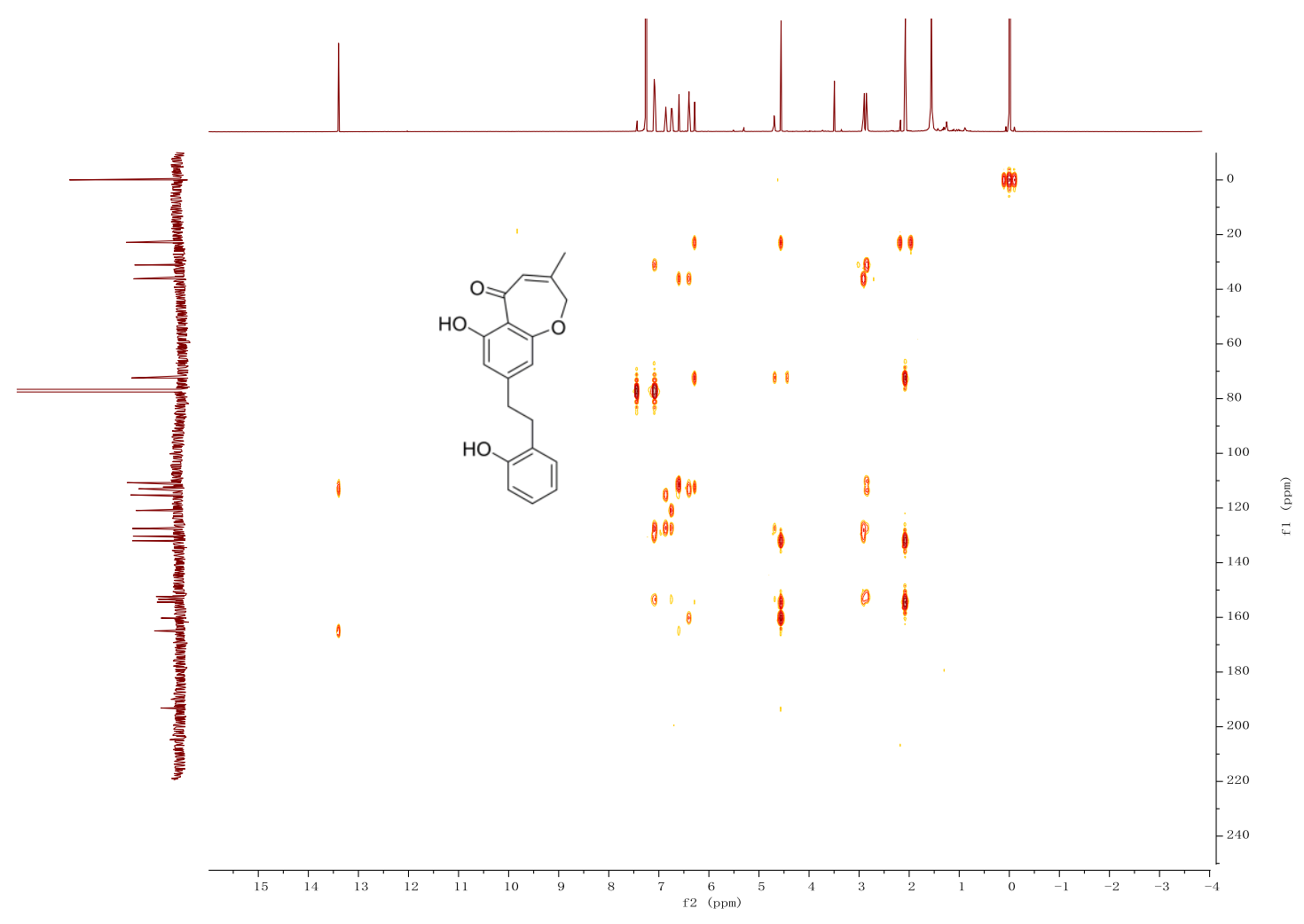

Figure S77. HRESIMS spectrum of 8 .

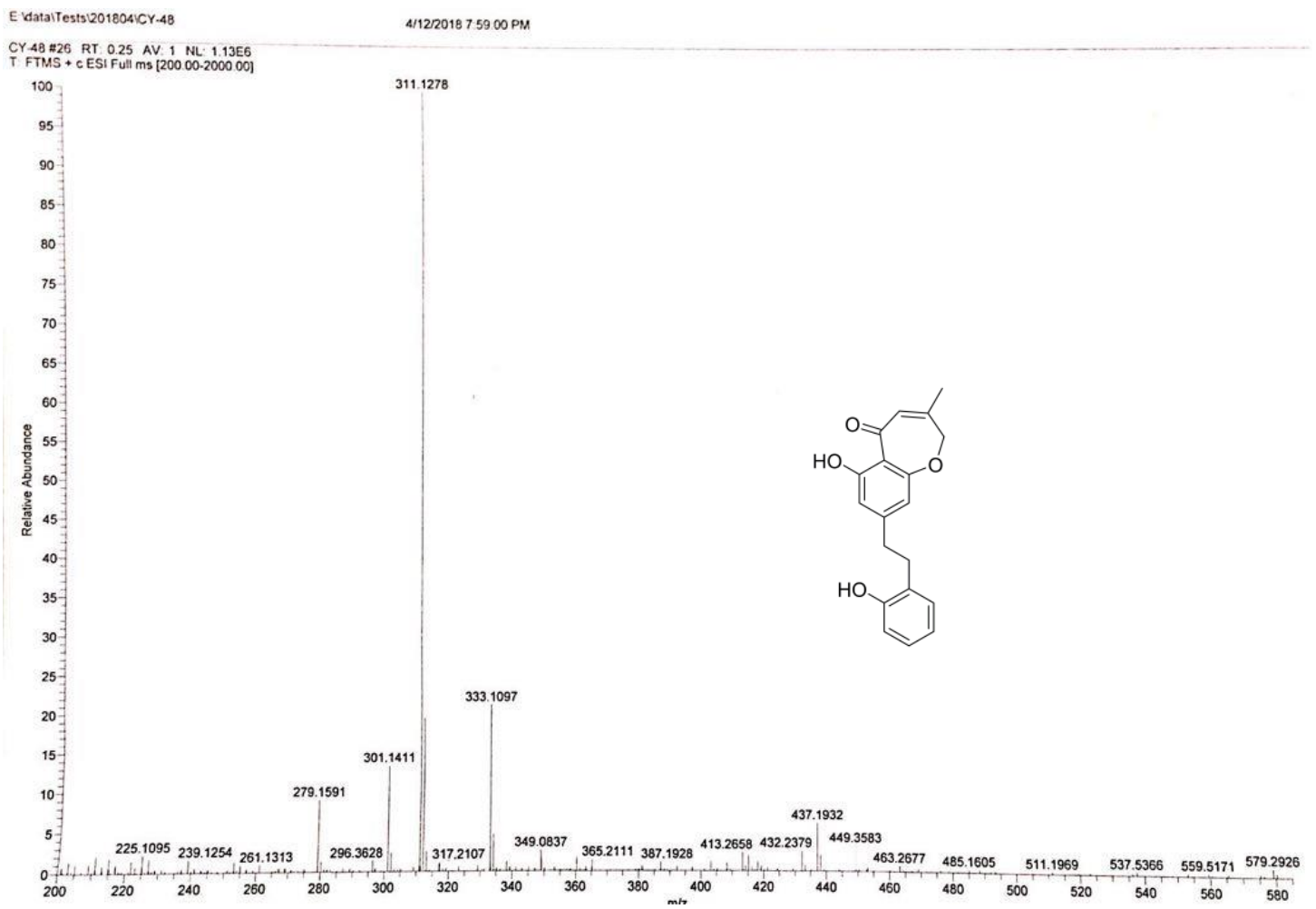


Figure S78. IR ( $\mathrm{KBr}$ disc) spectrum of $\mathbf{8}$.

Center of Drug Analysis and Test, School of Pharmacy, SDU

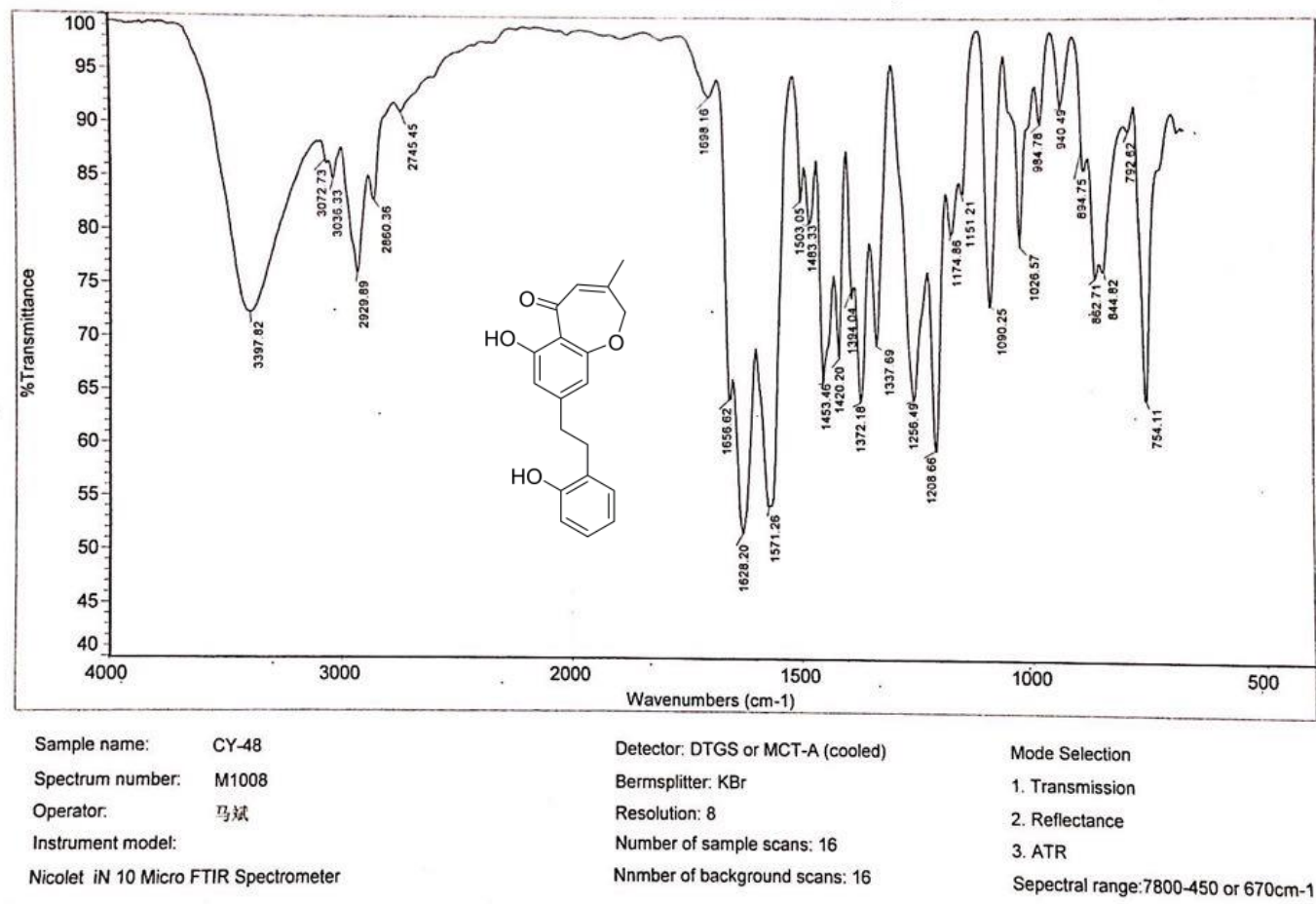

Figure S79. UV spectrum of 8.

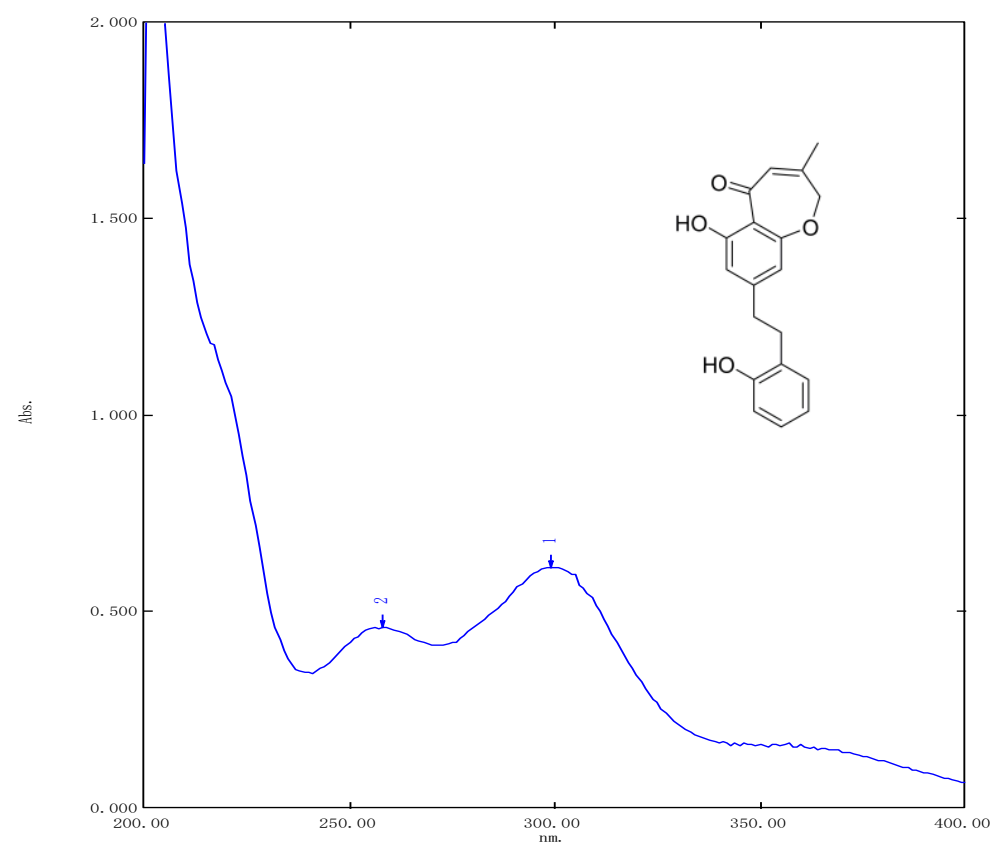


Figure S80. ${ }^{1} \mathrm{H}$ NMR spectrum $(400 \mathrm{MHz})$ of 9 in $\mathrm{CD}_{3} \mathrm{OD}$.

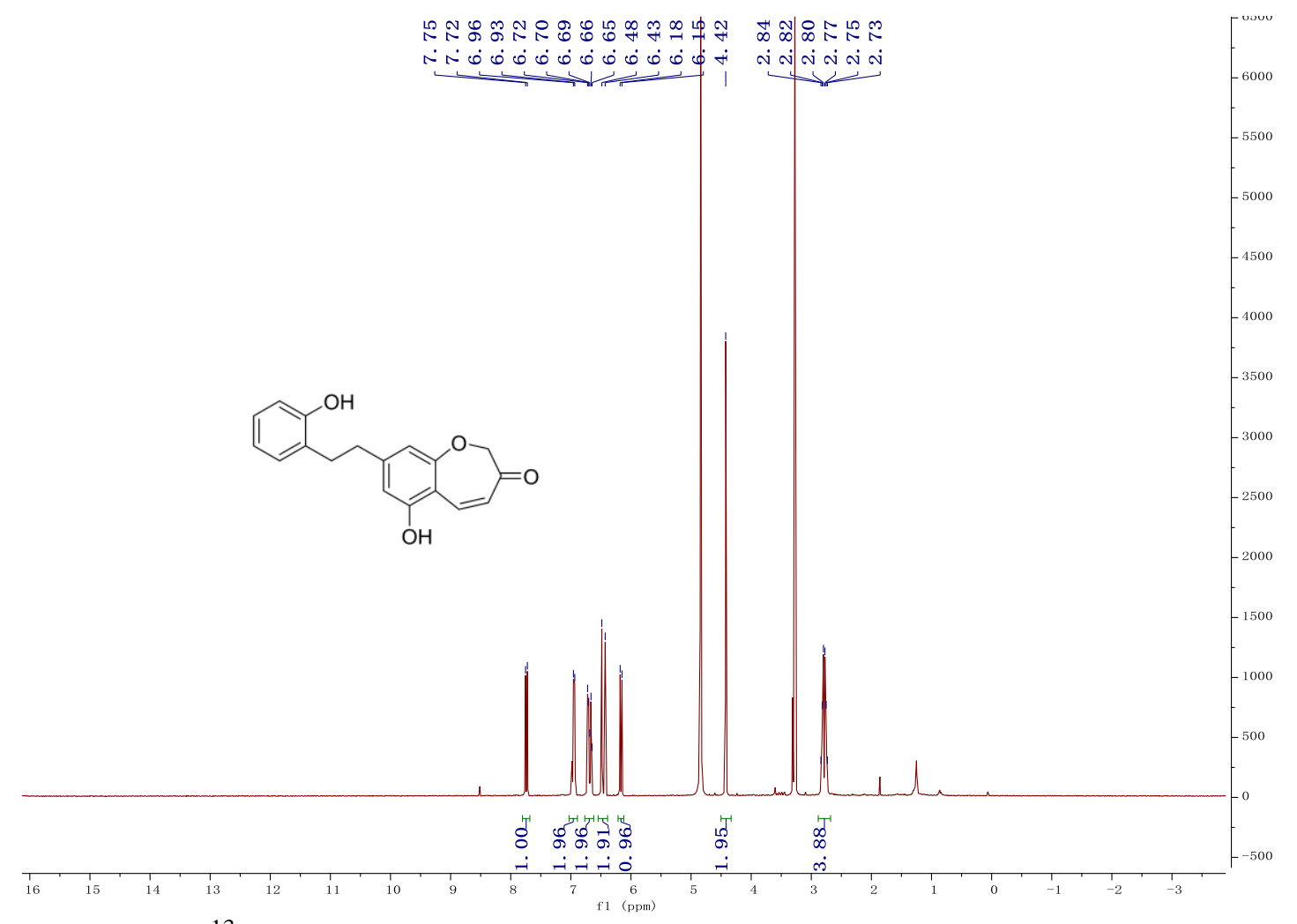

Figure S81. ${ }^{13} \mathrm{C}$ NMR spectrum $(100 \mathrm{MHz})$ of 9 in $\mathrm{CD}_{3} \mathrm{OD}$.

$\stackrel{\circ}{\stackrel{\circ}{\leftrightarrows}}$

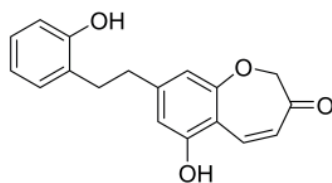

$\sqrt{\infty}$ 
Figure S82. HSQC spectrum (400 MHz) of 9 in $\mathrm{CD}_{3} \mathrm{OD}$.

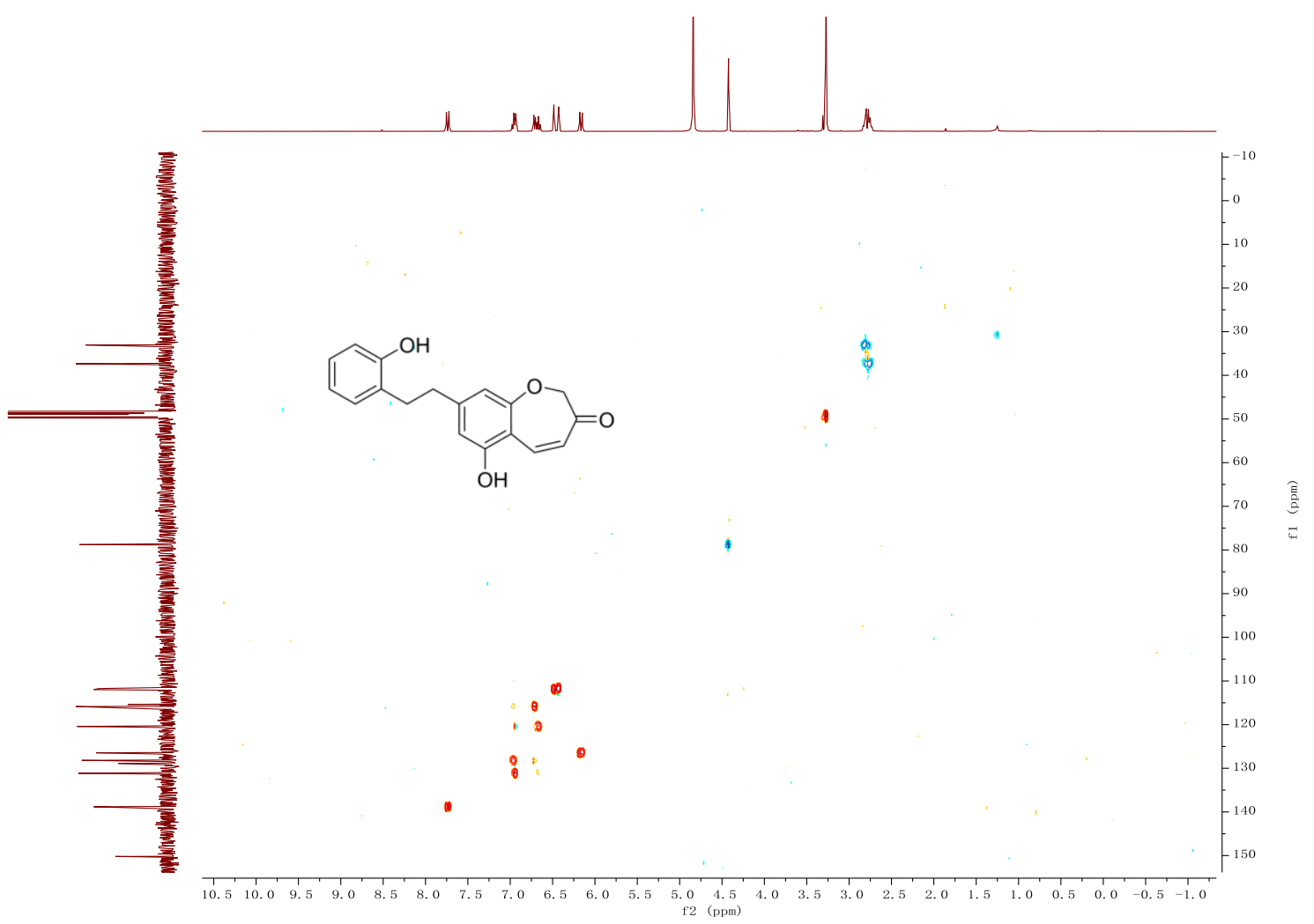

Figure S83. ${ }^{1} \mathrm{H}^{-1} \mathrm{H}$ spectrum $(400 \mathrm{MHz})$ of 9 in $\mathrm{CD}_{3} \mathrm{OD}$.

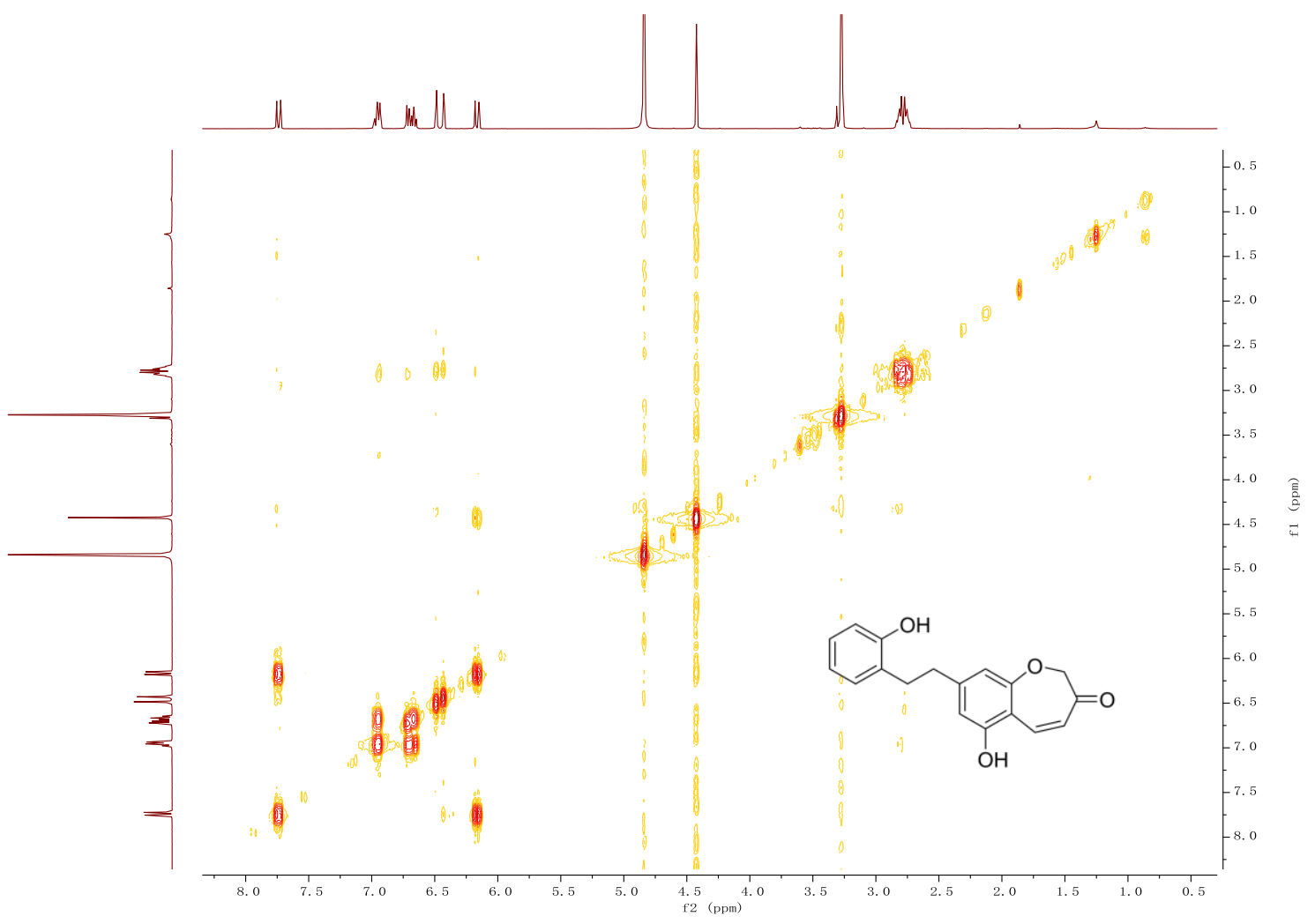


Figure S84. HMBC spectrum $(400 \mathrm{MHz})$ of 9 in $\mathrm{CD}_{3} \mathrm{OD}$.

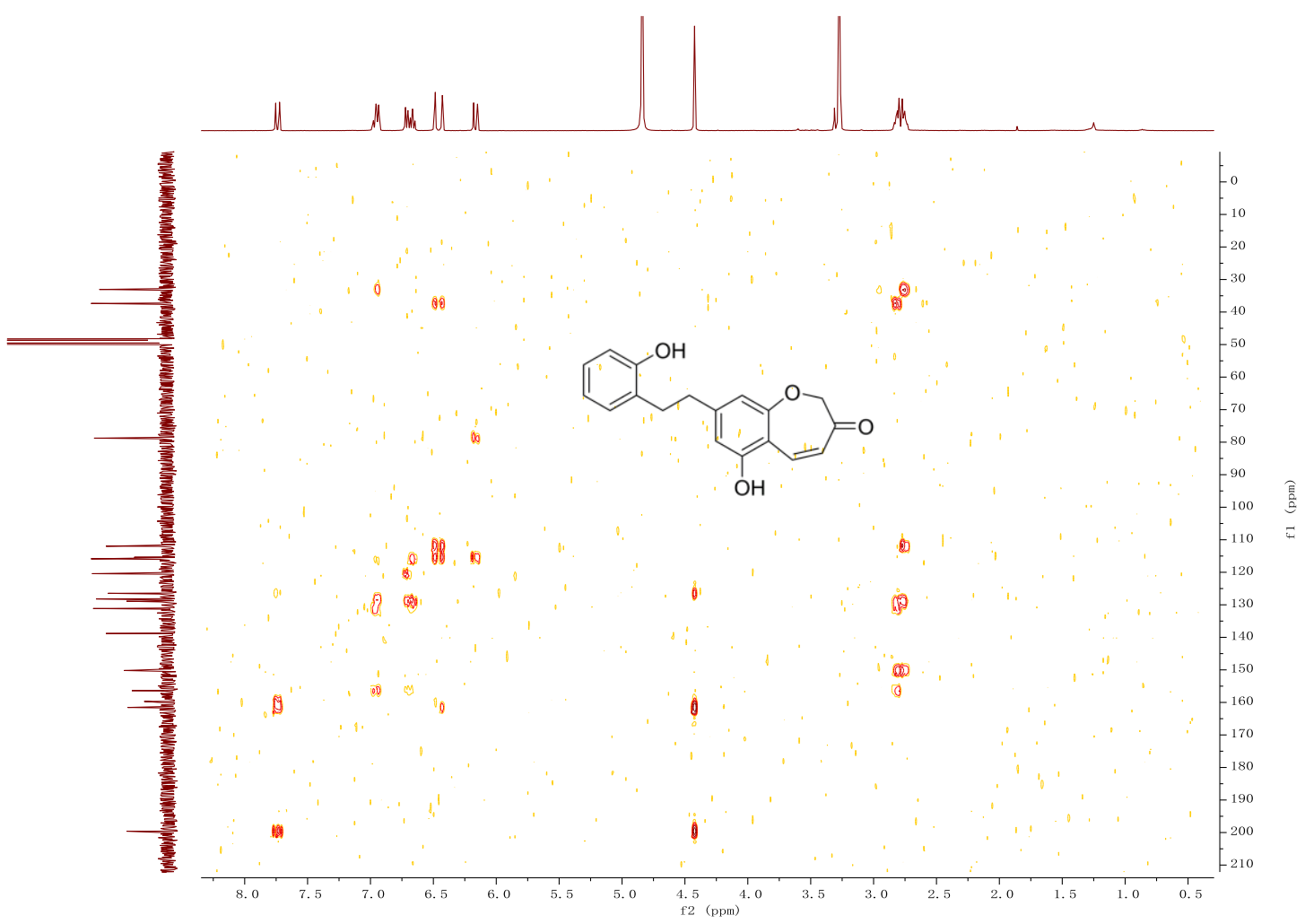

Figure S85. HRESIMS spectrum of 9.

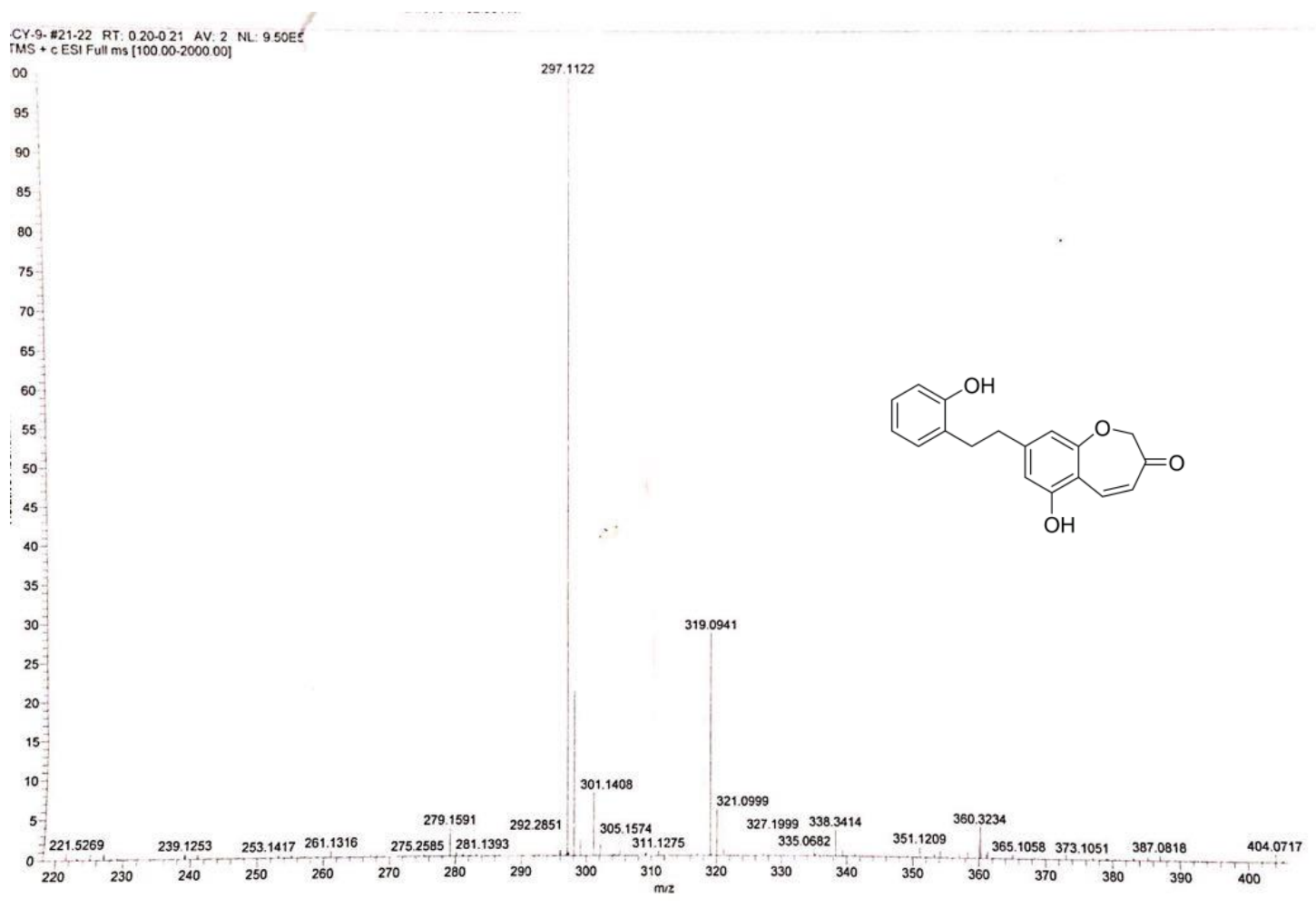


Figure S86. IR ( $\mathrm{KBr}$ disc) spectrum of 9.

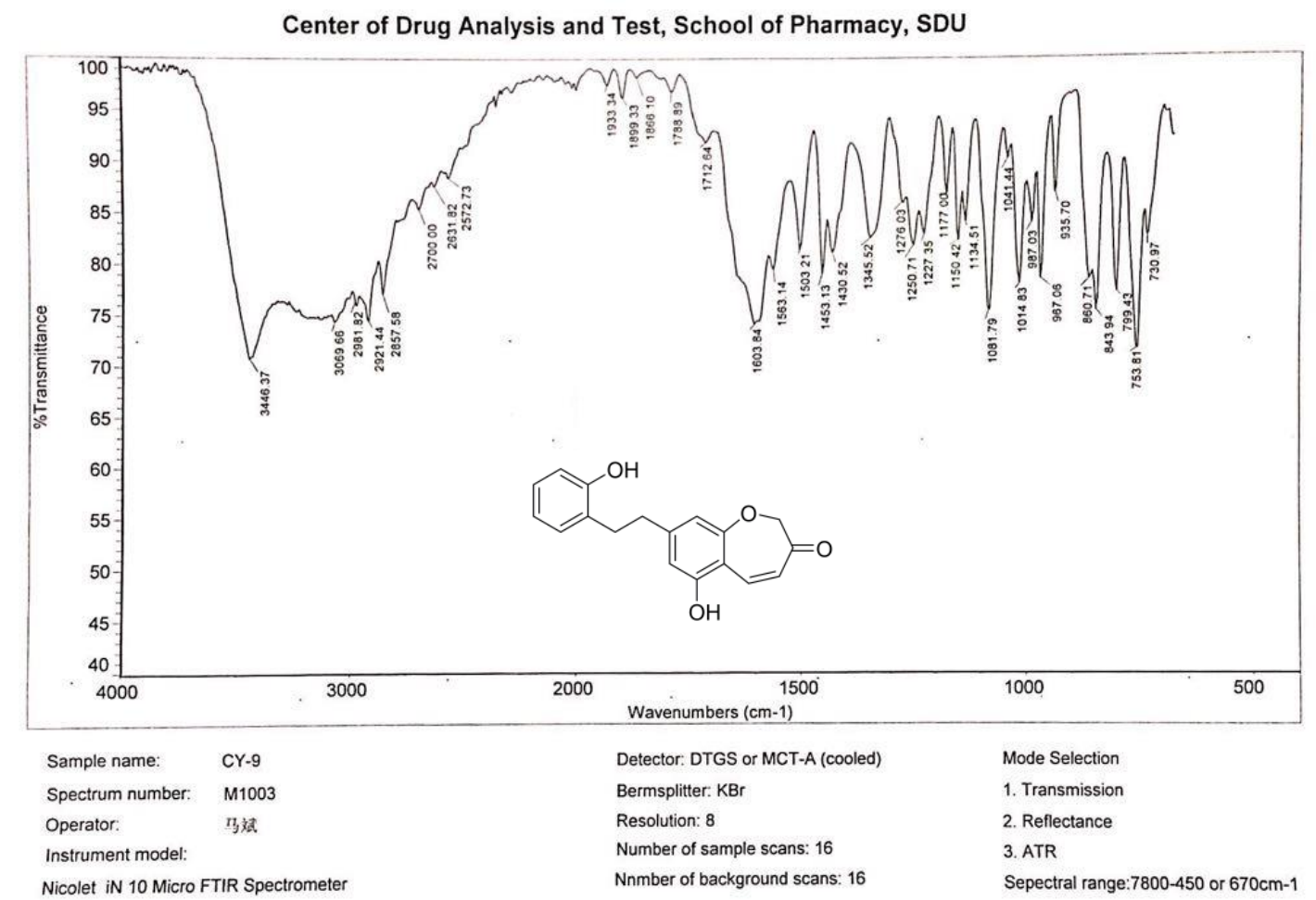

Figure S87. UV spectrum of 9.

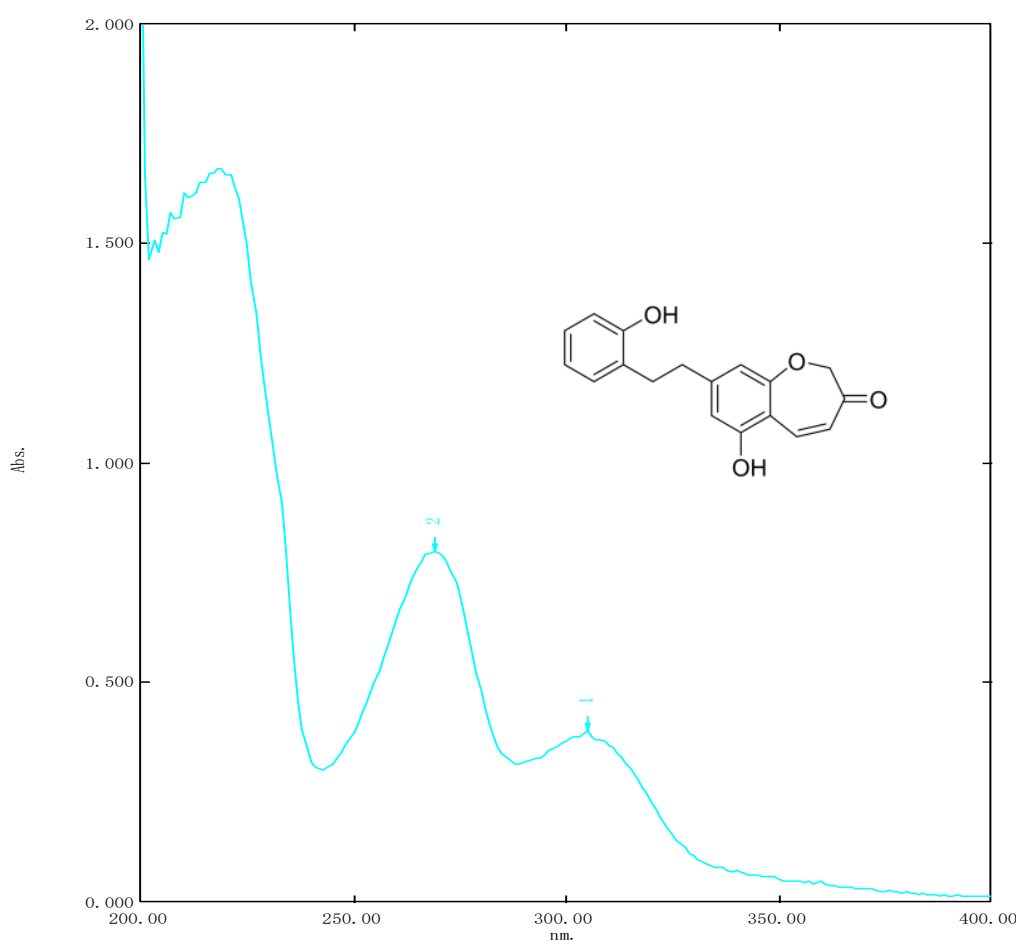


Figure S88. Compounds Induces Vacuolization.

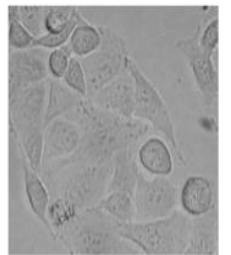

Control

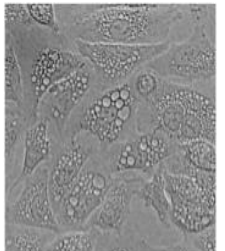

Cpd. 10

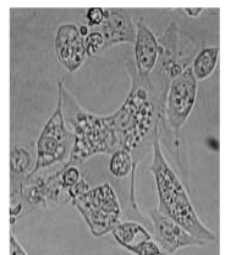

Cpd. 12

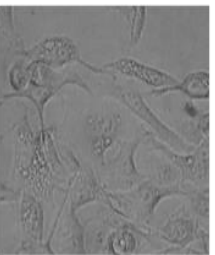

Cpd. 13
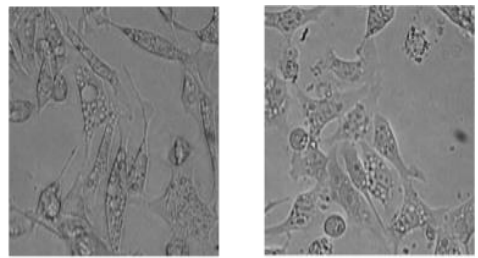

Cpd. 18

Figure S89. The Histogram of Annexin V and PI Staining in A549 and NCI-H1299

Cells (A549 and NCI-H1299 Cells were Treated with the $10 \mu \mathrm{M}$ of Compound $\mathbf{1 0}$ for $24 \mathrm{~h})$.
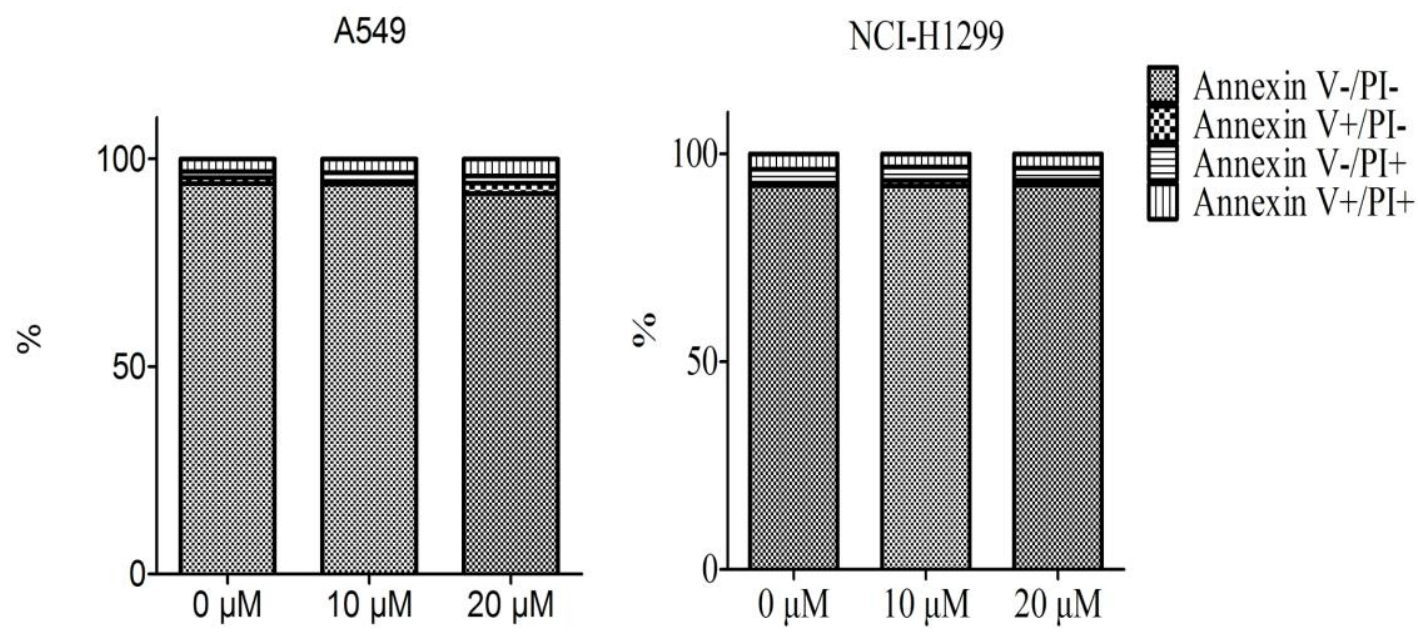
Table S1. Cytotoxicity of Compounds and Adriamycin in Several Human Cancer Cell Lines.

\begin{tabular}{|c|c|c|c|c|c|c|c|c|c|}
\hline Compound $^{\mathrm{a}}$ & NCI-H1299 & A549 & HepG-2 & $\begin{array}{c}\text { SMMC- } \\
7721\end{array}$ & MCF-7 & $\mathrm{U} 251$ & Sw620 & HT29 & $\mathrm{KB}$ \\
\hline 1 & $>40$ & $36.6 \pm 0.1$ & $34.9 \pm 0.2$ & $9.0 \pm 1.0$ & $37.9 \pm 0.8$ & $8.7 \pm 0.6$ & $22.2 \pm 0.8$ & $29.6 \pm 0.2$ & $>40$ \\
\hline 2 & $>40$ & $>40$ & $>40$ & $>40$ & $>40$ & $>40$ & $>40$ & $>40$ & $>40$ \\
\hline 3 & $>40$ & $>40$ & $>40$ & $>40$ & $>40$ & $>40$ & $>40$ & $>40$ & $>40$ \\
\hline 4 & $>40$ & $>40$ & $>40$ & $>40$ & $>40$ & $>40$ & $>40$ & $>40$ & $>40$ \\
\hline 5 & $>40$ & $>40$ & $>40$ & $38.7 \pm 0.7$ & $>40$ & $36.7 \pm 0.7$ & $>40$ & $>40$ & $29.6 \pm 0.6$ \\
\hline 6 & $>40$ & $>40$ & $>40$ & $>40$ & $>40$ & $>40$ & $>40$ & $>40$ & $>40$ \\
\hline 7 & $>40$ & $26.0 \pm 0.4$ & $20.4 \pm 0.7$ & $15.8 \pm 0.5$ & $18.7 \pm 0.5$ & $9.1 \pm 0.9$ & $15.2 \pm 2.0$ & $19.8 \pm 1.0$ & $16.8 \pm 1.9$ \\
\hline 8 & $>40$ & $>40$ & $>40$ & $>40$ & $>40$ & $>40$ & $>40$ & $>40$ & $>40$ \\
\hline 9 & $>40$ & $>40$ & $>40$ & $14.7 \pm 2.0$ & $33.2 \pm 2.5$ & $21.7 \pm 1.0$ & $13.8 \pm 1.1$ & $>40$ & $>40$ \\
\hline 10 & $5.8 \pm 0.3$ & $6.0 \pm 0.1$ & $6.3 \pm 0.2$ & $8.6 \pm 1.3$ & $10.2 \pm 0.7$ & $9.0 \pm 0.2$ & $6.3 \pm 1.4$ & $5.0 \pm 0.5$ & $6.7 \pm 1.6$ \\
\hline 11 & $>40$ & $>40$ & $>40$ & $>40$ & $>40$ & $>40$ & $>40$ & $>40$ & $>40$ \\
\hline 12 & $>40$ & $28.9 \pm 1.9$ & $28.2 \pm 2.7$ & 40 & $>40$ & $38.6 \pm 0.6$ & $>40$ & $24.3 \pm 1.8$ & $>40$ \\
\hline 13 & $>40$ & $>40$ & $>40$ & $>40$ & $>40$ & $>40$ & $>40$ & $>40$ & $>40$ \\
\hline 14 & $>40$ & $>40$ & $>40$ & $>40$ & $>40$ & $26.1 \pm 1.3$ & $>40$ & $>40$ & $>40$ \\
\hline 15 & $>40$ & $>40$ & $35.0 \pm 2.0$ & $24.8 \pm 1.3$ & $>40$ & $8.9 \pm 2.0$ & $18.5 \pm 0.9$ & $>40$ & $28.1 \pm 0.7$ \\
\hline 16 & $>40$ & $>40$ & $36.0 \pm 1.9$ & $24.5 \pm 2.0$ & $>40$ & $9.3 \pm 1.0$ & $25.6 \pm 0.1$ & $>40$ & $25.7 \pm 2.1$ \\
\hline 17 & $>40$ & $25.5 \pm 1.0$ & $22.2 \pm 1.6$ & $29.5 \pm 2.7$ & $28.9 \pm 1.0$ & $>40$ & $19.7 \pm 1.7$ & $29.0 \pm 0.4$ & $17.2 \pm 0.2$ \\
\hline 18 & $15.0 \pm 0.5$ & $9.8 \pm 0.2$ & $13.1 \pm 0.7$ & $13.5 \pm 2.5$ & $20.0 \pm 0.4$ & $25.6 \pm 2.5$ & $10.4 \pm 2.5$ & $10.0 \pm 0.7$ & $16.0 \pm 1.7$ \\
\hline 19 & $>40$ & $28.0 \pm 1.2$ & $31.6 \pm 2.4$ & $28.4 \pm 2.6$ & $37.0 \pm 1.8$ & $14.6 \pm 1.9$ & $21.3 \pm 2.3$ & $35.3 \pm 2.2$ & $38.0 \pm 1.3$ \\
\hline 20 & $>40$ & $>40$ & $>40$ & $>40$ & $>40$ & $>40$ & $>40$ & $>40$ & $>40$ \\
\hline Adriamycin & $0.8 \pm 0.4$ & $1.8 \pm 0.3$ & $1.5 \pm 1.5$ & $0.8 \pm 1.6$ & $1.0 \pm 0.9$ & $2.8 \pm 1.6$ & $1.2 \pm 0.4$ & $3.8 \pm 0.7$ & $3.2 \pm 0.3$ \\
\hline
\end{tabular}

${ }^{a}$ Cytotoxicity of compounds and adriamycin (used as a positive control) were examined in NCI-H1299, A549,

HepG-2, SMMC-7721, MCF-7, U251, Sw620, HT29, and KB cell lines by MTT assay. The cells were treated with various concentrations of compounds for $48 \mathrm{~h}$. Data are mean $\pm \operatorname{SD}(n=3)$ 